\title{
La Biblioteca del Antiguo Colegio de Santa Catalina de la Compañía de Jesús de Córdoba (España): estudio bibliográfico de las secciones de Historia Profana y Filosofía
}

The old College of ST. Catherine 'S Library of the Society of Jesus in Cordoba (Spain): bibliographic study of sections of profane history and philosophy

Marcela A. Suárez, Luis Sánchez y María Soledad Justo*

Resumen: El presente artículo se orienta al conocimiento y divulgación de las bibliotecas institucionales españolas que han sido condenadas al olvido y se propone reconstruir la herencia bibliográfica y cultural que las bibliotecas jesuíticas representan dentro del campo de la historia del libro, a partir del estudio de las características de la Biblioteca del antiguo colegio de Santa Catalina de la Compañía de Jesús de Córdoba (España) y sobre la base de la transcripción, identificación y análisis de los fondos bibliográficos histórico y filosófico.

Palabras clave: Biblioteca, jesuitas, fondo antiguo, Historia, Filosofía

\begin{abstract}
This paper focuses on the knowledge and dissemination of Spanish institutional libraries that have been condemned to oblivion and intends to rebuild the literature and cultural heritage that the Jesuit libraries represent in the field of book's history, from the study of the characteristics Library of old college of St. Catherine of the Society of Jesus in Cordoba (Spain) and by means of the transcript, identification and analysis of historical and philosophical sections.
\end{abstract}

Key words: Library, jesuits, old collection, History, Philosophy.

\footnotetext{
"Facultad de Filosofía y Letras-UBA-CONICET. Argentina. Email: m.suarez61.ms@gmail.com 
Recibido: 3 de setiembre de 2016

Evaluado: 30 de octubre de 2016 
"No contamos con la publicación del inventario de ninguna biblioteca española de importancia de la Compañía." sostiene:

Al referirse a las bibliotecas eclesiásticas en la Edad Moderna, Mateo Ripoll

"La cultura material de las élites durante la Edad Moderna, y más concretamente el estudio de sus bibliotecas, es una de las líneas de investigación que mayor relevancia está cobrando en los últimos años, si bien ya venía siendo cultivada desde tiempo atrás. Pero mientras los patrimonios librarios particulares han gozado, en términos cuantitativos, de gran atención, las librerías institucionales no han corrido la misma suerte".

El interés por las bibliotecas particulares de los siglos XVI a XVIII ha merecido siempre especial atención, según lo demuestran las diversas publicaciones vinculadas con el tema. ${ }^{3}$ No han tenido el mismo destino las bibliotecas institucionales, olvidadas en parte por prejuicios relacionados con los fondos conventuales y por el ingente trabajo que supone el análisis y publicación de sus catálogos. Sin embargo, dentro de este panorama las bibliotecas jesuíticas revisten gran importancia y han despertado un profundo interés. Así se han llevado a cabo estudios para conocer los libros que formaban a los jesuitas. Los resultados arrojaron importantes fondos librarios creados desde los comienzos de la andadura fundacional. Con respecto al camino emprendido, García Gómez afirma:

"De las numerosas fundaciones que la Compañía tenía en España en el momento de la expulsión, solo se han reconocido los contenidos de una mínima parte de las bibliotecas que había en ellas". 4

En Murcia, María Victoria Játiva Millares ha dedicado su investigación al estudio de la Biblioteca Jesuítica del Colegio de San Esteban, mediante la realización de un catálogo concordado en base a la información ofrecida por el inventario del fondo bibliográfico de dicha institución. Tal como la autora sostiene:

"La identificación de los libros de la biblioteca de Murcia nos ha permitido conocer los intereses teológicos, científicos, literarios, lingüísticos y culturales en general de los miembros de la Compañía. Además a través de ellos podemos recomponer las directrices pedagógicas implantadas en el colegio". 5

Otro trabajo vinculado con el estudio de las bibliotecas institucionales es el de Miguel Ángel Sánchez Herrador ("La biblioteca del colegio de la Encarnación de los jesuitas de Montilla"). La particularidad de esta investigación radica en el hecho de que los ejemplares supérstites han podido ser analizados, lo cual permite aportar información sobre

\footnotetext{
${ }^{1}$ Solana Pujalte, 2007: 114.

${ }^{2}$ Mateo Ripoll, 2002: 13.

${ }^{3}$ Huarte Morón, 1955; Chevalier, 1976; Hernández González, 1998.

${ }^{4}$ García Gómez, 2010: 19-20.

5 Játiva Miralles, 2007: 263. Su tesis doctoral puede ser leída en Internet (http://www.tesisenred.net/TDR1105107-122610/index_cs.html).
} 
la vida del colegio y la biblioteca (lecturas y anotaciones en los impresos, donaciones a la biblioteca, adquisiciones, servicio a la docencia y otras).

El presente artículo aborda el estudio de las características de la Biblioteca del antiguo colegio de Santa Catalina de la Compañía de Jesús de Córdoba (España), a partir de la transcripción de las secciones de Historia Profana y Filosofía, y la posterior identificación de cada uno de los registros.

En las Constituciones ignacianas se lee:

"Haya librerías, si se puede general, en los colegios, y tengan llave de ella los que el rector juzgare deben tenerla. Sin esto los particulares deben tener libros que les fueran necesarios...con esto no los deben glosar, y tengan cuenta dellos el que tiene cargo de los libros". 6

La formación de una buena biblioteca, su mantenimiento y el acceso directo a los libros desde las bibliotecas personales de los integrantes de las comunidades jesuíticas es una marca distintiva que vincula a la Orden con sus cometidos específicos: los de carácter pedagógico, los de formación de los novicios y los de sustento de un cuerpo profesional. Sin embargo, la expulsión llevada a cabo en 1767 da comienzo al proceso de desintegración de las librerías de la Compañía.

Así sobreviene la obsesión por inventariar todos los bienes y propiedades de los llamados a partir de ese momento, "jesuitas expulsos". Una parte importante del proceso de inventario afecta a los libros y papeles que existían en las casas y colegios de la Compañía. La razón de este inventario gira en torno a la necesidad, por un lado, de completar las bibliotecas de seminarios y universidades del reino, y, por otro, de encontrar argumentos que permitieran justificar la expulsión. No faltan quienes consideran que existe una razón más innoble y dolorosa relacionada con la posibilidad de vender propiedades y libros inventariados para solventar los gastos ocasionados por la expulsión y otros menesteres del gobierno carolino. ${ }^{7}$

El proceso de catalogación e inventario se caracteriza por dos etapas bien diferenciadas: en la primera se incluyen disposiciones generales referidas a archivos, libros y bibliotecas; en la segunda, se establece una legislación específica que propone un método individual de formalizar los índices de modo que se ejecuten con uniformidad. ${ }^{8}$ Como se busca la mayor claridad posible y trata de evitarse toda clase de confusiones, los comisionados siguen la normativa y dividen los libros en impresos y manuscritos confeccionando de este modo dos tipos de inventarios. ${ }^{9}$ En el caso de los inventarios de manuscritos deben copiarse los dos primeros renglones y los dos últimos e incluir el número de folios. En cuanto a los inventarios de impresos, se recoge el apellido del autor, el nombre propio entre paréntesis, título, lugar y año de edición, según lo estipulado en la Instrucción de lo que deberán ejecutar los Comisionados para

\footnotetext{
${ }^{6}$ Constituciones Ignacianas, parte IV, cap. VI, art. 7.

${ }^{7}$ Vergara, 2009: 375.

${ }^{8}$ Acerca de las disposiciones, ver Vergara, 2009: 376 ss; Martínez Tornero, 2010: 111-14.

${ }^{9}$ García Gómez, 2010:49 afirma: "La técnica de ejecución de los inventarios, en la expulsión, es siempre la misma: primeramente se realiza el índice de los libros de los aposentos, in situ, y posteriormente, en la sala o librería general, todos los documentos o libros en un inventario general, aunque una Instrucción de lo que deberán ejecutar los Comisionados para el Extrañamiento no especificaba detalles de estos momentos de la ejecución."
} 
el Extrañamiento. ${ }^{10}$ En dichos inventarios se incluye información relacionada con el formato, encuadernación y número de tomos.

Al referirse al conocimiento de la riqueza bibliográfica de la Compañía, dice García Gómez: "Los inventarios de sus bibliotecas, posibles, deseados testigos de la memoria cultural, ideológica y espiritual de sus fundaciones pueden ayudarnos en su búsqueda". 11

El colegio de Santa Catalina de la Compañía de Jesús, fundado en 1554, se encuentra en el s. XVI a la cabeza de los colegios andaluces junto con el de Sevilla, no solo por el número y la formación de sus profesores, sino también por la cantidad de alumnos que asistían. ${ }^{12}$

La biblioteca de esta institución está considerada una de las más importantes en España al momento en que se produce la expulsión por orden de Carlos III en 1767. En efecto, según su tamaño, las bibliotecas jesuíticas se clasifican en tres tipos: grandes (con más de 6.000 volúmenes); medianas (entre 2.000 y 6.000 volúmenes) y pequeñas (con apenas 2.000 volúmenes). ${ }^{13}$ De acuerdo con el inventario, la biblioteca del colegio de Santa Catalina se ubica dentro del grupo de las librerías grandes, pues en el momento de la expulsión cuenta con 6.854 obras y 10.213 volúmenes. ${ }^{14} \mathrm{Su}$ fondo bibliográfico, ignorado por los estudiosos que se han ocupado de las bibliotecas jesuíticas españolas, ha comenzado a ser estudiado por investigadores españoles y argentinos. Para ello la fuente consultada ha sido el "Índice Original de los libros y Papeles impresos de la Biblioteca que fue de los Regulares expulsos" (1773), legajo manuscrito que se conserva en la Biblioteca Diocesana de Córdoba. Se trata del inventario que concluyeron y firmaron en recto del último folio el 18 de enero de 1773, Pedro José González y Juan Moreno y Risques, comisionados del obispo y de la Real Junta Municipal, de acuerdo con la real Cédula de 6 de mayo de 1772 de Carlos III que ordenaba

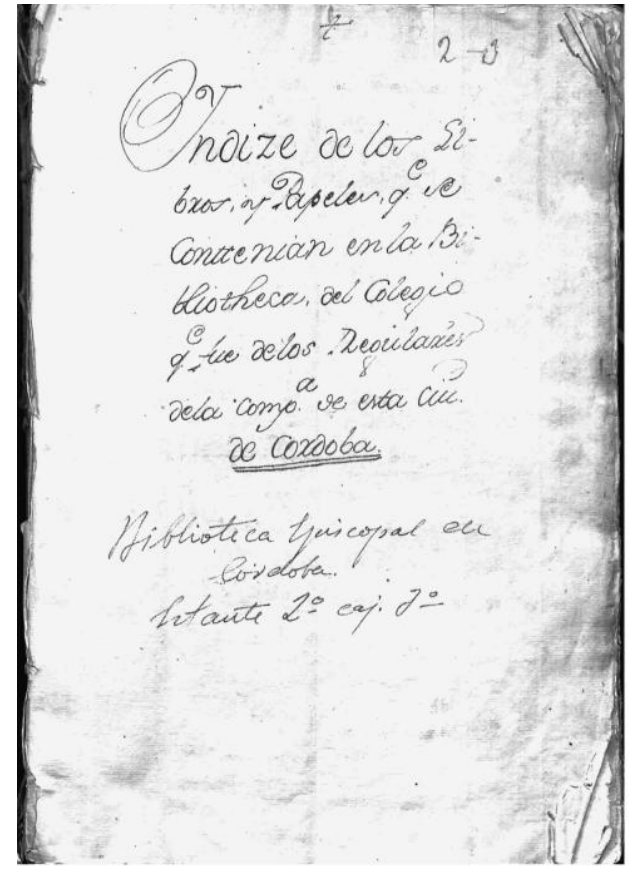

Fig. 1. Portada.

\footnotetext{
${ }^{10}$ Colección General de las Providencias: 46-50.

${ }^{11}$ García Gómez, 2010: 20.

${ }^{12}$ En 1591 el colegio cuenta con 66 jesuitas: 22 eran sacerdotes, 26 hermanos escolares y 18 hermanos coadjutores. De entre ellos 7 se dedicaban a la docencia y eran maestros. El interés por un profesorado de calidad no se daba en otros colegios andaluces de la Compañía. De hecho, en el colegio de Sevilla de los 11 profesores, 6 eran maestros. Solana Pujalte, 2007a: 118.

${ }^{13}$ Entre las librerías grandes se encuentran la del Colegio Imperial de Madrid (con 30000 volúmenes aproximadamente), la del Colegio de San Pablo de Granada (con 29483 volúmenes), la del Colegio de Salamanca (con 12000 volúmenes) y la del Colegio de Alcalá de Henares (con 11000). Dentro de las medianas se destacan la del colegio de Monterrey de Galicia (con 5984 volúmenes) y la del Colegio de Montilla de Córdoba (con 3834 volúmenes). En cuanto a las bibliotecas pequeñas, basten dos ejemplos: la del colegio de Albacete con 545 títulos y 810 volúmenes, y la del colegio de Tudela con 1014 títulos. Solana Pujalte, 2007a: 122-23.

${ }^{14}$ Como solo se anotan los libros de los que se aportan datos constantes a lo largo de todo el Índice, es de suponer que el número real era notablemente superior.
} 
levantar con todo detalle un inventario de los libros y papeles de los jesuitas (Fig. 1).

Los folios [3] y [4] ofrecen en una "Advertencia" (Fig. 2) información de interés sobre la biblioteca y la forma en la que el inventario se ha levantado, de la cual destacamos la división de libros según las siguientes clases: escritura sagrada y expositores, Santos Padres, Teología Dogmática, Teología Escolástica, Teología Moral, Derecho canónico, Derecho Civil, Predicable, Liturgia, Mística y espirituales, Historia Sagrada y Eclesiástica, Historia Profana, Medicina, Matemáticas, Filosofía, Miscelánea y varia erudición, Gramática, Libros en reserva.
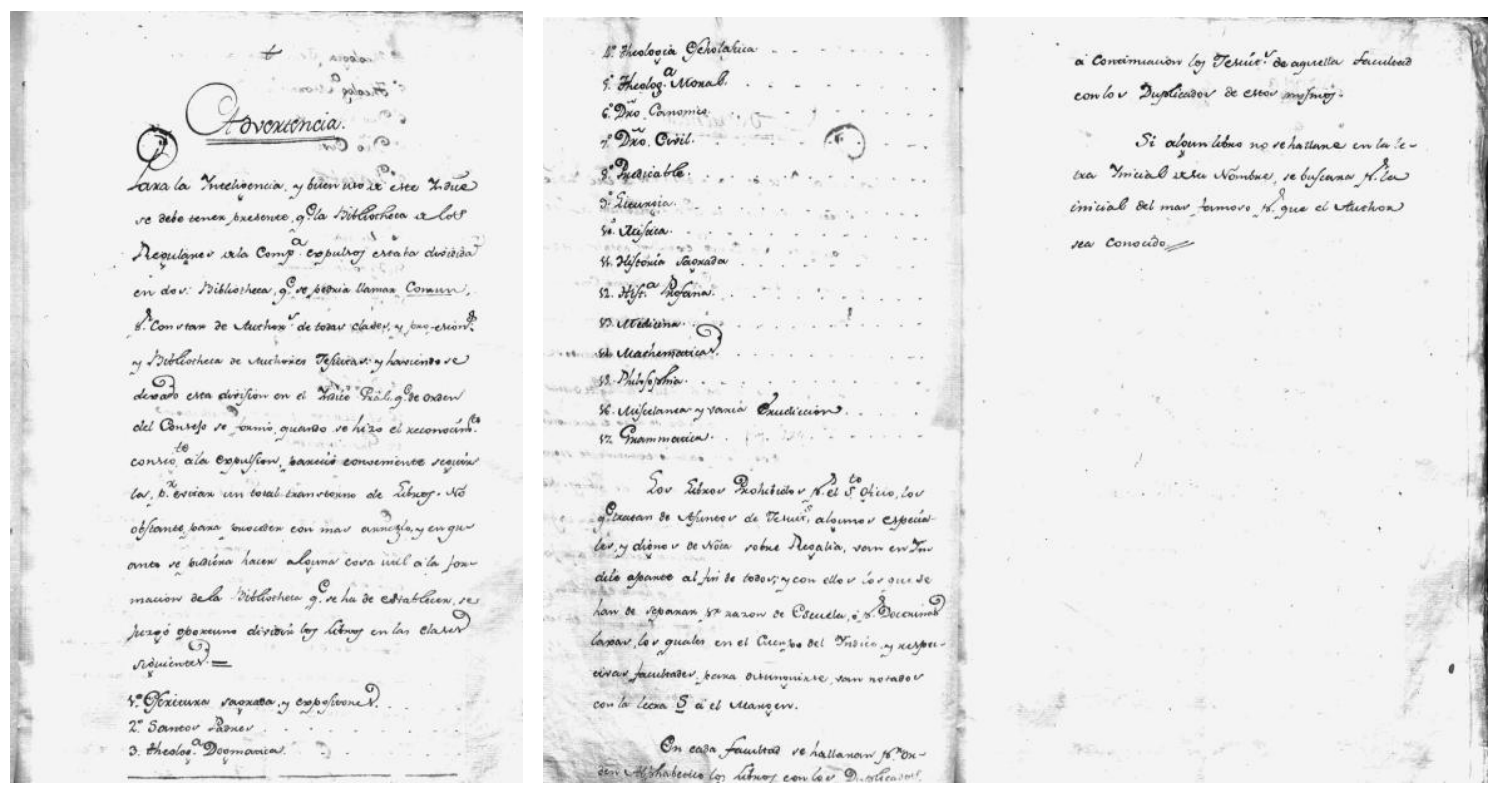

Fig. 2. Advertencia.

La ordenación del Índice se realiza por materias y dentro de cada una se agrupan, por un lado, las obras generales y, por otro, las de autores jesuitas.

Julián Solana Pujalte, que se ha dedicado arduamente al estudio de las bibliotecas jesuíticas, ha contribuido de manera fecunda al estudio bibliográfico de la biblioteca del colegio de Santa Catalina, tal como lo demuestran sus últimas publicaciones, en las que ha enfatizado la importancia de la librería en virtud de la cantidad de obras y volúmenes que la ubican entre las "grandes" de la Compañía en España; ha destacado en particular el fondo del siglo XVI, superior al de otras bibliotecas mayores, y el fondo gramatical de autores jesuitas que ocupa un lugar relevante, acorde con la importancia que la Ratio Studiorum concedió a los estudios gramaticales; y ha abordado el análisis de los libros de autores clásicos grecolatinos utilizados en los colegios de la Compañía.

En los últimos años se ha sumado además el estudio y la descripción de la sección Teología, a cargo de Miguel Ángel Sánchez Herrador, titulado Estudio bibliográfico de la sección de Teología de la Biblioteca del antiguo colegio de Santa Catalina de la Compañía de Jesús de Córdoba (2006), que ha significado un valioso aporte al conocimiento del material librario ${ }^{15}$ con el cual se manejaban los jesuitas. ${ }^{16}$

\footnotetext{
${ }^{15}$ Respecto del concepto de "fondo bibliográfico", dice Martín Abad, 2004: 15-35: "cuando descubrimos signos de pertenencia y procedencia en un conjunto de ejemplares decimos que constituyen un fondo, no 
Los fondos librarios más ricos están representados por las siguientes materias: Teología, Sagrada Escritura y Gramática. La Filosofía y la Historia ocupan el sexto y décimo lugar, lo cual representa el $6.54 \%$ y $3.88 \%$ del total, respectivamente.

Abordar las secciones propuestas -Filosofía e Historia Profana- implicó tres etapas. La primera consistió en una transcripción literal del documento. En este sentido, las mayores dificultades estuvieron vinculadas básicamente con: a) la interpretación del trazo del copista, en especial en los segmentos manchados y tachados; b) el manejo de su particular sistema de abreviaturas, no siempre consistente a lo largo de los registros; c) el desciframiento de algunas inconsecuencias gráficas, como por ejemplo, la alternancia de dos o tres grafías distintas para una misma letra (f minúscula), sobre todo, para las mayúsculas (F y $\mathrm{P}$ ), y la escritura de los números arábigos, realmente confusa en muchos pasajes (Fig. 3, 4 y 5).
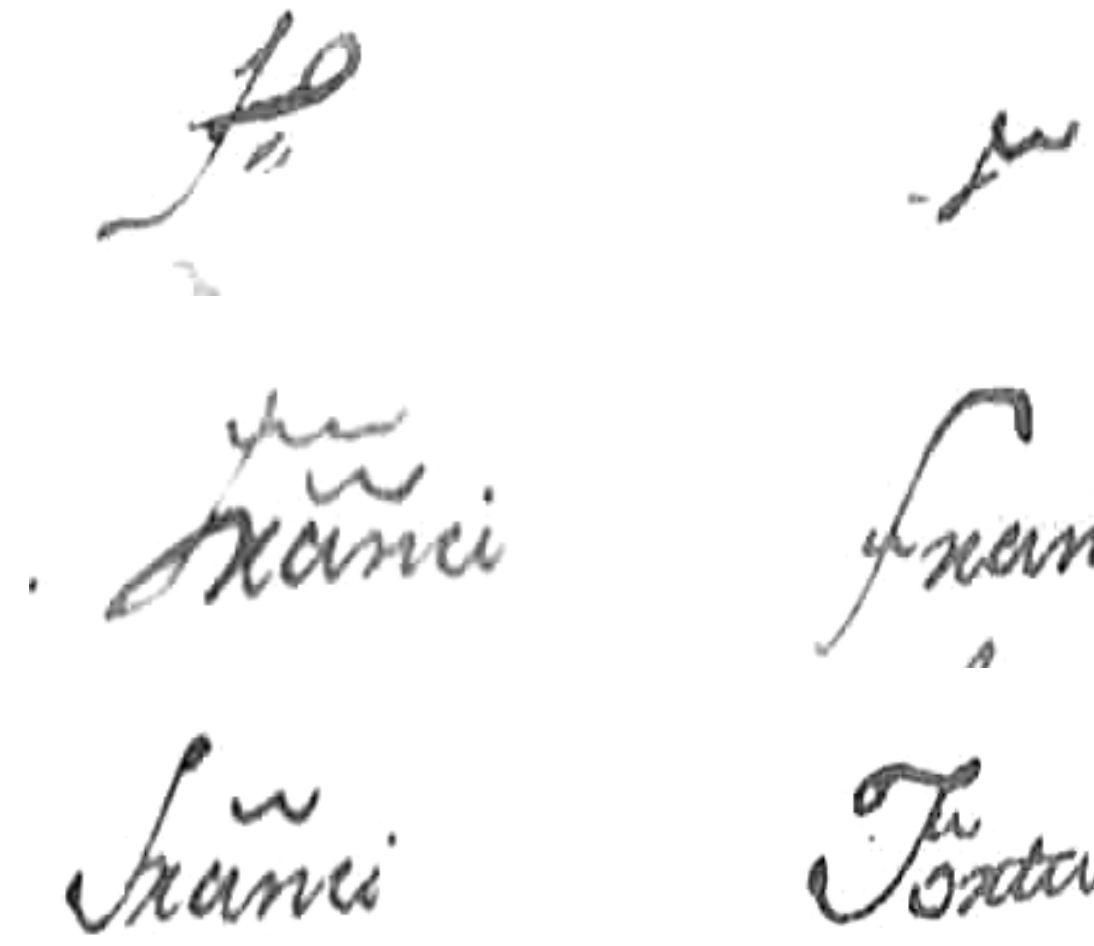

Fig. 3. Alternancia de grafías: f/F
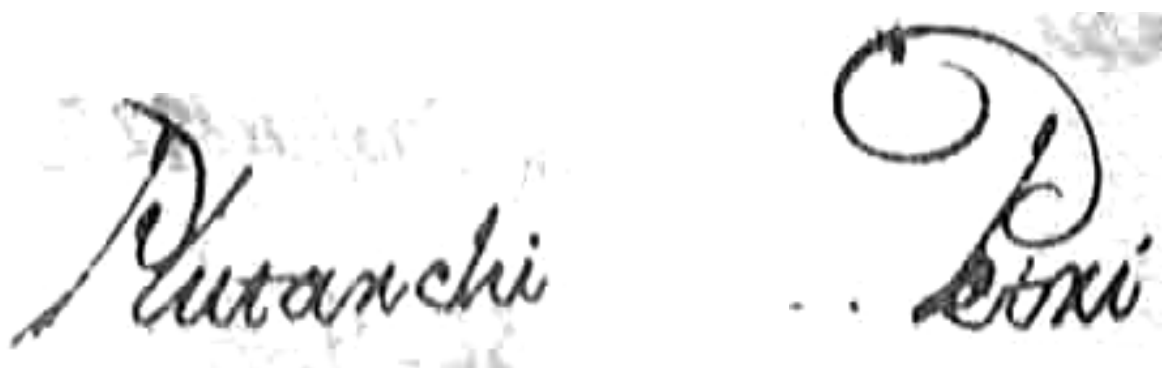

Fig. 4. Alternancia de grafías P.

una colección. Los ejemplares de un fondo están unidos naturalmente por su pertenencia a una persona o institución histórica antes de quedar incorporados al conjunto de ejemplares". 

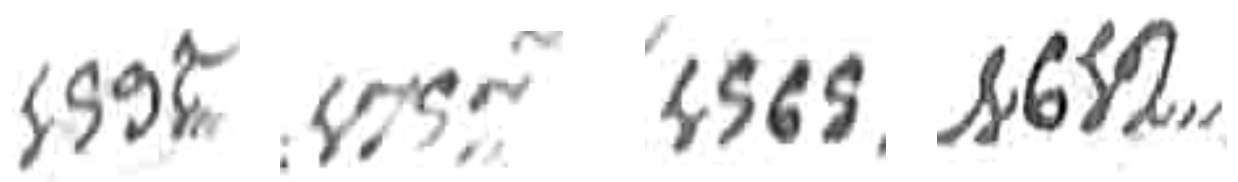

Fig. 5. Alternancia de grafías: números arábigos.

La transcripción reveló que la sección está estructurada de la misma manera que el resto del catálogo, es decir, cuenta con un ordenamiento en tres columnas: la primera menciona la cantidad de volúmenes de que consta la obra, la segunda consigna el título, el autor, la fecha y el lugar de edición, y la tercera refiere el formato del libro.

\section{Acerca de las secciones: Filosofía e Historia Profana}

El contenido de ambas secciones -"Filosofía" e "Historia Profana"- (Fig. 6) consta de una primera parte que enumera obras "generales" y de una segunda parte, donde se incluyen libros de autores jesuitas. Cada subgrupo se divide además en obras que solo tienen una única edición y obras que cuentan con más de una, estas últimas ordenadas bajo el título de "duplicados". Cabe aclarar que el concepto de duplicados no incluye ediciones de las que existe más de un ejemplar, sino obras que tienen más de una edición registrada, ${ }^{17}$ con lo que cada sección completa posee cuatro partes tituladas de la siguiente manera: "Philosophia", "Duplicados de Philosophia", "Philosophia de Authores jesuitas" y "Duplicados de Philosophia de Authores jesuitas"; "Historia
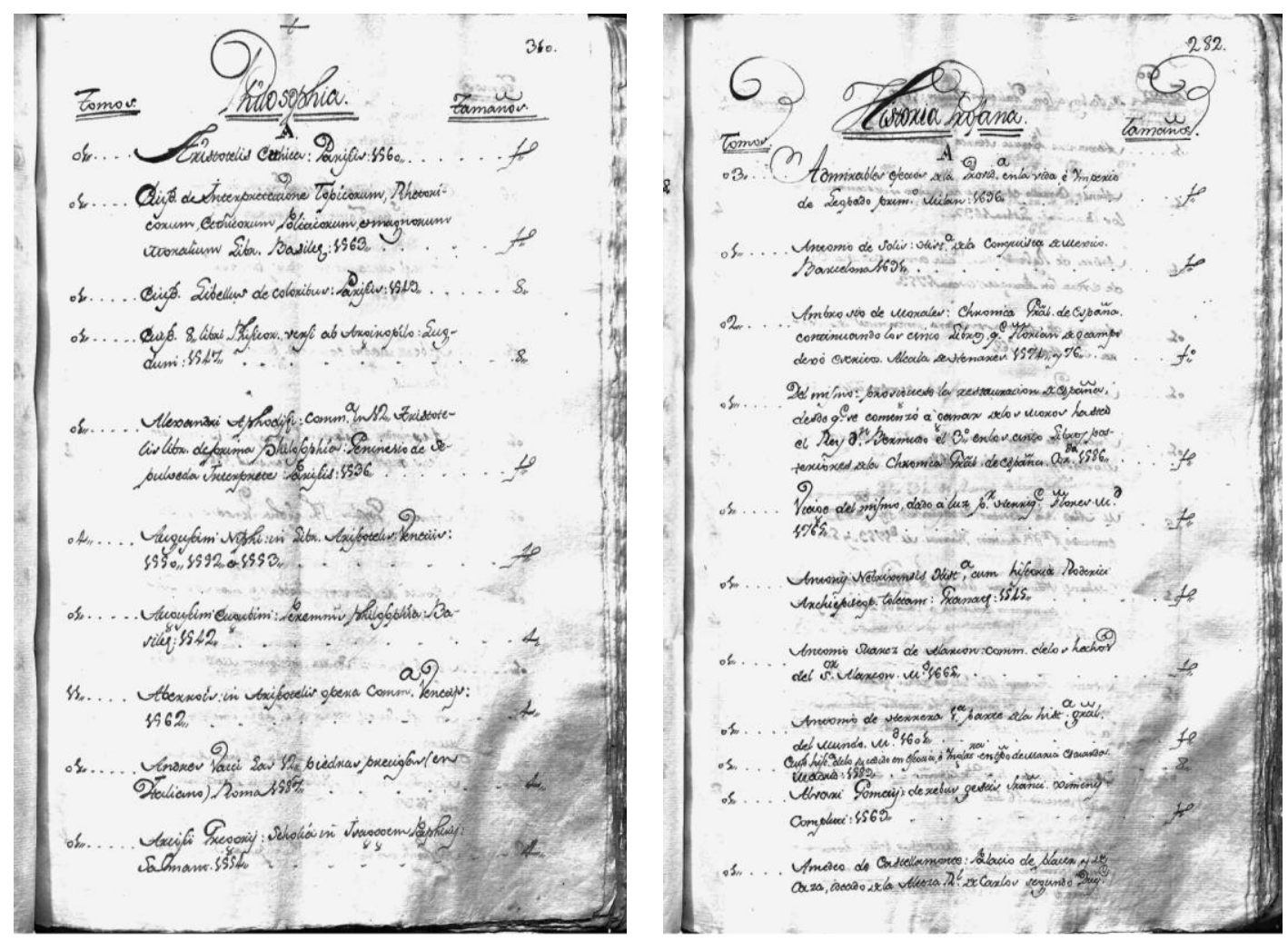

Fig. 6. Portadas de las secciones de Filosofía e Historia Profana.

${ }^{17}$ Sobre la noción de “duplicados”, ver Solana Pujalte, 2007b.

165 Marcela A. Suárez, Luis Sánchez y María Soledad Justo. La Biblioteca del Antiguo... 158-254. 
Profana", "Duplicados de Historia Profana," "Historia Profana de Authores jesuitas" y "Duplicados de Historia Profana de Authores jesuitas". Esas obras incluyen no solo traducciones, comentarios y paráfrasis de autores, como Aristóteles, Platón, Cicerón, Séneca, Plinio, Boecio, Galileo, Descartes, sino también obras de autores jesuitas como Francisco Suárez, Luis Losada, Antonio Rubio, entre otros.

Mediante la búsqueda en catálogos de bibliotecas actuales los libros han podido ser identificados. El cotejo entre ambos registros muestra a las claras que los títulos consignados en el Índice están generalmente resumidos o parafraseados, como ocurre, por ejemplo, en el siguiente caso:

1) en el Índice figura Institutio Philosophiae cartesianae; en el Catálogo Colectivo del Patrimonio Bibliográfico (CCPB), Institutio philosophiae secundum principia D. Renati Descartes nova methodo adornata et explicata.

2) En el Índice se consigna Bartholome Ximenex, Historia de la antigua nobleza de Jaén. Jaén, 1628; en el CCPB, en cambio, Historia de la antigua y continuada nobleza de Jaén, muy famosa, y muy noble, y muy leal guarda, y defendimiento de los Reyes de España. Y de algunos varones famosos hijos de ella.

Esta tendencia a resumir los títulos se ha observado también en las obras en español y en la traducción de los títulos que están en una lengua extranjera moderna.

Diversos relevamientos estadísticos permitieron visualizar diferentes tendencias de la Biblioteca catalogada, como cantidad de obras de autores jesuitas, lenguas predominantes, principales lugares de edición y formatos, entre otras. De los 6.854 títulos que conforman la totalidad del catálogo, la sección "Filosofía" suma 334, lo que representa poco menos que el 5\% del total. De esos 334 se han calculado los siguientes porcentajes en relación con el siglo y la pertenencia de los autores a la Compañía de Jesús:

\begin{tabular}{|l|l|l|l|}
\hline Fechas & Autores jesuitas & Autores no jesuitas & Total \\
\hline s. XV & --- & 3 & $3 / 0,9 \%$ \\
\hline s. XVI & 22 & 153 & $175 / 51 \%$ \\
\hline s. XVII & 49 & 55 & $104 / 31,13 \%$ \\
\hline s. XVIII & 27 & 21 & $48 / 14,37 \%$ \\
\hline sin fecha & 3 & 6 & $9 / 2,6 \%$ \\
\hline Total & $101 / 29,8 \%$ & $238 / 70,2 \%$ & 339 \\
\hline
\end{tabular}

La sección "Historia Profana" arroja 242 títulos, lo que representa poco menos que el 3,4 \% del total. De esos 242, 194 pertenece a autores fuera de la Compañía, es decir, el $82 \%$ y el $18 \%$, a autores de la Compañía con 48 títulos.

\begin{tabular}{|l|l|l|l|}
\hline Fechas & Autores jesuitas & Autores no jesuitas & Total \\
\hline s. XV & --- & 2 & $2 / 0,082 \%$ \\
\hline s. XVI & 9 & 93 & $102 / 42 \%$ \\
\hline s. XVII & 27 & 67 & $94 / 39 \%$ \\
\hline s. XVIII & 11 & 28 & $39 / 16 \%$ \\
\hline sin fecha & 1 & 4 & $5 / 02 \%$ \\
\hline Total & $48 / 18 \%$ & $194 / 82 \%$ & 242 \\
\hline
\end{tabular}

166 Marcela A. Suárez, Luis Sánchez y María Soledad Justo. La Biblioteca del Antiguo... 158-254. 
Como se puede apreciar en las obras de filosofía, el porcentaje de títulos pertenecientes al siglo XVI sobrepasa el 50\%. Esto manifiesta una clara predominancia de obras pertenecientes a dicho siglo, a partir del cual comienza un marcado descenso hasta el siglo XVIII, cuyos títulos apenas superan el 14\% del total.

Con respecto a la sección "Historia", el porcentaje de títulos pertenecientes al siglo XVI llega al $42 \%$, en una relación un poco más elevada a las obras del siglo siguiente que ronda el $39 \%$. En el siglo XVIII se produce un pronunciado descenso (16 $\%)$.

En lo que respecta a las obras de autores jesuitas se observa un fuerte predominio de estas en el siglo XVII, lo cual puede tener su explicación en circunstancias socio-históricas concretas, como el auge intelectual y de producción literaria que experimenta la Compañía en ese siglo. Asimismo se advierte un marcado descenso en el siglo siguiente, lo cual también podría explicarse en virtud de la expulsión, ocurrida en la segunda mitad del XVIII. Por otra parte, si comparamos la evolución del número de títulos de autores no jesuitas desde el siglo XVI al XVIII vemos que la tendencia de estos es siempre descendente, en contraste con los títulos de autores jesuitas que va en aumento hasta el XVII y sufre una mengua en el siglo siguiente. Esta tendencia, que se repite en otras secciones del catálogo, como la sección "Gramática", probablemente sea un indicio de que las bibliotecas "para jesuitas" se van convirtiendo paulatinamente en Bibliotecas "de Jesuitas". ${ }^{18}$ Otras tendencias dignas de consideración son las referidas a las lenguas, formatos preferidos y lugares de edición.

\section{Lengua}

En la sección Filosofía, sea por los títulos, sea por la mención explícita de parte del copista, prevalecen los títulos en latín, aproximadamente el $82 \%$, seguidos por un $10 \%$ de títulos en castellano. Muy por debajo le siguen 4 obras en italiano, 3 en griego (una de ellas en versión bilingüe griego-latín), 2 en francés y 1 en portugués, que en conjunto apenas superan el $2 \%$ del total.

En la sección Historia profana el $47 \%$ de las obras están escritas en español, frente a las escritas en latín que llegan al 44,11\%. Esta preferencia por la lengua nacional se completa con 14 libros en italiano (5, 88 \%), 4 en francés (1, 60\%), 1 en portugués. Esta diferencia marcada respecto de la sección Filosofía, en la cual los libros en latín alcanzan hasta el $82 \%$ del total, se explica muy bien por la cuestión disciplinar. En la sección "Historia profana", una disciplina típica del Humanismo, las historias que abordan temas del siglo XVI, XVII y XVII generalmente están escritas en lenguas vernáculas. Las obras escritas en latín, por el contrario, son las que se refieren a historias del período clásico o medieval.

\section{Formato}

En cuanto a los formatos de la sección Filosofía, se destaca el tamaño $4^{\circ}$, con el $40 \%$, y el tamaño folio, con más del $34 \%$. Le siguen el tamaño $8^{\circ}$ con aproximadamente un $20 \%$ y muy por debajo el $12^{\circ}$ con un $3 \%$. A diferencia de lo que ocurre en otras

${ }^{18}$ Solana Pujalte, 2007a: 135. 
materias mencionadas en el catálogo, no se han encontrado registros de libros de filosofía con formato $16^{\circ}$.

La sección Historia Profana se caracteriza por el predominio del formato folio, con el $44 \%$, con el $35 \%$ le sigue el formato $8^{\circ}$ y, finalmente, con el $26,6 \%$ continúa el tamaño $4^{\circ}$. Muy por debajo figura el $12^{\circ}$ con un $0,84 \%$ (solamente 2 libros). A diferencia de lo que ocurre en otras materias mencionadas en el catálogo, no se registran libros de filosofía con formato $16^{\circ}$.

\section{Lugares de edición}

En cuanto a los lugares de edición, la proporción entre imprentas españolas y extranjeras es relativamente pareja. El $56 \%$ en imprentas del reino español y aproximadamente $44 \%$ del extranjero.

Aproximadamente un $60 \%$ de los libros de Filosofía proviene de imprentas extranjeras, mientras que el $40 \%$ lo hace de imprentas españolas. Entre los principales lugares de impresión del extranjero se destacan Lyon (46 obras), Venecia (34), París (31), Basilea (13), Roma y Amberes (11 respectivamente), Lisboa, Frankfurt y Colonia (6 cada una), entre otras ciudades. Entre las imprentas españolas, claramente lideran el número de títulos editados en las ciudades de Alcalá de Henares (35 obras), Salamanca (21) y Madrid (19), seguidas por Sevilla (9), Zaragoza (6), Valencia (5), Barcelona y Valladolid (3 cada una), Granada y Burgos (2). Cabe destacar la presencia de un libro editado en México, en 1719, titulado "Florilegio Medicinal" de Juan de Steynefer, único ejemplo de libro filosófico editado fuera del territorio europeo.

Entre los principales lugares de impresión del extranjero relevados en la sección Historia Profana, figuran Basilea (17 obras), Venecia (17), Lyon (14), Londres (11), París (8), Colonia (6), Amberes (4), Colonia (4), Nápoles (4), Maguncia (3), Roma (2), Florencia (3), Frankfurt (3), Lisboa (3), Milán y Berna (2), y Evora, Turín, Palermo, Hannover, Heidelberg (un ejemplar por ciudad). Entre las imprentas españolas, lidera, de manera abrumadora los títulos editados en Madrid (50 obras), Sevilla (10), Córdoba (6), Toledo (6), Valencia (6), León (5), Granada (4), Salamanca (4), Zaragoza (4), Pamplona (3), Jaén (2), Alcalá de Henares (2), Cádiz (1), Barcelona (1). Hay que destacar que, a diferencia de la sección filosofía en que sobresalen las ciudades universitarias con obras escritas en su enorme mayoría en latín y editoriales extranjeras, en la sección Historia Profana el resultado es marcadamente distinto. Los libros que predominan están escritos en español y el pie de imprenta es Madrid, ciudad a la que le sigue Sevilla. Esto indica que los libros no estaban dirigidos únicamente a universitarios, como en la sección Filosofía, sino destinados a un público más amplio. Cabe destacar la presencia de 2 libros editados en México (Don Antonio De Villa Señor, Teatro americano, México, 1746; Josephi Eguiara, Bibliotheca mexicana, México, 1755) y finalmente uno en Manila (Pedro Murillo Velarde, Historia de la provincia de Filipinas de la Compañía, Manila, 1749). ${ }^{19}$

Al referirse a los inventarios e índices, García Gómez afirma: “de todos, los sabidos y de los desconocidos, de su reconocimiento y estudio, queda una enorme labor

\footnotetext{
${ }^{19}$ Es de notar que la enorme producción historiográfica de la Compañía escrita para contar los avances de las misiones jesuitas en el mundo, desde la Historia Natural y Moral de las Indias de José de Acosta hasta la Conquista espiritual del Paraguay de Antonio Ruiz de Montoya figura en la sección Historia Sagrada.
} 
por llevar a cabo." ${ }^{20}$ En este sentido, el estudio de las secciones de Filosofía e Historia Profana ha intentado contribuir al conocimiento de las Bibliotecas Institucionales y ha pretendido sentar las bases de un abordaje cualitativo para trazar el perfil de la Biblioteca del antiguo Colegio de Santa Catalina, mediante el análisis de sus fondos bibliográficos.

\section{Normas de transcripción}

A la hora de transcribir el inventario manuscrito, se han aplicado una serie de normas basadas en aquellas que habitualmente se utilizan en España para de realizar este tipo de trabajos ${ }^{21}$ y reproducir el texto lo más exactamente posible.

Se indican a continuación las normas aplicadas:

1. Como pauta general de trabajo, se ha respetado la grafía original que presenta el documento. Sin embargo, en palabras latinas la grafía " $j$ ” en desinencias tales como librij se ha unificado en "i”, de acuerdo con las pautas del latín clásico.

2. Se han respetado algunos signos de puntuación, en tanto que otros han sido adaptados al sistema actual:

2.1. La doble coma (,,) que aparece detrás de ciertos números, cifras o dígitos ha sido sustituida por un solo punto (.). Ej: el año de publicación 1563, ha sido transcripto 1563.

2.2. Los dos puntos (: ) han sido sustituidos por la coma (,).

2.3. Ha sido eliminada la serie de puntos $(. . . . . .$.$) colocados después del año de$ publicación.

3. Se ha actualizado la separación de palabras (dela > de la).

4. Se han mantenido las abreviaturas y siglas tal como figuran en el documento

5. Se ha respetado la notación para transcribir el número de tomos.

6. Se han eliminado los guiones bajos al final de algunas palabras.

7. Se ha respetado el uso de las mayúsculas y minúsculas según el criterio que aparece en el documento.

8. En el inventario la indicación de tomos y formatos encabeza y cierra cada registro. En la transcripción dicha indicación figura al final, a continuación del año.

\footnotetext{
${ }^{20}$ García Gómez, 2010: 30.

${ }^{21}$ Játiva Miralles, 2007.
} 


\section{SECCIÓN FILOSOFÍA}

1. Aristotelis Ethica. Parisiis, 1560. 1t., $4^{\circ}$.

Aristotelis ... Ethicorum ad Nicomachum libri decem / Ioanne Argyropylo ... interprete nuper ad Graecum exemplar diligentissimè recogniti \& cum Donati Acciaioli ... commentariis castigatissimis denuò in lucem editi. Parisiis : apud Ioannem Roigny ..., 1560 (excudebat Andreas Wechelus ...)

CCPB000849960-8

2. Eiusd., De Interprettatione Topicarum, rhetoricorum, Ethicorum Politicorum, et magnorum Moralium Libr. Basileę, 1563. 1t., fol.

Aristotelis Stagiritae tripartitae Philosophiae opera omnia absolutissima ... ; accessit rerum \& verborum in his memorabilium locupletissimus Index. Basileae: per Ioannem Heruagium, 1563 (ex officina Heruagiana)

CCPB000152621-9

3. Eiusd., Libellus de Coloribus. Parisiis, 1549. 1t., $8^{\circ}$.

Aristotelis vel Theophrasti De coloribus libellus / a Simone Portio ... latinitate donatus [et] commentarijs illustratus ... Parisiis : apud Vascosanum ..., 1549

ССРB000570632-7

4. Eiusd., 8 Libri Phisicor. Versi Argiropilo. Lugduni, 1547. 1t., $8^{\circ}$.

Physicorum Aristotelis sive de naturali auscultatione libri octo / Ioanne Argyropylo ... interprete. Lugduni : apud Theobaldum Paganum, 1547

CCPB000152608-1

5. Alexandri Aphrodisięi, comm. ${ }^{\text {a }}$ in 12 Aristotelis libr. de prima philosophia; Geninesio de Sepulveda interprete. Parisiis, 1536. 1t., fol.

Alexandri Aphrodisiei Commentaria in duodecim Aristotelis libros de prima Philosophia / interprete Ioane Genesio Sepulueda ...

Parisiis : apud Simonem Colinaeum, 1536 (ex officina ... Ludouici Cyanei)

CCPB000030639-8

6. Augustini Niphi, in Libr. Aristotelis. Venetiis, 1550, 1552 o 1553. 4t., fol.

Augustini Niphi Medices philosophi suessani In libros Aristotelis de Generatione \& Corruptione interpretationes \& commentaria / ab ipso auctore nouissime recognitae \& castigatae ; eiusdem Augustini Niphi in commentarijs \& interpretationibus eorundem librorum Aristotelis de generatione \& corruptione Paralipomena ... ; eiusdem quaestio De infinitate primi motoris ; addito nuper ... locupletissimo índice. Venetiis : apud Hieronymum Schotum, 1550

CCPB000152657-X

Augustini Niphi... Expositio super octo Aristotelis Stagiritae libros de Physico Auditu / cum duplici textus tralatione... Averrois etiam Cordubensis in eosdem libros prooemium ac comm ${ }^{-}$etaria, cum ipsius Augustini Suessani refertissima expositione, annotationibus, ac postremis in omnes libros recognitionibus, castigatissima conspiciuntur ...Venetiis : apud Iuntas, 1552

CCPB000456672-6

Augustini Niphi ... Super libros priorum Aristotelis commentaria castigatissima : quae figuris quibusdam ex optimis exemplaribus desumptis, syllogismorum omnium in 
quacunq[ue] figura contextorum tam utiles, quàm inutiles coniugationes ingeniosissime ostendentibus, luculentiora reddita sunt, necnon quamplurimis margineis annotationibus illustrata ...Venetiis : apud Iuntas, 1553 (apud haeredes Lucaeantonij Iuntae)

CCPB000018742-9

7. Augustini Eugubini, Peremnis Philosophia. Basileę, 1542. 1t., $4^{\mathrm{o}}$.

Augustini Steuchii ... De perenni philosophia libri X ... ; Idem de Eugubij, urbis suae, nomine. Basileae: per Nicolaum Bryling et Sebastianum Francken, 1542 CCPB000188832-3

8. Aberrois, in Aristotelis opera comm. ${ }^{a}$ Venetiis, $1562.11 \mathrm{t} ., 4^{\circ}$.

Aristotelis omnia quae extant opera... : Averrois... in ea opera... comentarij...Venetiis : apud Ivnctas, 1562

CCPB000119475-5

9. Andres Vacci, Las 12 piedras preciosas (en Italiano). Roma, 1587. 1t., $4^{\circ}$.

Le XII pietre pretiose, le quali per ordine di dio nella santa legge, adornauano i vestimenti del sommo Sacerdote ... : discorso dell'Alicorno, et delle sue singolarissime virtù et della gran Bestia detta Alce da gli Antichi / di Andrea Bacci. In Roma : appresso Bartolomeo Grassi, 1587 (nella stamparia di Vicenzo Accolti, in Borgo nouo)

CСРB000030948-6

10. Arcisii Gregorii, Scholia in Isagogem Porphirii. Salmant, 1554. 1t., $4^{\circ}$.

F. Arcisii Gregorii valentini ... in Eisagôgen Prophyrianam scholia quaestionesq[ue] breuissimae : omnibus philosophiae studiosis ... / ab ipso authore nunc primùm in lucem aeditae. Salmanticae : excudebat Andreas à Portonarijs, 1554

CCPB000012293-9

11. Antonii Le Grand, Institutio Philosophię cartesianę. Norimberg, 1591. 1t., $4^{\circ}$.

Edición no localizada. Posiblemente se trate de un error de fecha del amanuense:

Antonii Le Grand Institutio philosophiae, secundum principia Renati Descartes. Nova methodo adornata, \& explicata. In usum juventutis academicae. Norimbergae: J. Zieger, 1695

CCFR: 8079 MAGASIN

12. El Abate Nollet, Leccion. ${ }^{\mathrm{s}}$ de Phisica experim traducid. por Zacagnini. Madrid, 1757. 6t., $4^{\circ}$.

Lecciones de Physica Experimental / escritas en Idioma Francés por el Abate Nollet ... ; traducidas al Español por el P. Antonio Zacagnini ... ; Tomo Primero. En Madrid : Joachin Ibarra ..., 1757

CCPB000144419-0

13. Apulęi Madaurensis, opus philosophicum. Lugduni, 1614. 1t., $4^{\circ}$.

L. Apulei madaurensis philosophi platonici opera... / cum Philippi Beroaldi... commentariis ; recénsque Godescalci Stennechi in L. Apuleij opera ommia quaestionibus... emendationibus adiectis. Lugduni: apud viduam Anthonii de Harsy..., 1614 (ex typographía Iacobi Mallet)

CCPB000053474-9

14. Alberti Magni, compend. philosophię natularis. Venetiis, 1t., $4^{\circ}$. 
Edición no localizada

15. Alessandri Piccolominęi, Paraphrasis in mecanicas quęst. ${ }^{\mathrm{s}}$ Aristotelis. Venetiis, 1565. 1t., $8^{\circ}$.

Alexandri Piccolomini in mechanicas quaestiones aristotelis paraphrasis paulo quidem plenior eiusdem commentrium de certitudine mathematicarum disciplinarum ... et in fine logicae facultatis ...Venetiis: apud Traianum Curtium, 1565

CCPB000721959-8

16. Antonii Goudin, Philosophia. Venetiis, 17361 . $^{\mathrm{s}}$ tom. ${ }^{\mathrm{s}}$ deficiunt cęteri. $1 \mathrm{t} ., 8^{\mathrm{o}}$.

Philosophia juxta inconcussa tutissimaque divi Thomae dogmata : quatuor tomis comprehensa / authore P.F. Antonio Gaudin ... Ordinis Praedicatorum ... ; tomus primus ... Venetiis : typis Dominici Lovisa, 1736

CCPB000670158-2

17. Alonso de Barros, Probervios morales. Lisboa, 1617. 1t., $4^{\circ}$.

Perla de los prouerbios morales / de Alonso de Barros ... Impressos em Lisboa : por Iorge Rodriguez, 1617

CCPB000034772-8

18. Alonso Nuñez, Seneca impugnado. Madrid, 1650. 1t., $4^{\circ}$.

Seneca impugnado de Seneca en questiones politicas y morales... / por don Alonso Nuñez de Castro... (En Madrid : por Pablo de Val : a costa de Pedro Coello, 1650)

CCPB000033901-6

19. Annęi Senecę, opera a J. Lipsio emendata. Antuerp., 1605. 1t., fol.

L. Annaei Senecae... Opera quae exstant omnia / a Iusto Lipsio emendata et scholijs illustrata. Antuerpiae: ex Officina Plantiniana, apud Ioannem Moretum, 1605

CCPB000136687-4

20. Del mismo, Philosoph. ${ }^{\mathrm{a}}$ moral traducida, 5 libros. Amberes.

Edición no localizada.

21. Augustini Oregii, Philosophicum Pręludium. Romę, 1637. 1t., fol.

Augustini Oregii S.R.E. cardinalis archiepiscopi Beneventani ad suos in vniversas theologiae partes Tractatus philosophicum praeludium ... opus posthumum. Romae: ex typographia Manelphi Manelphij, 1637

CCPB000907393-0

22. Alphonsi a vera cruce, Philosophia. Salm., 1562. 2t., fol.

Resolutio dialectica cum textu Aristotelis / ad modum ... Fratris Alphonsi à Vera Cruce Sacri ordinis Eremitarum Diui Augustini ... ; accessit breue epitome totius Dialecticae ; nunc secundò summo studio, fide, exactaqz cura reuisa ab autore, \& à plurimis mendis correcta, \& aliquando aucta. Salmanticae: excudebat Ioannes Maria à Terranoua, 1562 CCPB000031385-8

23. Antonii Iribarren, Cursus Philosophicus. Cęsaraugustę, 1699. 3t., $4^{\text {o }}$.

Fr. Antonii Iribarren bilbilitani ex sacro praedicatorum ordine ... Cursus phylosophici tomus prior : tractatus prior [-secundus]... Caesar-Augustae : apud Emmanuelem Roman..., 1699 


\section{ССРB000049154-3}

24. Augustini Pallavicini, explicat. paraphrastica in 4 Libr. Metheororum Aristot. Genuę, 1610. 1., $4^{\circ}$.

Augustini Pallavicini Francisci F. Patricii Genuensis Explanatio paraphrastica in quatuor libros meteororum Aristotelis... Genuae : Ex Typographia Iosephi Pauonis, 1613

CCPB000210931-X

25. Eiusd., in Libros Phisicorum. Romę, 1617. 1t. $4^{\circ}$.

Augustini Pallauicini Francisci F. Patritii genuensis Explanatio paraphrastica in octo libros physicorum Aristotelis... Romae : apud Bartholomaeum Zannettum, 1617

CCPB000210933-6

26. Eiusd., de Generatione et Corruptione. Genuę, 1614. 1t. $4^{\circ}$.

Augustini Pallauicini, Francisci Fil... Explanatio paraphrastica in duos Aristotelis libros de generatione et corruptione. Genuae : ex typographia Iosephi Pauonis, 1614

CCPB000210932-8

27. Antonio de Fuente la Peña, el ente dilucidado. Madrid, 1676. 1t. $4^{\circ}$.

El ente dilucidado : libro en el cual se trata de diferentes especies, o materiales, ya del Nacimiento de Criaturas, y animales de las hedades del hombre ... / compuesto por Antonio de Fuentelapena. Madrid : [s.n.], 1676

CCPB001005366-2

28. M. el Abad de Pluche, Espettaculo de la Naturaleza, traducido p. ${ }^{\mathrm{r}}$ el P. ${ }^{\mathrm{e}}$ Terreros. Madrid, 1753, hasta 1755. 16t., $4^{\circ}$.

Espectáculo de la Naturaleza o Conversaciones a cerca de las particularidades de la Historia Natural... / escrito en el Idioma Francés por el Abad M. Pluche ; traducido al Castellano por el P. Estevan de Terreros y Pando... ; tomo I [-XIV] En Madrid : en la oficina de D. Gabriel Ramirez..., 1753-1755

CCPB000059964-6

29. Alberti de Saxonia, in Libr. Phisicor. De Cęlo, et Mundo, de Ortu et interitu, thimoris in libr. Metheororum, et Buridani in Libr. De Anima Sensu, et Sensatu, memoria, somno, et aliis quęst. recognitę accuratione summa, et iudicio Georgii Lokert. Lugduni, 1534.1t., fol.

Questiones et decisiones physicales insignium virorum : Alberti de Saxonia in Octo libros physicorum ; Tres libros de celo et mundo ; Duos lib. De generatione et corruptione. Thimonis in Quatuor libros meteorum. Buridani in Aristotelis tres lib. de anima ; lib. de sensu et sensato ; Librum de memoria et reministentia ; Librum de somno et vigilia... / recognite... Georgi Lokert per quem collecte sunt tabule ... Venundantur Lugduni : apud Iacobum Giuntam impensa, 1534 (apud Ioanne Moylin) CCPB000150210-7

30. Bartolomęi Mastrii, Cursus Philosoph. Venetiis, 1685. 5t., fol.

Theologica moralis ad mentem DD. Seraphici, et subtilis concinnata et in disputationes vigiutiocto distributa / auctore F. Bartholomaeo Mastrio de Meldula... Venetiis: apud Ioannem Iacobum Hertz, 1685

CCPB000128535-1 
31. Benedicti Curcii, hortorum libr. $3^{\circ}$. Lug., 1560. 1t., fol.

Hortorum libri triginta / autore Benedicto Curtio Symphoriano, equite in ecclesia Lugdunensi ; in quibus continetur arborum historia, partim ex probatissimis quibusq[ue] autoribus, partim ex ipsius autoris obseruatione collecta. Lugduni: excudebat Joannes Tornaesius CCPB000006769-5

Typographus Regius, 1560

32. Boecio traducido, y emendado p. ${ }^{r}$ Fr. Agustin Lopez. Valladolid, 1604. 1t., fol. Boecio De consolacion / traduzido y comentado por ... Fray Augustin Lopez ... de la orden de S. Bernardo y enriquecido con aduertencias sentenciosas y tratados espirituales aproposito de lo que enseña Boecio. Impresso en Valladolid : por Iuan de Bostillo ... : $\begin{array}{lllll}\text { vendese en } & \text { casa Antonio Cuello, }\end{array}$ CCPB000035135-0

33. Bonaventurę a S. ${ }^{\text {to }}$ Augustino, Anima. Salm, 1725. 1t., fol.

Artium Cursus : Thomus IV. Tres Libros Philosophi de Anima Comprehendens... / Auctore RR. P.M. Fr. Bonaventura a S. Augustino, Hieronymiano. Secunda $\begin{array}{lllll}\text { Edditio. Salamanca } & \text { : } & \text { Sebastián } & \text { de } & \text { Estrada, }\end{array}$ CCPB000183518-1

34. Benjamin Martin, Gramatica de las ciencias philosophicas (en francès). Paris, 1749. $1 \mathrm{t} ., 4^{\mathrm{o}}$.

Grammaire des sciences philosophiques, ou Analyse abregée de la philosophie moderne / appuyée sur les experiences, traduit de l'Anglois de Benj. Martin. Paris : chez Briasson..., 1749 ССРВ000224354-7

35. Conradi Gesneri, opera. Francofurti, 1602, 1604. 3t., fol.

Conradi Gesneri medici Tigurini Historiae animalium liber primus : de quadrupedibus $\begin{array}{llll}\text { viuiparis } \quad . . \text { Francofurti }: \text { in bibliopalio Cambieriano, } & 1602\end{array}$ CСРB000048163-7

Conradi Gesneri ... Historiae animalium : liber IV : qui est de piscium \& aquatilium animantium natura ... ; Paralipomena quedam ad finem adiecta sunt. Francofurti : In bibliopolio Andreae Cambieri, 1604 CCPB000048162-9

36. Chrisofori Javeli, opera. Lugd., 1568. 2t. fol.

Dn. Chrysostomi Iavelli canapicii Ordinis Praedicatorum ... Totius rationalis naturalis, diuinae ac moralis philosophiae compendium ...: in duos tomos digestum ...: his adiecimus in libros Physicorum, De anima, Metaphysicorum eiusdem quaestiones ... : ad haec omnia accedit index ... Lugduni : apud haeredes Iacobi Iunctae, 1568 (excudebat Iacobus Faurus)

CCPB000013491-0

37. Carlos Principe de Viana, traduccion en Romance de la Philosophia moral de Aristoteles. Zaragoza, 1509. 1t., fol.

La philosofia moral del Aristotel : es a saber Ethicas, Polithicas y Economicas : en romançe / [transladados por Carlos principe de Viana ... nueuamente han sido 
trasladados del latin en romançe de la traslacion de Leonardo Aretino] Impresos en ... Çaragoça: por industria $y$ despensa de Gorge Coci aleman, 1509 CCPB000119494-1

38. Complutens Discalceatorum, Logica, Generatio, et Anima. Barcinone, 1635. 3t., $4^{\circ}$. Collegij Complutensis Discalceatorum fratrum beatae Mariae de Monte Carmeli Disputationes in duos libros Aristotelis de Generatione et Corruptione seu de Ortu et Interitu : iuxta miram angelici doctoris diui Thomae \& Scholae eius dostrinam... $\begin{array}{lllll}\text { Barcinone }: \text { ex typographia Sebastiani à Cormellas..., } & 1635\end{array}$ CCPB000047330-8

39. Christophori Cavero, Brevis Summularum recapitulatio. Vallisoleti, 1623. 1t., $4^{\circ}$. Breuis Summularum recapitulatio succinctaque totius logicae euisceratio / auctore fr. Chrisostomo Cabero ... cisterciensi ... monacho ... Vallisoleti : ex officina Ioannis Baptistae Varesii : expensis Francisci Becerrili ..., 1623 CCPB000037759-7

40. Caii Plini Secundi, Hist. Naturalis. Basileę, 1530. 1t., fol.

C. Plinii Secundi... Epistolarum libri X : ad exemplar... Rodolphi Agricolae... recogniti; Panegyricus Traiano caesari dictus; De viris illustribus rei militaris \& administrande rei publicae. Accesserunt... Suetonij Tranquili liber de... grammaticis \& $\begin{array}{llll}\text { rhetoribus... Basileae } \quad \text { apud } & 1530\end{array}$ CCPB000188257-0

41. Catonis, Distica Moralia, cum Boetii Libris de Consolatione; et floribus Senecę, et Ciceronis. Lug., 1529. 1t., $8^{\circ}$.

Catonis disticha moralia cum scholijs Des. Erasmi Roterodami ... Lugd. : Seb. Gryphius Germ. excud., 1529

CCPB000029102-1

42. Dominici Soto, comm. ${ }^{a}$ in Summulas Aristotelis. Salm., 1580. 1t., fol.

Reuerendi Patris Dominici Soto Segouiensis Theologi Ordinis Praedicatorum In Dialecticam Aristotelis commentarij. Salmanticae : apud Vincentium à Portonarijs, 1580

CCPB000023944-5

43. Eiusd., comm. ${ }^{\text {a }}$ in 8 libros Phisicor. Arist. Salmant, 1572. 1t., fol.

Reuerendi Patris Dominici Soto Segobiensis Theologi ordinis Praedicatorum ... Super octo libros Physicorum Aristotelis commentaria. Salmanticae : in aedibus Dominici à Portonarijs 1572 CCPB000182828-2

44. Danielis Senertii, Phisica Hippomnemata. Lug., 1637. 1t., $8^{\circ}$.

Physica hypomnemata ... / autore Daniele Senner ... Lugduni : Sumptibus Petri Ravaud ..., 1637

CCPB000577587-6

45. Didaci Ortiz, Sumularum brevis copilatio. Hispalis, 1639. 1t., $4^{\circ}$. 
Logicae breuis explicatio : cum grauioribus quaestionibus a logicis disputari solitis / authore F. Didaco Ortiz... Ordinis Praedicatorum... Hispalis : ex officina S. Pauli, 1639 CCPB000133867-6

46. Eduardi Varo Erbet, de veritate distincta.

Edición no localizada.

47. Eusebii Amort, Philosophia Polingana. Venetiis, 1734. 6t., $8^{\circ}$.

Philosophia pollingana ad normam Burgundicae : in quinque tomos distributa ... / authore R.D. Eusebio Amort, canonico regulari lateranensi ...; tomus primus, summulas et logicam continens. Venetiis : apud Jo. Baptistam Recurti, 1734 CCPB000070127-0

48. Eliani, Hist. ${ }^{a}$ naturalis. Lug., 1565, 1t., $8^{\circ}$.

Aeliani de Historia Animalium libri XVII / quos ex integro ac veteri exemplari graeco Petrus Gillius vertit vnà cum noua elephantorum descriptione ; item Demetrii de cura accipitrum, \& de cura \& medicina canum eodem Petro Gillio interprete ... Lugduni : $\begin{array}{lll}\text { apud } & \text { Guliel. } & \text { Rovillium, }\end{array}$ ССРВ000008871-4

49. Franci Ruicii, Index locupletissimus apud Zenobium S. Facundi, et primitivi. 1540. t1., fol.

Index locupletissimus duobus tomis digestus in Aristotelis Stagiritae opera quae extent / auctore R. Patre F. Francisco Ruizio vallisoletano, S. Facundi ordinis S. Benedicti Abbate ... ; eiusdem auctoris iudicium de Aristotelis operibus, quae nuper Simon Grynaeus ex impressione repraesentauit habes in calce secundi tomi [Sahagun] : Apud inclytum Sanctorum martyrum Facundi \& Primitiui Coenobi ${ }^{-} \mathrm{u}, 1540$ (excudebat $^{-}$ Nicolaus CCPB000025576-9

Tierryus)

50. Franci. Valesii, versio 8 lita. Aristot. Complut., 1562. 1t., fol.

Francisci Vallesi Couarrubiani ... Octo librorum Aristotelis de physica doctrina versio recens \& commentaria ... Compluti : ex officina Andreae ab Angulo, 1562 CCPB000027235-3

51. Eiusd., Sacra Philosophia. Lug., 1588. 1t., $8^{\circ}$.

Francisci Vallesii De iis quae scripta sunt physicè in libris sacris, siue de Sacra Philosophia liber singularis ... ; cui propter argumenti similitudinem, adiuncti sunt duo alij ... Leuini Lemnii de platis sacris et Francisci Ruei de Gemmis ... Lugduni : sumptibus Sib.

à Porta,

1588

\section{CCPB000188992-3}

52. Eiusd., comm. ${ }^{\mathrm{a}}$ in Libr. Methęororum. 1558. 1t., $4^{\mathrm{o}}$.

Francisci Vallesii Couarruuianii ... Commentaria in quartum librum meteoron Aristotelis. Compluti $\quad$ in officina Ioannis Brocarij, 1558

CCPB000027236-1

53. Franci Titelmmani, Philosophię naturalis compendium. Lug., 15451t., $8^{\circ}$. Philosophiae naturalis compendium libri XII ... / per Fratrem Franciscum Titelmannum Hassellensem ordinis fratrum Minorum ... Lugduni : apud Antonium Vincentium : 
Godefridus et Marcellus Beringi fratres excudebant, 1545

\section{CCPB000441111-0}

54. Eiusd., Dialectica. Salm., 1554. 1t., $8^{\circ}$.

Edición no localizada.

55. Franci Bonamici, de Motu libr. 10, et de aliis rebus Phisicis. Florentię, 1591. 1t., fol. Francisci Bonamici Florentini ... De motu libri X ... Florentiae : apud Bartholomaeum Sermartellium, CCPB000003792-3

1591

56. Franci Palanco, Cursus Philosophicus. Matriti,1703 et 1705. 3t., $4^{\circ}$.

Cursus philosophicus : iuxta miram Angelici praedeptoris doctrinam digestus et pro communi studentium : vtilitate tribus tomis absolutus ; pars prima, complectens minorem, et maiorem dialecticam / auctore ... Francisco Palanco Campo-Regalensi ... Ordinis Minimorum ... Matriti : Apud Lucam Antonium Betmar \& Narbaez ... \& $\begin{array}{lllll}\text { Supremi Castelle } & \text { Senatus à } & \text { Camera } & \text { Ostiarij, } & 1703\end{array}$ CCPB000254528-4

Cursus philosophicus : iuxta miram Angelici praeceptoris doctrinam digestus... tribus tomis absolutus : pars secunda, continens octo libros Physicorum / auctore... Fr. Francisco Palanco Campo-Regalensi Sac. Ordinis Minimorum... Matriti : apud Lucam $\begin{array}{lllll}\text { Antonium } & \text { Bedmar } & \text { \& } & \text { Narvaez..., } & 1705\end{array}$ CCPB000180907-5

57. Franci Silbestri Ferrariensis, Quęst. In Libr. Phisic. Romę, 1576. 1t., $4^{\circ}$.

Quaestiones eruditissimae in libros Physicorum ... / F. Francisci Sylvestri ... totius Ordinis Praedicatorum Generalis ; cum quibusdam aliis quaestionibus et additionibus R.P.F. Mathiae Aquarii ... Romae : apud Haeredes Antonii Bladii ..., 1576 CCPB000023624-1

58. Franci de Leyva et Aguilar, Antiparadoxa. Cordubę, 1634. 1t., 4º.

Antiparadoxa Negans un quam corpori phisico non viventi duplicem motum localem contrarium ab interno principio activo naturaliter convenire contra singularem \& paradoxicam opinionem quae affirmat posse... / Auctore Francisco de Leiva \& Aguilar, Medico cordubensi ... Cordubae : Apud Salvatorem de Cea Tesa, 1634 CCPB000583631-X

59. Franci Raxo, de Comentis. 1578. 1t., $4^{\circ}$.

De cometis, et prodigiosis eorum portentis libri quatuor ... / Francisco Fernandez Raxo... autore. Excudebat Madriti : Guillelmus Drouy ..., 1579 [i.e. 1578?] CCPB000155364-X

60. Fortuni Liceti, Alegoria Peripatetica in Arist. Enigma Elialelia Crispis. Patavii, 1639. $1 \mathrm{t} .4^{\mathrm{o}}$.

Allegoria peripatetica de generatione, amicitia et priuatione in Aristotelicum Aenigma Elia Lelia Crispis / Fortunius Licetus ... Patauij : apud Gasparem Criuellarium, 1639 CCPB000882951-9

61. Fran. ${ }^{\mathrm{co}}$ Gurmendi, Dottrina Phisica y moral de Principes. Madrid,1615. 1t., $8^{\mathrm{o}}$. 
Doctrina Phisica y moral de principes... / traduzido de arabigo en castellano por Francisco de Gurmendi... En Madrid : por Andres de Parra y Gaspar Garcia, 1615 CCPB000037003-7

62. Fran. ${ }^{\text {co }}$ Thamara, Ciceron en romance los libros de oficios de amisitia y de Senectutis. Salamanca, 1582. 1t., $8^{\circ}$.

Libro de Marco Tulio Ciceron en que se trata de los officios, de la amicicia, de la senetud, con la Economica de Xenophon / traduzidos de latin en romance castellano por Francisco Thamara... ; añadieron se agora nueuamente los Paradoxos y el Sueño de Scipion, traduzidos por Iuan Iaraua. En Salamanca : en casa de Pedro Lasso : a costa de Diego Lopez,

1582

CCPB000000050-7

63. Franci Alfonsi, Institutionum dialectican libr. 5. Comp., 1642. 1t., $8^{\circ}$.

Institutionum dialecticarum libri quinque / authore P. Francisco Alfonso ... Societate $\begin{array}{lllll}\text { Iesu } \quad . . \text { Compluti: } & \text { apud Antonium }\end{array}$ ССРВ000032370-5

64. Ferdinandi de Encinas, Tract. ${ }^{\mathrm{s}}$ Silogismorum. Maguntię, 1528. 1t., fol.

Edición no localizada. No se halló una edición de Moguncia, sino las siguientes:

Tractatus sillogismorum Magistri Fernandi de Enzinas permulta scitu dignissima complectentes ac tertio recogniti cum modo assignandi eorum defectus qui in omnmiu[m] propositionum genere pterunt contingere : adiectis quibusdam regulis quibus promptu[m] erit consequentis aliquo errore infectis instare. Impressum Lugd[uni] : per Antonium du Ry, 1528

CCPB000243968-9

$\mathrm{y}$

Tractatus sillogismorum Magistri Fernandi de Enzinas. Parrhisius: veneunt in Gormontiana libraria e regione Collegij Coquerettici ad insigne Geminarum Cipparum, 1518

CCPB000449322-2

65. Franci Patricii, de Institunione Reipublicę. Parisiis, 1569. 1t., fol.

Francisci Patricii ... Pontificis Caietani, De institutione Reipublicae libri nouem, : historiarum sententiarúmque varietate refertissimi, cum annotationib[us] margineis, indicéq[ue] vocabularum ... copiosissimo ... digesto. Parisiis: apud Aegidium Gorbinum ..., 1569

ССРB000324225-0

66. Gasparis Cardillo, Summa Summularu. Compluti, 1557. 1t., $8^{\circ}$.

Edición no localizada. Posiblemente se trate de un error de fecha:

Summa summularum, autore Gasparo Cardillo Villalpandeo. Compluti: j. Inniguez a Laquerica excudebat, 1577

CCFR: R-10804 - Tolbiac - Rez de Jardin - Philosophie, histoire, sciences de l'homme Magasin

67. Eiusd., Apologia Aristotel. Comp., 1560. 1t., $4^{\circ}$. 
Apologia Aristotelis aduersus eos, qui aiunt sensisse animam cum corpore extingui ... / Autore Gasparo Cardillo Villalpandeo ... Compluti : ex officina Ioannis Brocarij, 1560 CCPB000004298-6

68. Eiusd., comm. ${ }^{\mathrm{s}}$ in cathegorias Arist. et in Prędicabilia Porphirii. Com., 1558. 1t. $4^{\circ}$. Commentarius in categorias Aristotelis vna cum quaestionibus in easdem / autore Gasparo Cardillo Villalpando ... Compluti : ex officina Ioannis Brocarij, 1558 CCPB000151081-9

69. Eiusd., Comm. ${ }^{a}$ in Libr. Priorum. Comp., 1562. 1t., $8^{\circ}$.

Commentarius in libros de priori resolutione Aristotelis / authore Gasparo Cardillo Villalpandeo ... Compluti : ex typographia Sebastiani Martinez, 1562 CCPB000268275-3

70. Eius., in Libr. Posteriorum Comm. Comp., 1558. 1t., $4^{\circ}$.

Commentarius in libros Aristotelis de posteriore resolutione : cui adiectae sunt quaestiones proposito negotio consentaneae / autore Gasparo Cardillo Villalpandeo ... $\begin{array}{lllll}\text { Compluti: ex } & \text { officina } & \text { Ioannis } & \text { Brocarij, } & 1558\end{array}$ CCPB000004308-7

71. Eius., in Libros Phisicorum. Comp., 1560

Edición no localizada.

72. Gallilleo Gallilęi, Discurso sbre el peso de los Cuerpos en el aire (en Italiano). Florencia, 1612. 1t., $4^{\circ}$.

Edición no localizada. Quizás de la siguiente:

Discorso al serenissimo don Cosimo 2. gran duca di Toscana intorno alle cose, che stanno in su l'acqua, ò che in quella si muovono, di Galileo Galilei filosofo, e matematico della medesima altezza serenissima. In Firenze : appresso Cosimo Giunti, 1612

IT\ICCU\LIAE\043476

73. Gabrielis Palęoti, de Bono Senectutis. Venetiis, 1598. 1t., $8^{\circ}$.

Gabrielis Paleoti ... De bono senectutis libri tres ... Venetiis : apud Minimam Societatem, 1598 CCPB000211262-0

74. Gasparis Contareni, Opera. Parisiis,1571. 1t., fol. Gasparis Contareni Cardinalis Opera. Parisiis : apud Sebastianum Niuellium ..., 1571 CCPB000006272-3

75. Georgii Trapesuntii, de re Dialectica liber. Lugduni, 1545. 1t., $8^{\circ}$.

Georgii Trapezuntii De re dialectica liber / scholijs Ioannis Neomagi [et] Bathol. Latomi illustratus ; accessit Georgii Vallae ... De expedita ratione argume[n]tandi libellus, cum Petri Mosellani ... in eiusde[m] Categoremata ac Categorias scholijs. Lugduni : apud Antonium Vincentium, 1545 (Godefridus et Marcellus Beringi fratres excudebant) CCPB000775396-9

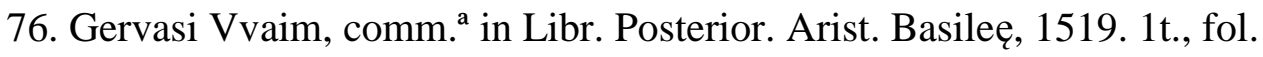


Tractatus noticiarum Gervasij VVaim Sueui ; eiusdem Questiones in libros posteriorum resolutionum philosophi [Parisijs] : impressus per Nicolaum de pratis : expensis Conradi Resch alemani. Commorantis in vico diui Iacobi ad signum scuti Basilie[n]sis, 1519, die vero xxviij mensis Martij CCPB000028344-4

77. Gaspari Cechinelli, Viridarium Politicum. Augustętaurinorum, 1650. 1t., fol. Viridarium politicum ex quo excerpuntur folres, \& fructus pro ministris principum, ecclesiasticis personis, patribusfamilias, \& alijs moralia sitientibus olim editum / ab ... D. Gasparo Cecchinellio...Tunc temporis nuncio apost. apud sereniss. Ducem sabaudiae, ... Augustae Taurinorum, 1650 (ex Typographia Ioannis Iacobi Rustis) ССРВ000883489-X

78. Gasparis de la Fuente, quęst. Dialectic. Et Phisic. Lug., 1631. 1t., 4.

R.F. Fr. Gasparis de la Fuente ... Minoritarum Regularis Observantiae ... Quaestiones dialecticae \& physicae ad mentem ... Ioannis Duns Scoti. Lugduni : sumptibus Iacobi \& Andreae Prost, 1631

CCPB000220904-7

79. Hieronymi Fracastorii, opera omnia. Venetiis, 1584. 1t., $4^{\circ}$.

Hieronymi Fracastorii... opera omnia quorum nomina sequens pagina plenius indicat : accessit index locupletissimus. Venetiis: Apud Iuntas, 1584 (Al fin: 1574) CCPB000010357-8

80. Hieronymi Pla, commentar. in Isagogem Porphirii, et Aristotleli Logicam. Valentię, 1597. 1 t., $4^{\circ}$.

Hieronymi Pla bonarum artium magistri ... in ... valentina academia ... Commentarii vna cvm Qvaestionibus in Porphirii Isagogen [et] vniuersam Aristotelis logicam. Valentiae : $\begin{array}{llllllll}\text { apud Petrum } & \text { Patricu } & \ldots & \text { : } & \text { expensis }\end{array}$ CCPB000021111-7

81. Hieronymi Provenzalis, tract. ${ }^{\mathrm{s}}$ de Sensibus. Romę, 1597. 1t., $4^{\mathrm{o}}$.

De Sensibus Hieronymi Provenzalis... tractatus. Romae: Apud Bernardum Basam, 1597 CCPB000021997-5

82. Hieronymi Osorii, de Regis institutionis disciplina, libr. 8; cum epistula ad Elisabetham Anglię Reginam. Olisipone, 15721t., $4^{\text {}}$.

D. Hieronymi Osorii Lusitani ... De regis institutione et disciplina, lib. VIII... Olysippone : Ex officina Ioannis Hispani, 1571 (excudebat Franciscus Correa, 1572)

CCPB000019372-0

83. Eiusd., de Gloria Libr. 5. comp., 1568. 1t., $4^{\circ}$.

$\begin{array}{lcccccr}\text { Hieronymi } & \text { Osorii } & \ldots & \text { De } & \text { gloria } & \text { libri } & \text { V... } \\ \text { Compluti } & : & \text { excudebat } & \text { Andreas } & \text { de } & \text { Angulo, } & 1568\end{array}$

CCPB000188645-2

84. Eiusd., de Nobilitate civil. Olisipone, 1542. 1t., $4^{\mathrm{o}}$. 
Hieronyni Osorii... De nobilitate civili libri duo : eiusdem de nobilitate christiana libri $\begin{array}{lllll}\text { tres. Olyssipone } \quad \text { : } & \text { apud Ludouicum }\end{array}$ CCPB000188646-0

85. Jacobi Fabri, in Logicam Aristotel. Paraphrassim. Parisiis, 1543. 1t., fol. Edición no localizada.

86. Eiusd., in Phisicam naturalem. Compluti, 1540. 1t., fol.

In hoc opere continentur totius Philosophiae naturalis Paraphrases : adiecto ad literam familiari commentario, declaratae \& hoc ordine digestae : Paraphrasis VIII Physicorum Aristotelis : duo dialogi Physici ; Paraphrasis IIII de coelo \& mundo completor $^{-} \mathrm{u}$; Paraphrasis II de generatione \& corruptione ; Paraphrasis IIII Metheororum completorum ; Paraphrasis III de anima completorum ; Paraphrasis libri de sensu \& sensato ; Paraphrasis libri de memoria \& reminiscentia ; Paraphrasis libri de somno \& vigilia ; Paraphrasis libri de longitudine \& breuitate vitae ; Introductio Metaphysica IIII dialogis declarata / [Iacobi Fabri Stapulensis] [Compluti] : excudebat Ioannes Brocarius $\begin{array}{lll}\text { in alma } & \text { Complutensi } & 1540\end{array}$ CCPB000015157-2

87. Eiusd., Phisica et Metaphisica et in moralia. Parisiis, 1533. 1t., $8^{\circ}$.

In hoc opere continentur totius philosophiae naturalis paraphrases, / Iacobi Fabri Stapulensis ... adiectis Iudoci Clichtouei Neportuensis scholijs! a Francesco Vatablo, ... recognitae, adiectis ad literam scholijs declaratae, \& hoc ordine digestae. ..Parisiis : typis Petri Vidouaei : Jean Petit!, 1533 (Parisiis : apud M. Petrum Vidouaeum: Jean Roigny!, 1533)

T\ICCU\BVEE\004914

88. Julii Guastavini, com. in Aristotel. Problemata. Lug., 1608. 1t., fol.

Iulii Guastauinii ... Commentarii in priores decem Aristotelis problematicum sectiones : nunquam antehac visi, nec in lucem dati adiecto in super indice ... Lugduni : sumptibus Horatii Cardon 1608 CCPB000497082-9

89. Joan. Buridani, comm. in Ethicam Aristot. Ad Nicomacum. Parisiis, 1513. 1t., fol. Questiones Ioannis buridani super decem libros ethicorum aristotelis ad nicomachum / [quas Egidius Delfus ... cum annotationib[us] in margine adiectis emendatius imprimi curauit .... Venundatur parrhisijs : a Poceto le preux ..., 1513 vicesima sexta die mensis Martij

CCPB000361550-2

90. Joachim Perioni, in Arist. Metaphisic. Lug., 1561. 1t., $8^{\circ}$.

Aristotelis Metaphysicorum, ut vocant libri XIII : quorum primus duos complectitur / Ioachimo Perionio Cormoeriaceno interprete ... Lugduni : apud Guliel. Rovilium ..., 1561

CCPB000489366-2

91. Eiusd., Organum Aristotel. una cum Porphirii Isagoge. Basileę, 1554. 1t., $8^{\circ}$.

Organum Aristotelis universum una cum Porphyrii Eisagoge, sive Institutione ad Chrysaorium - Joachimo Perionio... interprete adjectae sunt ejusdem quoque in eosdem libros Observationes. 1554 (Basileae: per Joannem Oporinum) 
CCFR: A 233 16ème siècle Beaune - BM

92. Eiusd., in Logicam Aristot. Colonię, 1559. Et de eius Principiis. Parisiis, 1554. 2t., $8^{\circ}$.

Tomus primus Aristotelis logicae, in quo sunt : Quinque vocum institutionum liber I ; Categoriarum liber I ; De interpretatione liber I ; De ratiocinatione libri 2 ; De demonstratione libri 2. Partim Joachimo Perionio,... partim Nicolao Gruchio,... interpretibus ... Una cum commentariss Gerardi Matthisii,... 1559 (Coloniae : Petrus Horst)

CCFR: 228466 fonds ancien

Aristotelis de natura, aut. de rerum principis lib. VIII. Iocchimo Periono interprete, et per Nicolaum Grocchium correcti et emendati / Aristote ; éd. par Nicolas de Grouchy; Trad. de Joachim Périon. Parisiis : ex typographia Matthaei Davidis , 1554

CCFR: QV6724 fonds ancien

93. Jacobi de Naberos, super 2, Libr. Perhiermenias. 1t., fol.

Edición no localizada.

94. Joan. Sanchez Sedeño, Logica Aristotel. Salm., 1600. 1t., fol.

Aristotelis Logica Magna variis et multiplicibus quaestionibus septem libris comprehensis elucidata : in quibus praecepta Logicalia ad D. Thomae Aquinatis [et] Doctoris Ecclesiae sententiam reuocantur [et] eiusdem Angelici Magistri doctrina contra aduersarios illius acerrimè defenditur / autore Fr. Ioanne Sanchez Sedeño Ordinis Praedicatorum ... [Salmanticae] : excudebant Salmanticae Ioannes Ferdinandus [et] Andreas Renaut, 1600 CCPB000022775-7

95. Jacobi Lodaici Strebei et Joan. Bernardi Feliciani, Versio Moralium ad Nicomachum; cum comment. eiusd. Strebei in 3, priores Aristotel. Libr. Parisiis, 1550. 1t., $8^{\mathrm{o}}$.

Aristotelis Stagiritae Moralium Nicomachiorum libri decem / ab Iacobeo Lodoico Strebaeo [et] Io. Bernardo Feliciano à graeco in latinum conuersi ; eiusdem Strebaei in tres priores Aristotelis libros moralium nicomachiorum Comentaria. Parisiis : apud Vascosanum ..., 1550

CCFR: Fa C 4215 Fonds ancien

96. Joan. Bapt. Duhamel, Philosophia vetus et nova. Venetiis, 1730. 6t., $4^{\circ}$.

Philosophia vetus et nova ad usum scholae accommodata, in Regia Burgundia olim pertractata / a Joh. Bapt. Du Hamel ; tomus secundus, qui philosophiam moralem $\begin{array}{lllll}\text { complectitur Venetiis } \quad \text { : } & \text { apud Jacobum } & \text { Zatta, } & 1730\end{array}$ CCPB000167848-5

97. Jani Lacini, Pretiosas Artis chimicę collectanea. Norimberg., 1562. 1t., $4^{\circ}$.

Edición no localizada.

Praeciosa ac nobilissima artis chymiae collectanea de occultissimo ac praeciosissimo philosophorum lapide / per Ianum Lacinium... nunc primum in lucem aedita...

98. Juan Saraba, Philosophia Nat. (en Italiano). Venecia, 1557. 1t., $8^{\circ}$. 
Della filosofia naturale di Ghovan Jarava libri quattro. ... Tradotta di Spagnuolo in volgare da A. di Ulloa. Venetia, P. Pietrasanta 1557.

CCFR: R-15129 Tolbiac - Rez de Jardin - Philosophie, histoire, sciences de l'homme Magasin

99. Joan. a S. ${ }^{\text {to }}$ Thoma, Cursus Philosophic. Tomi $1 .^{\mathrm{s}}$ et $3 .^{\mathrm{s}}$. Colonię, 1638. 2t., $4^{\circ}$.

Cursus philosophicus thomisticus, secundum exactam, veram et genuinam Aristotelis et doctoris Angelici mentem : secundae partis, Pars II \& III quae de ente mobili corruptibili ad libros Aristot. de Ortu ... / Auctore ... P.F. Ioanne à Sancto Thoma ... Coloniae Agrippinae : sumptibus Constantini Münich Bibliopolae, 1638 CCPB000571060-X

100. Joan. Gonzalii, Logica. Matriti, 1616. 1t., $4^{\circ}$.

Aristotelis stagiritae Logica ... / auctore Ioanne Gonsalio Martinio ... Mantuae $\begin{array}{lllll}\text { Carpetanae } \quad \text { a } & \text { Lud } & \text { Ludouicum }\end{array}$ CCPB000120487-4

101. Juan de Najera, Desengaños Philosophicos. Sevilla, 1737. 1t., $4^{\circ}$.

Desengaños philosophicos / Juan de Naxera ...sácalos a la luz D. Juan Vazquez de Cortes .. Impresso en Sevilla: en la imprenta de las Siete Revueltas, 1737 CCPB000337714-8

102. Joannis à Chokier, Thesaurus Politicor. Romę, 1611. 1t., $4^{\circ}$.

Thesaurus politicorum aphorismorum : in quo principum, consiliariorum, aulicorum institutio propriè continetur ... diuisus in libros sex / auctore Ioanne a Chokier .. Romae: apud Bartholomaeum Zannethum, $1611 \quad$ (1610) CCPB000054023-4

103. Joan. Baradoña. Varii Dialogi morales. Venetiis, 1518. 1t., $4^{\circ}$.

Ioannis Basadona... De ueriosi mortalium fine a foelicitate dyalogus primus ; eiusdem De intellectuali natura Dei ac diuina sapientia: dyalogus secundus ; eiusdem De singularium ac rerum omnium cognitione ab intellectu diuino: dyalogus tertius ; eiusdem De admirabili Dei prouidentia \& mortalium cura: dyalogus quartus ; eiusdem De diuina electorum praedestinatione: dyalogus quintus. Venetiis : in aedibus Ioannis Tacuini, 1518 CCPB000361321-6

104. Joan. Saguens. Athomismus Demonstratus. Tolosę, 1715. 1t., $4^{\mathrm{o}}$.

Atomismus demonstratus et vindicatus at impugnationibus philosophico-theologicus ... Francisci Palanco ... / authore R.P. Joanne Seguens ... Tolosae : ex typis Dominici Desclassan 1715 CCPB000135318-7

105. Juan de Quiñones, trat.do de las Langostas. 1620. 1t., $4^{\circ}$. Tratado de las langostas, muy util y necessario : en que se tratan cosas de prouecho y curiosidad para todos lo que professan letras diuinas y humanas, y las mayores ciencias / compuesto por el doctor Iuan de Quiñones... En Madrid : por Luis Sanchez..., 1620 CCPB000041054-3 
106. Joan. Cantero, Comm. ${ }^{a}$ in Porphirii Isagogem, et Cathegorias Aristot. Comp., 1566. $1 \mathrm{t} .4^{\mathrm{o}}$.

Commentana in Porphyrii Isagogem et categorias Aristotelis / autore Ioane Cantero ... compluti professore ... Compluti : excudebat Ioanes Villanoua \& Petrus Robles, [s.a.] CCPB000152405-4

107. Judacci Clictoveęi, Dialectica. Parisiis, 1537. 1t., $8^{\circ}$.

Fundamentum logicae. Introductio in terminorum cognitionem, in libros Logicorum Aristotelis, autore Iodoco Clichthoueo Neoportuensi, vna cum Ioannis Caesarij commentarijs. Paris, Simon de Colines, 1537.

IT\ICCU\RMLE\033851

108. Josephi Saenz de Aguirre, Philosophia moralis. Salm.cę, 1675 et 77. 2t., fol.

Philosophia Moralis ab Aristotele tradita decem libris Ethicorum ad Nicomachum a Ioanne Argyropilo byzantino latine reddita / nunc perpetuo commentario litterali et scholastico plenissime illustrata auctore R.P. Fr. Iosepho Saenz de Aguirre, Benedictinae congregationis ... Salmanticae : apud Lucam Perez, 1675 CCPB000037484-9

109. Juan Marquez, el Governador Xptiano. En Salam. ${ }^{\text {ca }}$, 1612. 1t., fol.

El Gouernador christiano : deducido de las vidas de Moysen, y Iosue ... / por el maestro F. Ioan Marquez, de la orden de San Augustin ... ; con quatro tablas muy copiosas ... En $\begin{array}{llllll}\text { Salamanca }: \text { por } & \text { Francisco de }\end{array}$ ССРB000033122-8

110. Joan. Soriani Pontani, opera. Florentię, 1520. 1t., $8^{\circ}$.

Ioannis Ioviani Pontani Opera omnia soluta oratione composita in sex partes diuisa : nomina librorum quae in hisce sex partibus continentur à tergo huius paginae notata inuenientur. Florentiae $:$ per haeredes Philippi Iuntae, 1520 CCPB000021498-1

111. Juan de S. ${ }^{\text {ta }}$ Maria, Politica y Republica Cristiana. Napoles, 1615

Edición no localizada. Hemos hallado una edición de Nápoles es de 1624, y una de 1615 de Madrid:

Republica y politicia christiana del reverendiss padre Fray Juan de Santa Maria des calco Francisco. 1624 (Napolis : D. Macarano)

CCFR: Royer in-4 AD 1 Fonds patrimoniaux

Tratado de republica y policia christiana para reyes y principes. Madrid, Impr. real , 1615. In- $4^{\circ}$

CCFR: Tolbiac - Rez de Jardin - Droit, économie, politique - Magasin

112. Isidoro Barreira, Trat. ${ }^{\text {do }}$ de las Significaciones de las Plantas las q. se refieren en las Escrituras (en Portuges). Lisboa, 1622. 1t., $4^{\circ}$.

Tractado das significacoens das plantas flores e fructos que se referem na Sagrada Escriptura : tiradas de diuinas, et humanas letras, côsuas breues consideraçoes / pello Padre Frey Isidoro de Barreira ... da sagrada Ordem de Christo. Em Lisboa : por Pedro Craesbeeck 1622 CCPB000045004-9 
113. Jacobi Simanci, collectaneorum de Republica libr. 9. Venetiis, 1569. 1t., $4^{\circ}$. Iacobi Simancae ... Collectaneorum de Republica libri novem ... Venetiis : apud Bologninum Zalterium, 1569

CCPB000023638-1

114. Justo Lipsio traducido p. ${ }^{\mathrm{r}}$ Juan Bapt. de Mesa. Sevilla, 1616. 1t., $4^{\mathrm{o}}$.

Libro de la constancia / de Iusto Lipsio ; traducido de latin en castellano por Iuan Baptista de Mesa ... Impresso en Seuilla : por Matias Clauijo, 1616 CCPB000034007-3

115. Joan. Bapt. Bernardi, Seminarium totius Philosophię Aristotelię et Platonicę. Lug, 1529. 1t., fol.

Edición no localizada. La primera edición es de Venecia, 1582, y la más antigua de Lyón que hemos hallado es la siguiente:

Seminarium totius philosophiae aristotelicae et platonicae... Tomus primus (-secundus), Joannis Baptistae Bernardi,... studio et labore collectus. Altera editio emendatior. Seminarium totius philosophiae stoicae tomus tertius, Joannis Baptistae Bernardi,... studio... collectus [Texte imprimé] Publication : Genevae : in officina J. Stoer et F. Fabri Lugdunensis, 1599-1605

CCFR :Tolbiac - Rez-de-jardin - magasin R- 737

116. Joan. Caramuel, Theolog. ${ }^{a}$ Rationalis. Francofurti, 1654. 1t., fol.

I. Caramuelis Theologia rationalis ... [Francofurti] : Ioannis Gottofredi Schönwetter, [s.a.]

CCPB000373755-1

117. Eiusd., Philosophia rationalis. Lovanii, 1642. 1t., fol.

Rationalis et realis philosophia / authore ... Ioanne Caramuel Lobkowitz Dunensi religioso, S. Th.. Lovaniensi Doctore, Abbate Melrosensi, Angliae, Scotiae, Hiberniae [et] Progenerali. Lovanii: Typis 1642 CCPB000454516-8

118. Joan. Hidalgo, Cursus Philosophicus ad mentem Egidii. 1736, 37, 38 et 39. 4t., $4^{\circ}$. Cursus Philosophicus ad mentem B. Aegidii Col. Rom... / authore R.P.M.Fr. Joanne Hidalgo Astigiensi... ; ab eadem provincia in lucem editus et dicatus... D. Fr. Gasparii de Molina et Oviedo, D. Jacobi Cubensis Primum, deinde Barcinonensis... ; Tomus I : complectens summulas, et Logicam. Cordubae: in Veco Cisterciensi, per Petrum Arias, 1736 CCPB000067160-6

119. Joan. Gemminianis, Summ. de exemplis et similitudinibus rerum. Ant., 1583. 1t., $8^{\circ}$.

Summa de Exemplis et rerum similitudinibus locupletissima : verbi dei concionatoribus cunctisque literarum studiosis maximo vsui futura / F. Ioanne à S. Geminiano ordinis Praedicatorum auctore. Antuerpiae : in aedibus Petri Belleri sub scoto Burgundiae, 1583 (typis Danielis Veruliet) CCPB000155351-8

120. Juan Locke, Ensayo Philosophico tocante al Entendim. ${ }^{\text {to }}$ humano: en francés. Amsterd., 1729. 1t., fol. 
Essai philosophique concernant l'entendement humain ... / par M. Locke ; traduit de l'anglois par M. Coste. A Amsterdam : Chez Pierre Mortier, 1729 CCPB000202453-5

121. Ludovici Lemosii, Paradoxorum Dialecticorum. Lib. $2^{\circ}$ Salm., 1558. 1t., $8^{\circ}$. Lodouici Lemosij ... Paradoxorum dialecticorum libri duo ... Salmanticae : excudebant $\begin{array}{lllll}\text { haeredes } & \text { Ioannis } & \text { à } & \text { Iunta } & \\ & & \end{array}$ CCPB000884931-5

122. Ludovici Granatensis, Collectanea Moralis Philosoph. Olisipone, 1571. 1t., $8^{\circ}$. Collectanea moralis philosophiae : in tres tomos distributa : quorum primus selectissimas sententias ex omnibus Senecae operibus, Secundus ex moralibus opusculis Plutarchi, Tertius clarissimorum principum \& philosophorum insigniora apophthegmata ... complectitur ... / collectore F. Ludouico Granaten. monacho Dominicano. Olisippone $\begin{array}{lrlll}\text { : excudebat } & \text { Franciscus } & \text { Correa } & \ldots, & 1571\end{array}$ ССРВ000016265-5

123. Maria Memmo, Dialogo Moral (en Italiano). Venecia, 1564. 1t., $4^{\circ}$.

Dialogo / del magn. caualiere M. Gio. Maria Memmo ; nel quale dopo alcune filosofiche dispute, si forma un perfetto prencipe, \& una perfetta reppublica, e parimente un senatore, un cittadino, un soldato, $\&$ un mercantante ; diuiso in tre libri In Vinegia : appresso Gabriel Giolito de Ferrari, 1564 CCPB000017555-2

124. Marsilii Ficini, de Immortalitate Animorum. Parisiis, 1559. 1t., $8^{\mathbf{o}}$.

Theologia Platonica de immortalitate animorum duo de viginti libris / Marsilio Ficino ... authore comprehensa, ad vetustissimi codicis exemplar summo studio castigata. Parisiis: apud Aegidium Gorbinum ..., 1559 (ex calcographia Ioannis Sauetier) CCPB000009872-8

125. Eiusd., de Sanitate tuenda et victu Salubri.

Edición no localizada.

126. Micher Carlos Montesa, filographia universal de todo el mundo. Zaragoza, 1584. 1t., $4^{\circ}$.

Philographia vniversal de todo el mundo, de los Dialogos de Leon Hebreo / traduzida de italiano en español, corregida, y añadida, por Micer Carlos Montesa ... En Çaragoça: en casa de Lorenço y Diego de Robles ... : vendense en casa del mismo autor, 1584 (1582) CCPB000015271-4

127. Maximi Tiri, Disputation. ${ }^{\mathrm{s}}$ 41. Parisiis, 1557.1 t., $8^{\circ}$.

Maximi Tyrii philosophi Platonici sermones sive disputationes XLI. Graece nunc primum editae (ab Henrico Stephano). Parisiis: ex officina H. Stephani, 1557

CCFR: Tolbiac - Rez-de-jardin - magasin FB- 17712

128. Michęlis de Palacios, Comment. in Animam Arist. Salmant,1557. 1t., fol.

Magistri Michaelis de Palacio granatensis ... in tres libros Aristotelis de anima Commentarij ... Salmanticae: excudebat Ioannes à Canoua, MVLVII [i.e. 1557] CCPB000019589-8 
129. Miguel Agustin, Secretos de Agricultura. Barcelona, 1749. 1t., $4^{\circ}$.

Libro de los secretos de agricultura, casa de campo y pastoril / traducido de lengua cathalana en castellano por Fr. Miquel Agustin ... que el mismo autor sacò à luz en ... 1617. Barcelona: en casa de Pedro Escuder ... : Vendese en su casa y en la de Jayme $\begin{array}{llllll}\text { Offet } & \text { y } & \text { Mauro } & \text { Marti } & 1749\end{array}$ CCPB000138713-8

130. Martin Martinez, Philosophia Sceptica. Madrid, 1730. 1t., $4^{\circ}$.

Philosophia Sceptica: extracto de la physica antiqua, y moderna, recopilada en dialogos, entre un Aristotelico, Cartesiano, Gasendista, y Sceptico, para instruccion de la curiosidad española / por el Doctor D. Martin Martinez ... En Madrid : [s.n.], 1730 CCPB000117757-5

131. Martini de Ayala, de Universalibus. Granatę, 1537. 1t., fol.

Dilucidarium quaestionum super quinque vniuersalia Porphyrij iuxta tres vias in scholis receptissimas ... / a Magistro Martino ab Ayala compositum. Granatae : [s.n.], 1537 CCPB000020371-8

132. Mig. ${ }^{1}$ Cabrera, Sbre. si la Electricidad es causa de los teremotos. Sevilla, 1756. 1t., $4^{\circ}$.

Explicacion physico-mechanica de las causas del temblor de tierra : como constan de la doctrina del principe de los philosophos Aristoteles ... / meditada por Miguel Cabrera ... del Orden de Minimos ... En Sevilla : en la Imprenta de D. Diego de S. Román y Codina ..., [s.a.]

\section{ССРB000165915-4}

133. Nemesii Philosophi, de Natura Hominis Liber. Lug., 1538. 1t., $4^{\circ}$.

Nemesii philosophi clarissimi De natura hominis liber utilissimus. Lugduni 1538

CCFR: DY 81

134. Oliva Sabuco, Nueva Philosophia, Madrid, 1728. 1t., $4^{\circ}$.

Nueva filosofia de la naturaleza del hombre no conocida ni alcanzada de los grandes filosofos antiguos : la qual mejora la vida, y salud humana : con las adicciones de la segunda impression / escrita y sacada a luz por doña Oliva Sabuco de Nantes Barrera ... En Madrid : en la Imprenta de Domingo Fernandez ... : a costa de Francisco Lopez Fernandez ..., 1728

CCPB000057282-9

135. Odorardi Obestanii, tract. ${ }^{\mathrm{s}}$ vitę civilis ac sacrę. Brugis, 1626. 1t., fol.

Theatrum vitae ciuilis ac sacrae siue De moribus reipub. christianae commentaria : in quinque libros distributa, in quibus omnes rationes tam speculatiue quam practice traduntur ... / auctore Edouardo Westono ... Brugis Flandrorum : ex officina Guilielmi de Neue, sub signo solis, 1626

CCPB000269082-9

136. Platonis, Opera. Basileę, 1551. 1t., fol.

Omnia divini Platonis opera / traslatione Marsilii Ficini ; emendatione et ad graecum codicem collatione Simonis Grynae, summa diligentia repurgata quibus subiectus est Index quam compiosissimus. Basileae : apud Hier. Forbenium et Nic. Episcopium, 
1551

ССРB000001479-6

137. Pauli Veneti, Summa Philosophię naturalis. Venetiis, 1492. 1t., fol.

Edición no localizada.

Summa philosophie naturalis magistri Pauli Veneti noviter recognita et a vitiis purgata ac pristine integritati restituta..."A la fin" : Emendata... per... fratrem Paulum de Geneçano... Venetiis vero sumptu ac expensis heredum... Octaviani Scoti,... per presbyterum Bonetum de Locatellis... impressa, anno a salutifera incarnatione tertio et quingentesimo supra millesimum, idibus martiis

Venise, 1503 (edición de venencia más antigua hallada)

138. Eiusd., expositio 10, libr. Phisicor. Arist. Venetiis, 1509. 1t., fol.

Edición no localizada. Posible error de escritura del año.

Expositio super octo libros Physicorum Aristotelis et super commento Averrois / Paulus Venetus [Venezia: Gregorio de' Gregori , 23 avril 1499]

CCFR: VCINC 20 Salle de réserve

139. Pauli Socinnatis, Metaphisica. Lug., 1579. 1t., fol.

Pauli Soncinatis Ordinis Praedicatorum Quaestiones Metaphysicales acutissimae : nunc demum summo studio et accuratius quam antehac vnquam castigatae, repurgatae et multis in locis illustratae ... Lugduni : apud Carolum Pesnot, 1579 CCPB000252609-3

140. Petri Serrani Cordubensis, comm. ${ }^{a}$ in 1, libr. Ethicor. Compluti, 1556. 1t., $4^{\circ}$. Commentaria in primum lib. Ethicorum Aristotelis ad Nicomachum / autore doctore Petro Serrano ... Compluti : ex officina Ioannis Brocarij, 1556

CCPB000850749-X

141. Petri Spinosa, Philosophia naturalis. Salm.cę, 1519

Edición no localizada.

Philosophia naturalis Petri a Spinosa ... : opus inquam tripartitum quo continet tres partes ...Uenundantur Salmantice : in vico sarracenorum in impressoria dom[?] magristri Roderici de Castañeda, 1535

142. Petri Martinez, in 3 libr. Aristot. De Anima. Sagunti, 1575. 1t., fol.

Petri Martinez Toletani a Brea ... In tres libros Aristotelis de Anima commentarij ; his accessit indiuiduus \& inseparabilis comes tractatus eiusdem, quo integrè \& copiosissimè ex peripatetica schola animae nostrae immortalitas asseritur \& probatur ... : Index locupletissimus duplex ... Segunti : excudebat Ioannes Gratianus, 1575 CCPB000400489-2

143. Eiusd., comm. ${ }^{\text {a }}$ in Aristotelis libr. De coelo et generatione. Comp., 1561. 1t., fol. Petri Martinez sacrae theologiae in Complutensis Academia doctori ... Comentarij in libros Aristotelis de Coelo \& Mundo, Generatione \& Corruptione \& Anima : his accesit rerum atque verborum locupletissimus index ... Compluti : excudebat Andreas ab Angulo, 1561

CCPB000017135-2

144. Plotini, de Philosophicis rebus libr. 54. Basileę, 1559. 1t., fol. 
Plotini Diuini... De rebus philosophicis libri LIIII in Enneades sex distributi / à Marsilio Ficino... è graeca lingua in latinam uersi et ab eodem doctissimis commentarijs illustrati, omnibus cum graeco exemplari collatis et diligenter castigatis. Basileae : per Thomam Guerinum, 1559

CCPB000227537-6

145. Plutarchi, opera Gręco-latina. Francofurti, 1620. 1t., fol.

Ploytarchoy Khaironeos Ta sozomena panta = Plutarchi Chaeronensis Quae exstant omnia / cum latina interpretatione Hermanni Cruserii, Guilielmi Xylandri ; accedit nunc primum libellus eiusdem De fluviorem montiumque nominibus / cum versione Mausacci ... Francofurti : in officina Danielis ac Davidis Aubriorum \& Clementis Schleichii, 1620

CCPB000594965-3

146. Petri Hieronymi Sanchez de Lizarazo, Methodus Lullii. Tirasone, 1619. 1t., $4^{\circ}$. Generalis et admirabilis methodus ad omnes scientias facilius et scitius addiscendas : in qua ... Raimundii Lullij Ars breuis explicatur \& multis exemplis ... reducitur / D. D. Petro Hieronymo Sanchez de Liçaraço ... Turiasonae : per Carolum na Lauayen : $\begin{array}{llll}\text { expensis Ioannis à } & \text { Bonilla, }\end{array}$ CCPB000051934-0

147. Petri Manso, cursus Philosophicus. Cord. be , 1709. 1t., $4^{\circ}$.

Cursus philosophicus ad mentem B. Aegidii Romani... Augustiniensi [-]... / aucthore... Fr. Petro Manso Augustiniano... ; tomus primus, Dialecticam doctrinalem, \& disputatam, Proemialia Logicae, \& Entia rationis complectens Cordubae : ex Typ. August., 1709

CCPB000116686-7

148. Petri de Oña, Logica. Compluti, 1588. 1t., $4^{\circ}$.

Almae Florentissimae Complutensium Academiae, Commentaria vnà cum Quaestionibus super vniuersam Aristotelis Logicam Magnam dicata / auctore P. F. Petro de Oña burguensis ... Redemptorum sanctae Mariae de Mercede de Obseruantia ... Compluti $:$ apud haeredes Ioannis Gratiani, 1588 ССРB000019027-6

149. Eiusd., Phisica. Comp., 1593. 1t., $4^{\circ}$.

Super octo libros Aristot. de Physica abscultatione commentaria : vna cum quaestionibus ... / authore P.F. Petro de Oña Burg. ... Sanctae Mariae de Mercede Redemptionis captiuorum de Obseruantia. Compluti : ex officina Ioannis Gratiani, 1593

CCPB000019029-2

150. Petri Gregorii Tolosani, de Arte mirabili. 1576 et 87, Lugduni. 6t., fol.

Se trata de dos libros diferentes:

Syntaxe[o]n artis mirabilis alter tomus : in quo omnium scientiarum \& artium tradita est epitome, vnde facilius istius artis studiosus, de omnibus propositis, possit rationes \& ornamenta rarissima proferre / authore Petro Gregorio ... Lugduni : apud Ant. Gryphium,

1576

CCPB000012105-3 
Commentaria in Syntaxes artis mirabilis, per quam de omnibus disputatur habeturque cognitio : tomi IIII ... / authore Petro Gregorio ... Lugduni : apud Ioa. Pillehotte ..., 1587

ССРВ000012095-2

151. Petri Fermoselli, Brevis Logicalium terminorum Relatio. Hispali, 1555. 1t., $4^{\circ}$.

Exactissima ac brevis logicalium terminorum ratio ... / authore per ... Petro Fermosello, Ordinis Minorum ... ; Habesetiam super totam nostri Titelmani Dialiecticam Tractatum argumentatiuum additis solutionibus ... Fermosello authore. Hispali : Excudebat $\begin{array}{llll}\text { Martinus à } & \text { Montesdoca, }\end{array}$ CCPB000454025-5

152. Petri Joan. Nunesii, oratio de causis obscuritatis Arist. et remedium, Item Dialectica. Valentię, 1554. 1t., $8^{\circ}$.

Petri Ioannis Nunnesii valentini Institutionum physicarum quatuor libri priores collecti methodicos ex decretis Aristotelis : praeposita est huic libello ratio methodi qua autor secutus est in eo confici ${ }^{-}$edo ... Valentiae : excudebat Ioannes Mey flander, 1554 CCPB000018844-1

153. Petri Tartareti, in Sumulas Petri Hispani animadversio. Venetiis, 1504. 1t., $4^{\circ}$. Expositio magistri Petri Tartereti in summulas Petri Hyspani : summa accuratione atq[ue] lucubratione penitus innouata atq[ue] reposita : vna cum toto textu summaq[ue] animaduersione impressa ... Venetiis : per Lazar ${ }^{-} \mathrm{u}$ de Soardis, 1504 CCPB000363935-5

154. Petri Zirueli, novus in priora analitica Aristot. comm. . . Comp., 1529. 1t., $4^{\circ}$. Nouus sed preclarissimus in posteriora analytica Aristotelis commentarius Excusum est ... Compluti : in Aedibus Michaelis de Eguia, 1529 Mense Decembris CCPB000005579-4

155. Rodolphi Agricolę, de Inventione Dialecticę. Colonię, 1539. 1t., $4^{\circ}$.

Rodolphi Agricolae Phrisii De inuentione dialectica libri omnes et integri \& recogniti, qui iam olim quidem in publicum prodierunt, sed trunci ac mutili nec minus item deprauati nunc demum ad autographi exemplaris fidem / per Alardum Aemstelredamum accuratius emendati, \& additis annotationibus illustrati ; cum aliis non parum multis eodem pertinentibus ... Coloniae : Ioannes Gymnicus excudebat, 1539

CCPB000031068-9

156. Raimundi Lullii, Practica compendiosa artis. Cambrai, 1523. 1t., $4^{\circ}$.

Practica compendiosa artis Raymundi Lul. explanatio compendiosa q[ue] applicatio artis illuminati ... Raymundi Lull ... / per ... Bernardum de Lauinheta ... edita. Lugduni ... : impressum in edibus Joannis Moylin al's de Cambray, 1523 ССРB000349668-6

157. Samuelis, Expositio triplex Phisicor. Arist. Cunei, 1510. 1t., fol.

Expositio triplex librorum octo phisicorum Aristotelis quarum prima est textualis, secunda construit textum, tertia elicit propositiones de textu, et her omnia de mente commentatoris et doctoris subtilis Libellus Isagogicum ad phisicos apices assequendos... Impressum ... Cunei : opera \& diligentia Simonis Beuilaqua ... et sui consocii Guidoti de Dulcis, 1510 


\section{ССРB000361206-6}

158. Stephani Spinula, Novissima Philosophia. Genuę, 1651. 1t., fol.

Nouissima philosophia : summulas, logicam et libros physicorum, de coelo, de generatione et corruptione ... complectens / auctore D. Stephano Spinula Congregationis Somaschae ... Genuae : apud Petrum Ioannem Calenzanum, 1651 CCPB000136739-0

159. Sebastiani Dupasquier, Summa Philosophię. Patavii, 1718. 4t., $8^{\circ}$.

Summa philosophiae scholasticae et scotisticae : in quatuor partes scripta [et] digesta breviter [et] clare / per Fr. Sebastianum Dupasquier Minor. Convent... ; tomus IV, De corporibus physicis [et] anima. Patavii : typis Seminarii, apud Joannem Manfrè, 1718. CCPB000227927-4

160. Sebastiani Basonę, Philosophia naturalis adversus Aristot. Aurelianis, 1621. 1t., $8^{\circ}$. Philosophiae naturalis adversus Aristotelem libri XII : in quibus abstrusa veterum physiologia restauratur, \& Aristotelis errores solidis rationibus reselluntur / a sebastiano $\begin{array}{llllll}\text { Bassone.. Aurelianae : } & 1621\end{array}$ CCPB000883552-7

161. Severini Boetii, opera. Basileę, 1546. 1t., fol.

Anitii Manilii Seuerini Boethi In omnibus philosophiae partibus inter latinos \& graecos autores principis opera, quae extant omnia, non solum liberalium disciplinarum, sed maiorum facultatum studiosis etiam ... sine quibus Aristoteles in praecipuis locis intelligi non potest ... ; inter quos in omni literarum genere summus ... Henrichus loritus Glareanus Arithmetican \& Musican demonstrationibus ... ; et Martianus Rota opus de tota differendi ratione, hoc est, organum, dialecticae \& rethoricae ... ilustrauit ... Basileae : apud Henrichum Petrum, 1546

CCPB000152347-3

162. Sentencias de varios Authores prim.a parte. en Cohimbra, 1555. 1t., $4^{\circ}$.

Primera parte de las sentencias que hasta nuestros tiempos, para edificación de buenos [sic] costumbres, estan por diuersos autores escritas ... Fue impressa ... en ... Coimbra : por Ioan Aluarez $\quad$..., $\quad 1554 \quad$ (1555) CCPB000001490-7

163. Theodori Gaza, Aristot. Problemata; cum libris 2, problematum Aphrodisęi, teophrasti libro de Plantis, et Aristot. Hist. ${ }^{a}$ Animalium. Parisiis, 1534. 1t., fol.

Contenta hoc volumine Problematum Aristotelis sectiones duae de quadraginta / Theodoro Gaza interprete. Problematum Alexandri Aphrodisiei libri duo / eodem Theodoro interprete ; index ... Parisiis : ex Officina Simonis Colinaei, 1534 CCPB000616291-6

164. Thomę de Mercado, comm. ${ }^{a}$ in textum sumularum Petri Hispani. Hispalis, 1571. 1t., fol.

Commentarii lucidissimi in textum Petri Hispani / reverendi patris Thomae de Mercado ordinis Praedicatorum ... Hispali : ex officina Ferdinandi Diaz ..., 1571

CCPB000696682-9

165. Thomę Vincentii Tosca, Cursus Philosophic. ${ }^{\text {s }}$ Valentię, 1721. 1t. $4^{\circ}$. 
Compendium philosophicum praecipuas philosophiae partes complectens : nempe Rationalem, naturalem et transnaturalem sive Logicam, Phisicam et Metaphysicam / auctore Thoma Vicentio Tosca ... ; Tomus primus. Valentiae : ex typographia Antonii Balle, 1721

\section{CCPB000118157-2}

166. Thom. ${ }^{\text {s }}$ de Urrutigoiti, Idea de la Prudencia. Zarag. ${ }^{\text {za }}$, 1661. 1t. $4^{\text {o. }}$

Idea de la Prvdencia, alivio contra la Fortuna : sentencias de Seneca ponderadas : acverdos de la Paciencia, dictamenes para la Resignacion / autor Fr. Tomas Frances de Verutigoiti, de la orden de Menores... Zaragoza : Iuan de Ibar, 1661

CCPB000040321-0

167. Thomę Votii, de Imperio Virtutis adversus Machiavellum. Romę, 1593. 1t. $4^{\text {o }}$.

De imperio virtutis siue Imperia pendere a veris virtutibus non a simulatis libri duo, aduersus Machiauellum / auctore Thoma Bozio Eugubino ... Romae : ex typographia Bartholomaei Bonfadini,

1593

ССРВ000151015-0

168. Themistii, opera Gręce cum Aphrodisęi libris de Anima, et fato. Venetiis, 1534. 1t., fol.

Ta tou Themistiou Euphradous hapanta, tout'esti paraphraseis, kai logoi. Alexandrou Aphrodisieos Peri psyches biblia duo ; kai Peri eimarmenes, en: Omnia Themistii opera, hoc est Paraphrases, et Orationes. Alexandri Aphrodisiensis Libri duo de anima, et De fato unus. Venetiis : in aedibus haeredum Aldi Manutii, \& Andreae Asulani, 1534 mense Maio

CCPB001054829-7

169. Thomę De vio Cajetani, in opusculum de ente, et essentia $\mathrm{S}$. thomi, et in posteriorum Arist. Libros. Venetiis, 1506. 1t., fol.

Reverendissimi in Christo patris fratris Thome de Vio caietani ... ordinis predicato[rum]... Commentaria subtilissima super Tractatum de ente [et] essentia sanctissimi doctoris Thome de Aquino ... ; item super libros posteriorum Aristotelis [et] predicamenta noviter per prefatum magistru[m] Thomam revisa ... ; ite[m] adiu[n]ct[us] Tractat' de analogia ... ; item mirabiles questio de Subiecto philosophie ; item Tractatus de cambijs per eiusdem magistrum Thomam noviter compositus ; item tabula ... in toto opere tractantur. Venetiis : per Simonem de Luere, 1506 CCPB000361937-0

170. Eiusd., in Libr. de Anima Arist. Comp., 1583. 1t., $4^{\circ}$

Commentaria Reuerendissimi Patris Fratris Thomae de Vio Caietani ... in libros Aristotelis de Anima : nouissime recognita, cunctisq[ue] erroribus expurgata Compluti : apud Ferdinandum Ramirez ..., 1583

CCPB000007556-6

171. Vitę et mortis compend. Basileę, 1586. 1t., $4^{\circ}$.

Vitae et mortis compendium auctorum diversorum, graece et latine, ad morum honestatem et linguae exercitia. Basileae : apud C. Waldkirch, 1586

CCFR: Tolbiac - Rez-de-jardin - magasin R- 25676

172. Vlipsii Aldrovandi, Hist. ${ }^{a}$ naturalis. Francofurti, 1610 y 1683. 1t., fol. 
Edición no localizada. Probablemente

Ulyssis Aldrovandi ... Ornithologiae tomus alter : qui est de avibus quae vel in mensae usum cedunt ... : Adiectus est index gemimis ; alter capitum ; alter rerum et verborum Francofurti : Typis Wolffgangi Ritcheri : impensis heredum Nicolai Bassaei, 1610 CCPB000043467-1

\section{DUPLICADOS DE FILOSOFIA}

173. Platonis, opera translatione Martini Fisinii et cum emendatione Simonis Grinęi. Parisiis, 1533

Platonis opera / tralatione Marsílii Ficíní, emendatione et ad Graecum codícem collatione Simonis Grynaei ... [Parisiis] : Iodoco Badio \& Ioanni Paruo, 1533 CCPB000304109-3

174. Eiusd., Gemmę sive illustriores Sententię, a Liburnio collect. Parisiis, 1552. 1t., fol.

Divini Platonis Gemmae sive Illustriores sententiae ad excolendas mostaliù mores et vitas recte instituedas / a Nicolao liburnio... collectae... Parisiis : apud Carolum Perier..., 1552

ССРB000444495-7

175. Eiusd., tom. 1us. Lugduni, 1550. 1t., fol.

Edición no localizada. Puede tratarse del mismo registro del siguiente.

176. Eiusd., tom. ${ }^{\mathrm{s}} 1$ us. Operum. Lug., 1550. 1t., $8^{\circ}$.

Divini Platonis Operum, a Marsilio Ficino tralatorum, tomus primus [-quintus]... Omnia emendatione, et ad graecum codicem collatione Simonis Grynaei summa diligentia repurgata. Lugduni : apud J. Tornaesium, 1550

CCFR: Tolbiac - Rez-de-jardin - magasin RES- R- 1734 < T. 1 >

177. Lucii Annęi Senecę, Philosoph, opera omnia cum commendationib. Iusti Lipsii et Joan Triderici Gronovii. Ambsterodami, 1659. 3t., $8^{\circ}$.

L. Annaei Senecae philosophi opera omnia Ex ult. I. LLipsii \& I.F. Gronovii emendat. et M. Annaei rhetoris quae exstant ex And. Schotti recens. Amstelodami : apud Elzevirios, 1659

CCFR: SA 92 A Sciences et Arts

178. Eiusd., opera cum Scholiis Erasmi et aliorum. Basileę, 1529. 1t., fol.

Opera L. Annaei Senecae ... / per Des. Erasmum Roterod. \& Matthaeum Fortunatum ... emendata ... ; adiecta sunt scholia D. Erasmi Roterodami in bonam partem operis ; Beati Rhenani in ludum de morte Claudij Cesaris ; Rodolphi Agricolae in declamationes aliquot commentarioli ; Fernandi Pinciani castigationes in uniuersum opus ; index rerum $\& \quad$ uerborum locuples. Basileae : $\quad$ [s.n., $\quad$ s.a.] СCРB000363880-4

179. Eiusd., opera cum Scholiis Iusti Lipsi. Ant., 1605. 1t., fol. ${ }^{22}$

${ }^{22}$ Se trata de la misma edición consignada en Nro. 19. 
180. Eiusd., opera cum emendatione Marcii Antonii Mureti et Pinciani. Parisiis, 1577. 1t., fol.

L. Annaei Senecae ... Opera quae extant omnia / M. Antonii Mureti, P. Pinciani aliorumque ... virorum opera et studio innumeris locis emendata, notisque illustrata ... Parisiis : apud Nicolaum Nivellium ..., 1587 (ex typographia Petri Ramier ...) CCPB000257689-9

181. Eiusd., tom $2{ }^{\mathrm{s}}$ operum suorum, continens epistolas. Parisiis, $1640.1 \mathrm{t} ., 8^{\circ}$.

L. Annaei Senecae Philosophi Tom. II : continens Epistolas. Parisiis : apud Sebast. Cramoisy ..., 1640

CCPB000464488-3

182. Eiusd., tom. 1 . $^{\mathrm{s}}$ et 3 . $^{\mathrm{s}}$ continens opuscula moralia. Parisiis, 1640.2 t., $8^{\circ}$.

L. Annaei Senecae philosophi Tom. I. [-III.] continens opuscula moralia. Parisiis : apud Sebast. Cramoisy, typogrphum regis, 1640

Biblioteca del Collegio Emiliani (Génova) ANT - A3, IV, 28.

183. Caii Plinii Secundi, Historię Mundi libr. 37 cum vindicationib. Aliquorum. Lug., 1563. 1t., fol.

C. Plinii Secundi Historiae Mundi libri XXXVII : maiore, quàm hactenus vnquam, studio, fide, religione à vitiis quibus multiplici impressione contaminati fuerant, vindicati / adiectis ad marginem ... castigatiunculis ... ; una cum indice totius operis copiosissimo .. Lugduni : apud Antonium Vincentium, 1563 (excudebat Symphorianus Barbier)

CCPB000325318-X

184. Eiusd., idem opus. Sine loco impresión, 1606. 1t., fol.

Edición no localizada.

185. Eiusd., idem opus. Lug., 1587. 1t., fol.

C. Plinii Secundi Historiae mundi libri XXXVII ... : accessere ... castigationes \& adnotationes eruditissimae ... vna cum indice totius operis ... / obseruationibus ... Iacobi Dalecampii ... Lugduni : apud Bartholomaeum Honoratum ..., 1587 CCPB000188261-9

186. Eiusd., idem opus. Lug., 1548. 1t., fol.

C. Plinii Secundi Historiae mundi Libri triginta septem... : Annexae sunt praeterea in calce operis Castigationes / Sigismundi Cetenij... Lugduni : ex officina Godefridi et $\begin{array}{lll}\text { Marcelli } & \text { Beringorum } & \text { fratrum, }\end{array}$

CCPB000444499-X

187. Dominici de Soto, Sumulę. Salmanticę, 1571. 1t., fol.

Reverendi Patris Dominici Soto segouiensis ... Ordinis Praedicatorum Summulae Salmanticae : in aedibus Dominici a Portonariis, 1571

CCPB000814749-3

188. Eiusd., comm ${ }^{\text {a }}$. in Dialecticam Aristot. Salmanticę, 1574. 1t. fol.

Reuerendi Patris Dominici Soto Segouiensis Theologi ordinis Praedicatorum In dialecticam Aristotelis commentarij. Salmanticae : in aedibus Dominici à Portonarijs ..., 1574

194 Marcela A. Suárez, Luis Sánchez y María Soledad Justo. La Biblioteca del Antiguo... 158-254. 


\section{CCPB000023943-7}

189. Eiusd., comm. ${ }^{\text {a }}$ in 8 , libr. Phisicor. Salm.cę, 1569 et 1572.2 t., fol. ${ }^{23}$

Reuerendi patris Dominici Soto segouiensis ... Ordinis Praedicatorum super octo libros Physicorum Aristotelis quaestiones. Salmanticae : in aedibus Dominici à Portonariis ..., 1569 (in aedibus Andreae à Portonariis ..., 1568) CCPB000727911-6

190. Augustini Nephi. Super libr. Prior. Arist. comm. ${ }^{a}$. Venetiis, 1553. 1t. fol.

Augustini Niphi ... Super libros priorum Aristotelis commentaria castigatissima : quae figuris quibusdam ex optimis exemplaribus desumptis, syllogismorum omnium in quacunq[ue] figura contextorum tam utiles, quàm inutiles coniugationes ingeniosissime ostendentibus, luculentiora reddita sunt, necnon quamplurimis margineis annotationibus illustrata ... Venetiis : apud Iuntas, 1553 (apud haeredes Lucaeantonij Iuntae) CCPB000018742-9

191. Eiusd., comm. ${ }^{a}$ in libr. Aristot. de Generatione et corruptione et Paralipomena in iisdem comment.is. Venet., 1543. 1t. fol.

Augustini Niphi medices ... In libros Aristotelis de generatione \& corruptione interpretationes \& commentaria ... Eiusdem Augustini Niphi In commentariis \& interpretationibus eorundem librorum Aristotelis ... Paralipomena ... Eiusdem quaestio de infinitate primi motoris. Addito nuper uocum \& rerum notatu dignarum locupletissimo indice. Venetiis : Apud Octauianum Scotum. D. Amadei. F., 1543.

IT\ICCU\TO0E\003980

192. Eiusd., Expositio in Topic. Arist. Parisiis, 1540. 1t. fol.

Aristotelis... Topica inuentio in octo secta libros / a... Avgvstino Nipho... interpretata atque exposita... Parissis : apud Ioannem Roigny ..., 1540 (excvdebat Ioannes Lodoicvs ...)

\section{ССРB000119491-7}

193. Joachini Perioni, organum Aristot. cum Porphirii Isagoge. Valentię, 1553. 1t. $8^{\circ}$. Ioachimi Perionii benedictini... In Porphyrij institutiones et in universaum Aristotelis organum versio... cui accessit Anonymi compendium de syllogismis e graecosermone in latinum conversum interprete / Pet. Ioan. Nunnesio... Valentię : typis Ioannes Mey... : $\begin{array}{llll}\text { mostant apud } & \text { Antonium } & \text { Sanahuiam..., } & 1553\end{array}$ CCPB000444482-5

194. Eiusd., in 8 lib. Phisicor. Sine loco et anno impresionis. 1t. fol. Edición no localizada.

195. Eiusd., in Moralia Arist ad Nicomachum. Lug., 1548. 1t., $8^{\circ}$.

Aristote. Stagyrite Ethicorum Lib. X cum Aver. corduben . exactiss. commentariis. item [et] eiusdem Aristote. Politicoru[m] . lib VIII. ac Oeconomicorum Lib. II / Leonardo Aretino interprete ... Lugduni : Apud Scipione de Gabiano, 1548

CCPB000293443-4

196. Plutarchi, opera. Venetiis, 1538, 1 tom. 2. , Francofurti, 1580. 2t., fol.

${ }^{23}$ La edición de 1572 está consignada en el Nro: 43. 
Summi et Philosophi et Historici parallela, id est vitae illustrium virorum Graecorvm et Romanorum, vtilissima historia expositae... / Plutarchi Chaeronensis. Francoforti Ad Moenum : [s.n.], 1580

CCPB000184460-1

197. Eiusd., idem opus quoad Moralia. Basileę, 1541. 1t., fol.

Plutarchi chaeronei ... Opera moralia ... Basileae : apud Mich. Isingrinium, 1541

CCPB000188720-3

198. Eiusd., quoad historialia. Francofurti, 1580. 1t., fol.

Plutarchi Chaeronensis ... Parallela, id est, Vitae illustrium virorum Graecorum et Romanorum ... inter se comparatae / Guilielmo Xylandro ... interprete. Impressum Francoforti ad Moenum : per Ioannem Feyerabendt : impensis Sigismundi Feyrabendt, 1580

CCPB000021334-9

199. Eiusd., tom 2. ${ }^{\mathrm{s}}$ opusculorum. Sine loco, et anno impres. $1 \mathrm{t} ., 8^{\circ}$.

Edición no localizada.

200. Eiusd., Vitę. Basileę, 1594. 1t., fol.

Edición no localizada. El CCPB solo contiene ediciones de Basilea de 1554 y 1564 :

Plutarchi Chaeronei, Gravissimi et Philosophi et Historici, Vitae comparatae illustrium Virorum, Graecorum \& Romanorum, ita digestae ut temporum ordo series ... / Hermano Cruserio I.C. atque illustriss. Ducis Clivensis \& Iuliacensis. Basileae : Apud Thomam Guarium, 1564

CCPB000275468-1

201. Petri Martinez, comm. in Libr. Arist. de coelo et mundo, generatione, corruptione et anima. Compluti, 1561. 1t., fol.

Petri Martinez sacrae theologiae in Complutensis Academia doctori ... Comentarij in libros Aristotelis de Coelo \& Mundo, Generatione \& Corruptione \& Anima : his accesit rerum atque verborum locupletissimus index ... Compluti : excudebat Andreas ab Angulo, 1561

CCPB000017135-2

202. Eiusd., idem opus. Compluti, 1561. 1t., fol.

Petri Martinez sacrae theologiae in complutensi academia ... Commentarij in libros Aristotelis de Generatione \& corruptione ... : cum indice locupletissimo. Compluti : excudebat Andreas ab Angulo, 1561

ССРВ000180106-6

203. Joannis a S. ${ }^{\text {to }}$ Thoma, Summulę. Matriti, 1648. 1t., $8^{\circ}$.

Artis Logicae : prima pars de Dialecticis Institutionibus quas Summulas vocant / authore... Fr. Ioanne de S. Thoma... Ordinis Praedicatorum... Matriti : Typis Mariae Quignonij, 1648

CCPB000036104-6

204. Eiusd., Phisica. Matriti, 1633. 1t., $4^{\circ}$.

Naturalis philosophiae prima pars : quae de natura in communi eiusque affectionibus disserit / auctore M. fr. Ioanne de S. Thoma ... Matriti : ex officina Francisci Martinez, 
1633

CCPB000051160-9

205. Eiusd., de Generatione et Corruptione. Comp., 1634. 1t., $4^{\circ}$.

Edición no localizada. El CCPB no contiene un libro de Juan de Santo Tomás con este título. Probablemente se trate de un error al copiar el siguiente:

Naturalis philosophiae tertia pars : quae de ante mobili corruptibili agit ad liberos Aristotilis de ortu \& interitu / auctore M. Fr. Ioanne de S. Thoma... Compluti : apud Antonium Vazquez..., 1634

CCPB000056834-1

206. Augustini Eugubini, de perenni philosophia libr. 10. Basileę, 1542. 1t., $4^{\text {o }} .^{24}$

207. Antonii Iribarren, cursus Philosophici tom. ${ }^{\mathrm{s}} 1{ }^{\mathrm{s}}$. Cęsar Augustę, 1715. 1t., $4^{\mathrm{o}}$.

Fr. Antonii Iribarren... ex sacro Praedicatorum Ordine... Cursus philosophici tomus prior : tractatus primus... Caesar-Augustae : apud haeredes Emmanuelis Roman... : a $\begin{array}{llll}\text { costa de Antonio } & \text { Rubio..., }\end{array}$ CCPB000117610-2

208. Franci Titelmanni, Compend. Philosophię naturalis. Lug., 1545. 1t., $8^{\text {o }}{ }^{25}$

209. Thomę de Mercado, comment. in textum Patri Hispani. Hispali, 1571. 1t., fol. ${ }^{26}$

210. Franci de Leyva, Antiparadoxa. Cordubę, 1634. 1t., $4^{\mathrm{o}} .^{27}$

211. Martini de Ayala, Dilucidarium de Universa lib. Granatę, 1537. 1t., fol. ${ }^{28}$

212. Hieonymi Osorii, de Regis Institutione libr. 8, quib. accedit epistola eiusd. ad Elisabetham Anglię Reginam. Olisipone, 1572. 1t., $4^{\text {o }}{ }^{29}$

213. Eiusd., libri 5, de Gloria. Comp., 1568. 1t., $8^{\text {o }}{ }^{30}$

214. Joan a S. ${ }^{\text {to }}$ Geminiano, Summa de Exemplis. Venetiis, 1499. 1t., 8.

Summa de exemplis ac similitudinibus rerum. [Basileae] : Johannes Froben et Johannes Petri (25 enero, 1499)

CCPB000110520-5

215. Gometii Pereira, Antoniana Margarita. Methimnę a Campo, 1554. 1t., fol.

Antoniana Margarita : opus nempe Physicis, Medicis ac Theologis non minus vtile quam necessarium / per Gometium Pereiram ... ; nunc primum in lucem aeditum. Methymnae Campi : excusum ... in officina calchographica Guillielmi de

\footnotetext{
${ }^{24}$ La misma edición está consignada en el Nro: 7.

${ }^{25}$ Se trata de la misma edición consignada en Nro: 53.

${ }^{26}$ Se trata de la misma edición consignada en Nro: 164.

${ }^{27}$ Se trata de la misma edición consignada en Nro. 58.

${ }^{28}$ Se trata de la misma edición consignada en Nro: 131.

${ }^{29}$ Se trata de la misma edición consignada en Nro: 82.

${ }^{30}$ Se trata de la misma edición consignada en Nro: 83 .
} 
Millis,

CCPB000000254-2

216. Augustini Palavicini, Explicatio paraphrastica in 4, libr. Metheororum Arist. Genuę, 1613. 1t., $4^{\circ}$.

Augustini Pallavicini Francisci F. Patricii Genuensis Explanatio paraphrastica in quatuor libros meteororum Aristotelis... Genuae : Ex Typographia Iosephi Pauonis, 1613

CCPB000210931-X

217. Fränci Vallesii, de Philosophia sacra, cui accedit Levini Lemnii de plantis sacris opus. Lug., 1588. 1t., $8^{\circ}$.

Francisci Vallesii De iis quae scripta sunt physicè in libris sacris, siue de Sacra Philosophia liber singularis ... ; cui propter argumenti similitudinem, adiuncti sunt duo alij ... Leuini Lemnii de platis sacris et Francisci Ruei de Gemmis ... Lugduni : sumptibus Sib. à

Porta,

1588

CCРB000188992-3

218. Hieronymi Pla, comm. ${ }^{\text {orum }}$ in Logicam Arist. tom. $2 .^{\mathrm{s}}$.Valentię, 1598. 1t., $4^{\circ}$.

Hieronymi Pla ... Comentariorum in Aristotelis Logicam tomus secundus : librum de interpretatione et reliquos posteriores continens ... Valentiae : apud Petrum Patricium iuxta templum D. Martini : expensis auctoris ..., 1598

CCPB000021108-7

219. M. el Abad de Pluche, Espectaculo de la Naturaleza traducido p. ${ }^{\mathrm{r}}$ el Pe. Terreros. M.d, 1753, ad 55. 16t. $4^{\circ}$.

Espectáculo de la Naturaleza o Conversaciones a cerca de las particularidades de la Historia Natural... / escrito en el Idioma Francés por el Abad M. Pluche ; traducido al Castellano por el P. Estevan de Terreros y Pando... ; tomo I [-XIV]. En Madrid : en la oficina de D. Gabriel Ramirez..., 1753-1755

CCPB000059964-6

220. Frânci Patricii Senensis, de Institunione Reipublicę libr. 9. Parisiis, 1569. 1t., $8^{\circ}$.

Francisci Patricii... De Institutione reipublicae libri novem historiarum sententiarumque varietate refertissimi... Parisiis : apud Gorbinum, 1569

CCFR: DX 18 c. 2

221. Aristotelis, opera, cum indice, et comment. Aphrodisię, et aliorum, deficit tom. ${ }^{\mathrm{s}} 2{ }^{\mathrm{s}}$ et $1 .{ }^{\mathrm{a}}$ part tom. $6 .^{\mathrm{s}}$ tomus $1 .^{\mathrm{s}}$ Lug. $1580,5{ }^{\mathrm{s}} 1579$, reliqui. Venetiis, $1572.7 \mathrm{t}$., fol.

Aristotelis stagiritae opera omnia, quibus nunc primum accesserunt politicorum seu de Republica, liber nonus \& decimus : item Theologiae seu Philosophiae Mysthicae libri quatordecim : tomus primus : organum, quod Logicam appellant continens. Genevae : apud Iacobum Berion typographus lugdunensis, 1580

CCPB000396696-8

Aristotelis Stagiritae opera ... Lugduni : apud Stephanum Michaélem, 1579 (excudebat Basilaeus Boiquetius, 1577)

CCPB000151152-1 
Aristotelis omnia quae extant Opera ... [Marciantonii Zimarae ... Tabula dilucidationum in dictis Aristotelis et Auerrois] Venetiis : apud Iuntas, 1575 (impressa in officina haeredum Luceantonij [sic] Iuncte, 1572) CCPB000620905-X

222. Eiusd., Tomi 1. ${ }^{\mathrm{s}}, 2 .{ }^{\mathrm{s}}, 3{ }^{\mathrm{s}}$, et $6 .^{\mathrm{s}}$ reliqui deficient. Lug., 1580. 4t. Fol.

Aristotelis Stagiritae Physicorum libri VIII : quibus adiecimus omnia illius opera quae ad naturalem philosophiam spectare videbantur... : tomus secundus. [Genevae] : excudebat Iacobus Berjon typographus lugdunensis, 1580

CCPB000180462-6

223. Eiusd., Ethica ad Nicomachum. Lug., 1559. 1t. $8^{\circ}$.

Aristotelis stagiritae peripateticorum principis ethicorum ad Nicomachum libri decem / Ioanne Argyropylo Byzantio interprete ... Lugduni : apud Antonium Vicentium, 1559 (excudebat Symphorianus Barbierus) CCPB000716055-0

224. Eiusd., Problemat. Mechanicę Mundi, auditionum ,et aliorum libr. Venetiis, 1562. 1 t., $8^{\circ}$.

Tomus undecimus operum. In quo libelli quidam spurii Aris. ascripti continentur. De rebus auditu admirabilibus. De Xenophane, Zenone, \& Gorgia. De mundo. Quæstiones mechanicæ. De lineis insecabilibus. Solutiones contradictionum in dictis Arist. \& Auerr. Marci Antonii Zimaræ ... In cuius autem calce Auer. vtilissimum, \& et iam desideratum Tractatum de spermate reperies .. Venetiis : [al segno della Fontana], 1560 (Venetiis : apud Cominum de Tridino, Montisferrati, 1560)

IT\ICCU\TO0E\014291

225. Eiusd., Politicorum et economicorum libr. Paris, 1505. 1t., $8^{\circ}$.

Contenta : Politicorum libri octo. Commentarii economicorum duo... 1505 (S. 1. : Petro et Beato Rhenano)

CCFR: res.4146 b fonds ancien

226. Eiusd., Phisicor. Libri. Lug., 1546. 1t., $8^{\circ}$.

Physicorum Aristotelis : seu De naturali auscultatione : libri octo / Ioanne Argyropylo Byzantio interprete. Lugduni : apud Seb. Gryphium, 1546 CCPB000268567-1

227. Eiusd., Libri ad Nicomachum. Parisiis, 1539. 1t., $8^{\circ}$.

Decem libri Ethicorum Aristotelis ad Nicomachum ex traductione Ioannis Argyropili Byzantii... : Adiectus Leonardi Aretini de moribus dialogus ad Galeotum... Parisiis : Apud Ambrosium Girault, 1539 CCPB000183941-1

228. Eiusd., Dialectica, Boetio Severino interprete. Lugduni, 1553. 1t., $8^{\circ}$.

Dialectica Aristotelis, Boethio Seuerino interprete. Adiectis iam recèns Angeli Politiani in singulos libros argumentis. Lugduni : apud Antonium Vincentium, 1553 (Lugduni : excudebat Michael Syluius, 1553)

[IT\ICCU\BVEE\013020]

229. Eiusd., opera omnia cum índice. Lug., 1549. 1t., fol. 
Aristotelis Stagiritae Opera : post omnes quae in hunc usque diem prodierunt editiones, summo studio emaculata $\&$ ad Graecum exemplar diligenter recognita : quibus accesit index locupletissimus recens collectus. Lugduni : apud Ioannem Frellonium, 1549 CCPB000119975-7

230. Eiusd., opera. Parisiis, 1608. 1t., fol.

Edición no localizada.

231. Eiusd., libri 10 ad Nicomachum cum variorum notis. Venetiis, 1535. 1t. fol.

Aristotelis... Ethicorum ad Nicomachum libri decem / Ioanne Argiropylo Byzantio interprete nuper recogniti, \& Cum Donati Accicioli... commentariis castigatissimis. Venetiis $:$ in Officina Lucaeantonii Iuntae, 1535 CCPB000119480-1

232. Eiusd., Libr. Phisicorum cum interpretationib. Perioni, Lug 1556. 1t., $8^{\circ}$.

Aristotelis libri physicorum / Ioachimo Perionio interprete, operaque; Nicolaij Grouchij correcti [et] emendati ... Lugduni : Antonium Vicentium : excudebat Ioannes d'Ogerolles, 1556

ССРВ000225480-8

233. Eiusd., Logica. Conimbricę, 1561. 1t., $4^{\circ}$.

Logica Aristotelis ... nunc denuo diligenti emendatione excusa. Conimbricae : in $\begin{array}{lllll}\text { Officina } & \text { Antonii } & \text { de } & \text { Mariz, } & 1561\end{array}$

CCPB000698919-5

234. Eiusd., et Xenophontis opera aliqua (Gręce). Basileę. 1t., $8^{\circ}$.

Aristotelis et Xenophontis Ethica, Politica, Oeconimica, cum aliis aliquot ex Plutarcho, Proclo \& Alexandro Aphrodisiensi commentationibus Basileae : apud Ioan. [s.a.]

\section{CCPB000699070-3}

235. Joan. Fęliciani. in Aristot. moralia ad Nicomachum, cum Eustratii, Michęlis Ephessii et aliorum explanatione. Venetiis, 1541. 1t., fol.

Aristotelis Stagiritae Moralia nichomachia : cum Eustratii Aspasii, Michaelis Ephesii ... explanationibus ... / nuper a Ioanne Bernardo Feliciano latinitate donata. Venetiis : apud haeredes Lucaeantonij Iuntae Florentini, 1541

CCPB000185855-6

\section{FILOSOFÍA DE AUTORES JESUITAS}

236. Antonii Casilii, Logica. Romę, 1643. 1t. fol.

Introductio in aristotelis logicam et reliquas disciplinas / auctore Antonio Casilio ... Romae: apud Christophorum Brandanum, 1643

CCPB000882845-8

237. Antonii Ruvii, Cursus Philosophic. ${ }^{\text {s }}$ 2, tom. Madriti, 1605 alii 3 Complut., 1603 et 11. 1 t., $4^{\mathrm{o}}$.

1) 
Commentarij in octo libros Aristotelis De physico auditu : vna cum dubijs \& quaestionibus hac tempestate agitari solitis / a patre Antonio Ruuio ... Societatis Iesu ... ; cum duplici indice ... Madriti : apud Ludouicum Sanchez, 1605

CCPB000056109-6

2)

Commentariorum in vniuersam Aristotelis Dialectiam : vna cum dubiis et quaestionibus hac Tempestate agitari solitis : posterior pars... / auctore patre Antonio Rubio... Societatis Iesu... Compluti : ex officina Ioannis Gratiani apud viduam, 1603 CCPB000040697-X

\section{3)}

Commentarii in libros Aristotelis Stagiritae ... de anima : vnà cum dubiis \& quaestionibus hac tempestate in scholis agitari solitis / a Patre Antonio Rubio Rodensi ... Societatis Iesu ... ; cum duplici indice, quorum vnus discussas omnes quaestiones, \& res omnes alicuius momenti alter complectitur ... Compluti : apud Andream Sanchez de Ezpeleta, 1611

CCPB000355213-6

238. Antonii Mayr, Cursus Philosophic. ${ }^{\mathrm{s}}$. Venet., 1745. 1t., $8^{\circ}$.

Philosophia peripatetica : antiquorum principiis et recentiorum experimentis conformata / auctore R.P. Antonio Mayr Societatis Iesu ...; Tomus secundus seu Phisica universalis Venetiis : apud Nicolaum Pezzana, 1745

CCPB000257715-1

239. Antonii Bernardi de Quiros, Cursus. Lug., 1666. 1t., fol.

R.P. Ant. Bernaldi de Quiros... è Societate Iesu... Opus philosophicum seu selectae disputationes philosophicae... Lugduni : sumptibus Philippi Borde, Laurentii Arnaud, $\begin{array}{llll}\text { Petri Borde, et Guill. } & 1666\end{array}$ CCPB000132161-7

240. Antonio Codorniu, Indice de la Philosophia moral. Gerona, 1746. 1t., $4^{\circ}$.

Indice de la philosofia moral, christiano-politica : dirigido a los nobles de nacimiento y espiritu ... / escrito por el P. Antonio Codorniu, de la Compañia de Jesus ... Gerona : por Jaime Bro ..., 1746

CCPB000057737-5

241. Antonii Cordeiri, Cursus Conimbricensis. Ollisipone, 1714. 1t.

Cursus philosophicus conimbricensis / auctore P.Antonio Cordeyro Societatis Jesu, Lusitano, Insulano, Angrensi, in tres partes distributus prima logicam amplectitur. Secunda physicam, cum corpoream, tum spiritualem ; tertia enucleabit metaphysicam Ulyssipone : ex officina Regia Deslandesiana, 1714

CCPB000933585-4

242. Adami Contzen, Politicor. lib. 10. Colonię, 1622. 1t., fol.

Eidicón no localizada. Posible error del gentilicio del editor con el lugar de edición. Las ediciones de Colonia registradas en el catálogo colectivo francés son a partir de 1629.

Politicorum libri decem, in quibus de perfectae Reipubl. forma, virtitubus, et vitiis, institutione civium, legibus, magistratu ecclesiastico, civili, potentia Reipublicae, itemque seditione et bello, adusum vitam que communem, accomodatè tractatur. 
Auctore Adamo Contzen, Societ. Jesu. [1621 ?] (Moguntiae : sumptibus Joannis Kinckii bibliopolae coloniensis)

CCFR: 10281 CGA

243. Benedicti Pererii, de communib. Rerum naturalium principiis. Parisiis, 1579. 1t., $4^{\circ}$.

Benedicti Pererii ... De communibus omnium rerum naturalium principiis et affectionibus libri quindecim : qui plurimum conferunt ad eos octo libros Aristotelis, qui de physico auditu inscribuntur, intelligendos ... Parisiis : apud Thomam Brumennium, 1579

CCPB000020319-X

244. Claudii Clementis, Machiabelismus iugulatus. Complut., 1637. 1t., $4^{\text {o }}$.

Machiavellismus iugulatus à christiana sapientia hispanica \& austriaca : dissertatio christiano-politica... / auctore P. Claudio Clemente è Societate Iesu... Compluti : apud Antonium Vazquez..., 1637

CCPB000039697-4

245. La misma obra en Castellano. 1t., $4^{\circ}$.

Edición no localizada.

246. Colegii Conimbricensis, Cursus Philosophicus. 5 tom. 3. Lug., ab anno 1594 ad 1607-2, Conimbricę, 1597 et 98. 1t., $4^{\circ}$.

Commentarii Collegii Conimbricensis Societatis Iesu in libros Meteororum Aristotelis Stagiritae ... Lugduni : ex officina Iuntarum, 1594

CCPB000005856-4

(Hay ediciones de Lyon de 1597, 1598, 1600, 1602, 1604, 1606 y 1607) ver: Comentários dos padres Jesuítas de Coimbra sobre as obras filosóficas de Aristóteles. Commentarii Colegii Conimbricensis Societatis Iesu... Aristotelis Stagiritae http://www.ghtc.usp.br/server/Lusodat/pri/00/htc-conimb.htm

Commentarii Collegii Conimbricensis Societatis Iesu in tres libros De anima, Aristotelis Stagiritae. Conimbricae : Typis \& expensis Antonij á Mariz, 1598

CCPB000005843-2

247. Didaci de Quadros, Palestra Scholastica. Matriti, 1722. 1t.

Palaestra Scholastica, sive Ars subsidiaria pro incipientibus ad ritè, et secte propugnandum, et impugnandum in publicis disputationibus / auctore P. Didaco de Quadros, Societatis Iesu... Matriti : ex Typographia Francisci Ferratini, 1722 CCPB000059107-6

248. Franci Alphonsi, Cursus Philosophic. ${ }^{\text {s }}$ Compluti, 1739 et 40. 4t., $4^{\circ}$.

1)

Disputationes in universam Aristotelis Logicam / authore R.P. Francisco Alphonso ... è Societate Iesu ... Compluti : apud Antonium Vazquez, 1639 CCPB000032367-5

2) 
Disputationes in tres libros Aristotelis De anima / authore P. Francisco Alfonso ... Societate Iesu ... Compluti : apud Antonium Vazquez ..., 1640

CCPB000033053-1

249. Franci Toleti, Cursus Philosophicus. Colonię, 157576 et $77.3 t ., 4^{\circ}$.

(Los títulos que figuran en el CCPB editados en colonia en los tres años mencionados son los siguientes):

1)

D. Francisci Toleti ... Commentaria vna cum Quaestionibus, in octo libros Aristotelis de Physica auscultatione. Item Commentaria, et Quaestiones eiusdem in lib. Arist. de Generatione \& Corruptione, iam ab authore adiecta ... Coloniae Agrippinae : apud haeredes Arnoldi Birckmanni, 1575

CCPB001065316-3

2)

D. Francisci Toleti Societatis Iesu Commentaria vnà cum quaestionibus in tres libros Aristotelis De anima. Coloniae Agrippinae : apud haeredes Arnoldi Birckmanni, 1576 ССРВ000703306-0

3)

D. Francisci Toleti Societatis Iesu Commentaria, vnà cum quaestionibus, in vniuersam Aristotelis logicam ... Coloniae Agrippinae : apud haeredes Arnoldi Birckmanni, 1577

CCPB000233179-9

250. Franci Gonzalez, S. Crucis. Phisica et Metaphisica. Romę, 1645 et 55. 2t. $4^{\circ}$.

Philosophia naturalis de physico auditu Aristoteles, et interpretum eius SS.PP. Augustini, et Thomae doctrinae valde conformis / disposita, et illustrata a P. Francisco Gonçalez Sanctacrucio Societatis Iesu ... Romae : Typis Hierony. Barberi ... : sumptibus $\begin{array}{lllllll}\text { eiusdem } \quad \& & \text { D. } & \text { Petri } & \text { Guiginea } & \ldots, & 1645\end{array}$ CCPB000618637-8

251. Franci Suarez, Cursus. Evorę, 1668 et 69. 2t., fol.

R.P.D. Francisci Soares Lusitani ... e Socitate Iesu ... Cursus philosophici : tomus secundus : continens universam doctrinam in libros Aristotelis Physicorum, de Coelo, Meteoris \& Parvis Naturalibus. Eborae : ex Typographia Academiae, 1668 CCPB000759090-3

252. Franci de Oviedo, Cursus. Lug., 1640. 2t., fol.

Integer cursus philosophicus ad unum corpus redactus in summulas, logicam, physicam, de caelo, de generatione, de anicua \& metaphisicam distributus : tomus primus. Lugduni $\begin{array}{llll}\text { : } & \text { sumptibus } & \text { Petri } & \text { Prost, }\end{array}$ CCPB000226810-8

253. Fran.co Garcia, el sabio instruido de la naturaleza de la gracia, 4 tom. En Barcelona desde 1675 hasta 1740,1, Zarag. ${ }^{\mathrm{za}}$, 1704. 5t., $4^{\circ}$.

El Olimpo del sabio instruido de la naturaleza y segunda parte de la maximas políticas y morales ilustradas con todo genero de erudición sacra y humana / por ... Francisco Garau de la Compañía de Iesus ... ; va a la fin un índice de materias predicables ... Barcelona: por Rafael Figuero, 1704 


\section{ССРB000141667-7}

254. Fran. ${ }^{\text {co }}$ Garcia del Valle, Hist. ${ }^{\text {a }}$ nat. y moral del Nacim. ${ }^{\text {to }}$ del mundo. 1. ${ }^{a}$ parte. M. $^{\text {, }}$, 1648. 1t., fol.

Historia natural y moral del nacimiento del mundo / del R.P. Francisco García del Valle, de la Compañía de IHS [anagrama] ... ; parte primera ; con dos tablas de ... sermones ... de verbos ... En Madrid : por Gregorio Rodríguez, 1648 CCPB000135611-9

255. Gabriel Daniel, Viage del mundo de Descartes. M. ${ }^{\mathrm{d}}$., 1t., $8^{\circ}$.

Viage de el Mundo de Des-Cartes / escrito en francés por el P. Gabriel Daniel, de la Compañía de Jesús ; traducido por Don Juan Bautista de Ybarra. En Madrid : en la Imprenta del Reyno [.., [s.a.] CCPB000059135-1

256. Gabrielis Henao, de Coelo Empireo. Lug., 1652. 1t., fol.

R.P. Gabrielis de Henao... Societatis Iesu... Empyreologia seu philosophia christiana, de empyreo coelo : pars prima: nouum opus maximéque necessarium philosophis,... concionatoribúsque diuini verbi. Lugduni : sumpt. Philippi Borde, Laurentij Arnaud \& Claudij Rigaud, 1652

CCPB000122763-7

257. Gabrielis Vazquez, Metaphisica. Matr., 1617. 1t., $4^{\circ}$.

Patris Gabrielis Vazquez Societatis Iesu Disputationes Metaphysicae : desumptae ex varijs locis suorum operum... Matriti : apud Ludonicum $\mathrm{S}^{-}$actium..., 1617

CCPB000042724-1

258. Hernando Castrillo, Magia nat. ${ }^{\mathrm{s}}$ trigueros. 1649. 1t., $8^{\circ}$.

Magia natural, o Ciencia de filosofia oculta : con nueuas noticias de los mas profundos misterios y secretos del uniuerso visible / por el P. Hernando Castrillo, de la Compañia de Iesus... ; primera parte, donde se trata de los secretos que pertenecen a las partes de la Tierra. Impresso en Trigueros : por Diego Perez Estupiñan, 1649 CCPB000038952-8

259. Honorati Fabri, Phisica. Lug., 1669. 1t., $4^{\circ}$.

Physica : id est, scientia rerum corporearum : in decem tractatus distributa / auctore Honorato Fabri Soc. Iesu ... Lugduni : sumptibus Laurentii Anisson, 1669

CCPB000048109-2

260. Eiusd., Dialogi Phisicor. Eod. loco et anno. 1t., 81.

Dialogi physici quorum : Primus est de Lumine ... prout in preafixi singularibus titulis planius declaratur / auctore Honorato Fabri ... Lugduni : apud Antonium Molin, 1669 CCPB000882696-X

261. Honorati Nigueti, Phisonomia humana. Lug., 1648. 1t., $4^{\circ}$.

R.P. Honorati Nicquetii e Societate Iesu... Physiosnomia humana : libros IV distincta. Lugduni : sumptib. haered. Petri Prost, Philippi borde, \& Laurentii Arnaud, 1648

ССРВ000489916-4 
262. Hieronimi Dandini, de Corpore animato lib. 7. Parisiis, 1610. 1t., fol.

Hieronymi Dandini Caesenatis e societate iesu de corpore animato lib. VII. Luculentus in Aristotelis tres de Anima libros, Commentarius Peripateticus. Parisiis : apud Claudium Chappeletum, via Iacobaea, sub signo Unicornis, 1610 CCPB000883412-1

263. Joann. Baptista Scortia, de natura et incremento Nili. Lug., 1617. 1t., $8^{\circ}$.

De natura et incremento nili : libri duo... / authore P. Ioanne Baptista Scortia... Societatis Iesu... Lugduni : sumptibus Horatij Cardon, 1617

CCPB000405646-9

264. Ignati Franci Peynado, Cursus Philosophic. ${ }^{\text {. }}$ Complut., â 1679 ad 98. 3t., 4º

Disputationes in vniversam Aristotelis Logicam / authore R.P.M. Ignatio Francisco Peinado... è Societate Iesu... [Compluti] : apud Franciscum Garcia Fernandez ... : sumptibus Collegii Complutensis Societatis Iesu, 1679

CCPB000040930-8

Disputationes in duos Aristotelis libros De Generatione \& Corruptione : opus posthumum / authore ... Ignatio Francisco Peynado è Societate Iesu ... Compluti : in officina Francisci Garcia Fernandez, typographi Universitatis, 1698 CCPB000051860-3

265. Iosephi de Aguilar, Cursus Philosophic. ${ }^{\mathrm{s}}$. Hispali, 1701. 2t., $4^{\mathrm{o}}$.

Cursus philosophicus dictatus Limae / a P. Iosepho de Aguilar Societatis Iesu ... ; Tomus secundus ... Hisp. : ex Offic. Ioann. Francisc. de Blas ..., 1701 CCPB000064702-0

266. Joan. Bap. de Benedictis, Cursus Philosophicus. Venetiis, 1749. 1t., $8^{\circ}$.

Philosophia peripatetica : tomis quatuor comprehensa / authore Jo. Baptista de Benedictis e Societate Jesu... ; tomus primus, logica ... Venetiis : ex Typographia Balleoniana, 1749

ССРВ000125620-3

267. Josephi Falk, Mundus aspectabilis. Augustę, 1738. 1t., fol.

Mundus aspectabilis philosophile consideratus / authore R.P. Josepho Falck Societatis Jesu... Augustae Vindelicorum : Sumptibus Martini Veith..., 1738 CCPB000169184-8

268. Joan. Ulloa, Prolegomena ad Scholasticas Disputat.s. Matr., 1748. 1t., fol.

Prodromus seu prolegomena ad scholasticas disciplinas : ubi axiomata, aphorismi ... : cum triplici indice ... / authore Joanne de Ulloa ... Societatis Jesu ... Matriti : ex typografia Antonii Marin, 1748

CCPB000180020-5

269. Eiusd., Cursus Philosophicus. Romę, a 1711 ad 715. 5t., $4^{\circ}$.

Dialectica seu logica minor : tribus disputationibus circumscripta / authore P. Joanne de Ulloa... Societatis Jesu... Romae : ex typographia Pauli Komareck, 1711

CCPB000247060-8 
De anima disputationes quatuor : ubi natura illius, proprietates, modis operandi, vitales que operationes... exponuntur... / authore Joanne de Ulloa... Societatis Jesu... Romae: $\begin{array}{lllll}\text { typis } & \text { Jo. } & \text { Francisci } & \text { Chracas..., } & 1715\end{array}$ CCPB000180021-3

270. Joan. Eusebii Nieremberg, Hist. ${ }^{a}$ naturę. Ant., 1635. 1t., fol. Ioannis Eusebii Nierembergii ... ex Societate Iesu ... Historia naturae, maxime peregrinae libri XVI distincta : in quibus rarissima Naturae arcana, etiam astronomica, \& ignota Indiarum animalia, quadrupedes, aues, pisces, reptilia, insecta, zoophyta, plantae, metalla, lapides \& alia mineralia, fluiiorumque \& elementorum conditiones, etiam cum proprietatibus medicinalibus, describantur, nouae \& curiosissimae quaestiones disputantur, ac plura sacrae scripturae loca eruditè enodantur / Accedunt De miris \& miraculosis Naturis in Europa libri duo item de iisdem in Terra hebraeis promissâliber unus. Antuerpiae : ex officina Plantiniana Balthasaris Moreti, 1635 CCPB000048453-9

271. Del mismo, obras Philosophicas en Castellano. tom. 3. ${ }^{\circ}$. M.d, 1664. 1t., fol. Obras philosophicas / del P. Iuan Eusebio Nieremberg, de la Compañia de Iesus ... ; tomo tercero de sus obras en romance ... En Madrid : en la Imprenta Real : a costa de la viuda de Francisco de Robles, 1664

CCPB000048903-4

272. Joan. Roverti, Curationes Magneticę et unguenti de manu divino. Luxemburgi,1618. 1t., $8^{\circ}$.

Goclenívs Heautontí morumenos id est, curationes magnetícae, et unguentí armaríi ruína ipso Rodolpho Goclenío ... nunc cum sigilis, \& characterís magicis ultro prorvente et praecípitante ... / aohan Robertí, Societ. Iesu ... Luxemburgí : excudebat Hubertus Reuland, 1618

CCPB000046902-5

273. Juliani Garcia, Cursus Philosophic. s. Bilbili., 1759. 3t., $4^{\circ}$.

Cursus philosophicus : juxta praescriptam provinciae Aragoniae Societatis Jesu... ad mentem ...Francisci Suarez / compendio digestus a P.Juliano Garcia de Vera ejusdem Societ...; pars prima... Bilbili : apud Joachim Estevan..., 1759

CCPB000180261-5

274. Juan de Torres, Philosophia moral de Principes. $2^{\mathrm{a}}$ parte. Burgos, 1596. 1t., fol. Philosophia moral de principes, para su buena criança y gouierno y para personas de todos estados / compuesta por el Padre Iuan de Torres, de la Compañia de Iesus ... En Burgos : por Philippe de Iunta y Iuan Baptista Varesio : a costa de Iuan Boyer, 1596 CCPB000030824-2

275. Juan de Steynefer, Florilogio Medicin.1. Mexico, 1719. 1t., 4.

Florilegio medicinal de todas las enfermedades : sacado de varios y clasicos autores para bien de los pobres ... en particular para las Provincias remotas, en donde administran los RR.PP. Missioneros de la Compañia de Jesus : reducido a tres libros, el primero de Medicina, el segundo de Cirugia, con un Appendix ... el tercero contiene un Catalogo de los medicamentos usuales ... con el modo de componerlos / escrito por el hermano Juan de Esteyneffer ... de la Sagrada Compañia de Jesus ... [Madrid] En Mexico por los Herederos de Juan Joseph Guillena Carrascoso año de 1712, y por su 
original en el año de 1719, a costa de Don Domingo Saenz Pablo, Familiar del Santo Oficio ... : por Alonso Balvas, [1729?]

CCPB000578157-4

276. Jph. Casani, Tratado de los cometas. M. ${ }^{\mathrm{d}}, 1737.1 \mathrm{t} ., 8^{\circ}$.

Tratado de la naturaleza, origen, y causas de los Cometas, con la historia de todos los que se tienen noticia haberse visto... y con el methodo de observar Astronomicamente sus lugares aparentes... / por el padre Joseph Cassani, de la Compañía de Jesus... En Madrid : por Manuel Fernandez..., [s.a.]

CCPB000057706-5

277. Ludovici de Lossada, Cursus Philosophicus. Salmant. ${ }^{\text {ce }}$, a 1724 ad 34. 4t., $4^{\circ}$.

Cursus philosophici regalis collegii salmanticensis societatis Iesu in tres partes divisi : prima pars ... / authore R. P. Ludovico de Lossada ... Salmant. : ex typ. Francisci Garcia ab Honorato et San Miguel, 1724

CCPB000062756-9

278. Mathię Heimbach, Philosophia argumentosa. Colonię, 1747. 2t., $8^{\circ}$.

Philosophia argumentosa quondam florilegium argumentorum sive ars practica inveniendi medium nuncupata, theses philosophicas acriter in utramque partem disputatas exhibens ... / authore R.P. Matthia Heimbach S.I... Coloniae Agrippinae : ex Officina Noetheniana, 1747

CCPB000884459-3

279. Michęlis de Biñas, Cursus philosophicus. Genuę, 1709. 3t., fol.

Philosophia scholastica : tribus voluminibus distincta ... / a Reuer. Patre-Michaele de Viñas ... Societatis Jesu ... Genuae : typis Antonii [cas]amarae ..., 1709

CCPB000142016-X

280. Martini Del-rii, Disquisition. Magicar. lib 6. Moguntię, 1603. 1t., fol.

Disquisitionum magicarum libri sex in tres tomos partiti ... / auctore Martino Delrio ... Moguntiae : apud Ioannem Albinum, 1603

CCPB000141345-7

281. Mathęi Aimerich, Proluctiones Philosophicę. Barcinone, 1756. 1t. $4^{\circ}$.

Matthaei Aymerich hispani e Societate Jesu... Prolusiones philosophicae seu Verae et germanae philosophiae effigies... Barcinone : apud Paulum Nadal..., 1756

CCPB000125474-X

282. Petri Fonseca, Cursus Philosophic. ${ }^{\text {s }}$ 5. tom. 2. Lugd.,1605 et 1612, duo. Romę, 1527 et 39, alter Venetiis, 1575. 5t., $4^{\circ}$.

Commentariorum Petri Fonsecae ... Societatis Iesu in Metaphysicorum Aristotelis Staginitae libros tomus tertius : continet hic tomus VI, VII, VIII et IX Lib. Explicationem. Lugduni : sumptibus Horatij Cardon, 1605

CCPB000177066-7

Commentariorum Petri Fonsecae... in metaphysicorum Aristotelis... tomus IV... Lugduni : sumptibus Horatis Gardou, 1612 (Iacobi du Creux, dicte Molliard) CCPB000173499-7 
Institutionum dialecticarum octo / Auctore Petro Fonseca ... Nunc primum ab ipso recogniti. Venetiis : apud Christophorum Zanettum, 1575

CCPB000010235-0

283. Pauli Vallii, Logica. Lug., 1622. 2t., fol.

Logica / Pauli Vallii Romani Societatis Iesu ; duobus tomis distincta, quorum primus artem veterem, secundus nouam comprehendit ; tomus primus ... Lugduni : sumptibus $\begin{array}{llll}\text { Ludouici Prost haeredis } & \text { Rouille, }\end{array}$

CCPB000055818-4

284. Petri Hurtado, Cursus. Lug., 1624. 1t., fol.

Universa Philosophia / R.P. Petro Hurtado de Mendoza Valmasedano e Societate Iesu ... Lugduni : sumpt. Ludovici Prost haeredis Roville, 1624

CCPB000123139-1

285. Roderici de Arriaga, Cursus. Ant., 1632. 1t., fol.

Cursus philosophicus / auctore R. P. Roderico de Arriaga ... Soc. Iesu. Antuerpiae : Ex officina Plantiniana, Balthasaris Moreti, 1632

СCPB000044551-7

286. Richardi Lincei, Cursus Philosoph. Lug., 1654. 3t., fol.

R.P. Richardi Lyncei societatis Iesu ... Universa philosophia scholastica : tomus primus [-tertius] ... Lugduni : sumpt. Philippi Borde, Laurentii Arnaud, \& Claudii Rigaud, 1654

CCPB000048347-8

287. Sebastiani Izquierdo, Pharus Scientiarum. Lug., 1659. 1t., fol.

R.P. Sebast. Izquierdo ... Soc. Iesu ... Pharus scientiarum : vbi quidquid ad cognitionem humanam humanitùs acquisibilem pertinet, vbertim iuxtà, atque succinctè pertractaur : scientia de scientia, ob summam vniuersalitatem vtilissima, scientificisque iucundissima, scientificâ exhibetur : Aristolis organum iam periè labens restituitur .. Lugduni : sumptibus Claudii Bourgeat \& Mich. Lietard., 1659 CCPB000130960-9

288. Thomae Comptoni Carliton, Cursus. Ant., 1654. 1t., fol.

Edición no localizada.

289. Theodori Moreti, de Aestu Maris. Ant., 1665. 1t., $4^{\circ}$.

Tractatus physico-mathematicus de aestu maris / auctore Theodoro Moreto ... Antuerpiae: apud Iacobum Meursium, 1665

CCPB001063892-X

290. Torquini Gallici, in 5, priores libros Arist. Parisiis, 1632. 1t., fol.

Tarquinii Gallutii ... e Societate Iesu In Aristotelis libros quinque priores moralium ad Nicomachum, noua interpretatio commentarii quaestiones Parisiis : sumptibus Sebastiani Cramoisy ..., 1632

CCPB000481421-5 


\section{DUPLICADOS DE AUTORES JESUITAS}

291. Antonio Rubio, Comm. in Librum Arist. de Anima. Comp., 1611. 1t., $4^{\text {o }} .^{31}$

292. Eiusd., in 8 libr. Phisicor. Complut., 1613. $4^{\circ}$.

Commentarii in octo libros Aristotelis De phisico auditu seu Auscultatione : vna cum dubijs \& quaestionibus hac tempestate agitari solitis / a patre Antonio Rubio... Societatis Iesu... ; cum triplici indice... Compluti : ex officina apud viduam Ioannis Gratiani, 1613 CCPB000040694-5

293. Antonii Mayr, Cursus Philosophic. ${ }^{\mathrm{s}}$. Venetiis, 1745 . 4t., fol. ${ }^{32}$

294. Eiusd., idem per omnia. 4t., fol.

Philosophia peripatetica : antiquorum principiis et recentiorum experimentis conformata / auctore R.P. Antonio Mayr Societatis Iesu ...; tomus tertius seu Physicae particularis pars prima. Venetiis : apud Nicolaum Pezzana, 1745

CCPB000495858-6

295. Benedicti Pererii, Philosophia. Rom., 1576. 1t., fol.

Benedicti Pererii Societatis Iesu De communibus omnium rerum naturalium principiis $\&$ affectionibus, libri quindecim : qui plurimum conferunt, ad eos octo libros Aristotelis, qui de Physico auditu inscribuntur, intelligendos ... Romae: apud Franciscum Zanettum \& Bartholomaeum Tosium socios : impensis Venturini Tramezini, 1576

CCPB000020318-1

296. Collegii Conimbricensis Soc. Jes., Comm. in aliquos Arist. libr. Conimbricę, 1592 et 94.2 t., $4^{\circ}$.

Commentarii Collegii Conimbricensis Societatis Iesu in octo libros physicorum Aristotelis stagiritae. Conimbricae : typis et expensis Antonij à Mariz ..., 1592

CCPB000005862-9

297. Fran. ${ }^{\text {ci }}$ Suarez, Disput. ${ }^{\text {s }}$ Metaphisicę. Parisiis, 1605. 2t., fol.

R. Patris Francisci Suarez e Societate Iesu, Metaphysicarum disputationum ... tomi Duo cum quinque Indicibus ... Parisiis : apud Michaélem Sonnium ..., 1605

CCPB000040536-1

298. Eiusd., operis tom. 2. . Salm., 1597. 1t., fol.

Metaphysicarum disputationum in quibus et universa naturalis theologia ordinate traditur et quaestiones omnes ad duodecim Aristotelis libros pertinentes accurate disputantur tomus prior / autore R.P. Francisco Suarez ... Salmanticae : apud Ioannem $\begin{array}{llll}\text { [et] Andream } & \text { Renaut } & \text { fratres, }\end{array}$ CСРB000031869-8

299. Franci toleti, comm. in Arist. logicam ac in 8 libr. Phisicor. Comp., 1577 et 78.2 t., $4^{\circ}$.

\footnotetext{
${ }^{31}$ Probablemente sea la misma edición consignada en el Nro 237.

${ }^{32}$ Se trata de la misma edición consignada en Nro: 238.
} 
D. Francisci Toleti Societatis Iesu Commentaria vnà cum quaestionibus in vniuersam Aristotelis Logicam: multò accuratius diligentiusq[ue] nunc denuò excussa : adiecto indice quaestionum. Compluti: apud Ioannem Gratianum, 1578

CCPB000026341-9

D. Francisci Toleti, Societatis Iesu, Commentaria vnà cum quaestionibus in octo libros Arist. de Physica auscultatione. Compluti : apud Ioannem Gratianum, 1577

CCPB000026331-1

300. Eiusd., comm. in 3 libr. Arist. de Anima. Colon., 1576. 1t., $4^{\text {o }}{ }^{33}$

301. Eiusd., id. Opus. Comp., 1577 et 82. 2t., $4^{\circ}$.

D. Francisci Toleti, Societatis Iesu, commentaria, vna cum quaestionibus, in tres libros Arist. de anima

Compluti : apud Ioannem Gratianum, 1577

CCPB000188387-9

D. Francisci Toleti Societatis Iesu Commentaria vnà cum quaestionibus in tres libros Aristotelis de Anima. Compluti : apud Ioannem Gratianum, 1582

CCPB000156809-4

302. Id. Opus. Venet., 1574. 1t., $4^{\circ}$.

D. Francisci Toleti Societatis Iesu Commentaria vnà cum quaestionibus in tres libros Aristotelis De Anima. Venetiis : apud Iuntas, 1575

CCPB000026314-1

303. It. in 8 , lib. Phisicor. Comp., 1577. 1t., $4^{\text {o }} .^{34}$

304. In universam Arist. Logicam. Comp., 1578. 1t., $4^{\mathrm{o}}$.

Edición no localizada. Quizá el mismo libro citado en 304:

305. Eiusd., id. Opus. Colonię, 1578, Id. per omnia Idz. 3t., $4^{\circ}$.

306. Franci Alphonsi, Disputat. ${ }^{\mathrm{s}}$ in Logicam. Complut., 1648. 1t., $4^{\mathrm{o}}$.

Disputationes in universam Aristotelis Logicam / authore R.P. Francisco Alphonso ... è Societate Iesu ... Compluti : apud Mariam Fernandez, 1648

CCPB000032369-1

307. Eiusd., id. Opus. Comp., 1649. 1t., $4^{\circ}$.

Edición no localizada. Posible error en la fecha:

Disputationes in universam Aristotelis Logicam / authore R.P. Francisco Alphonso ... è Societate Iesu. Compluti : apud Mariam Fernandez, 1659

CCPB000032368-3

308. Eiusd., Disputat. ${ }^{\mathrm{s}}$ in 3. libr. de Anima. Comp., 1640. 1t., $4^{\circ}$.

Disputationes in tres libros Aristotelis De anima / authore P. Francisco Alfonso ... Societate Iesu ... Compluti : apud Antonium Vazquez ..., 1640

\footnotetext{
${ }^{33}$ Se trata de la misma edición consignada en Nro: 249.

${ }^{34}$ Se trata de la misma edición consignada en Nro: 299.
} 


\section{CCPB000033053-1}

309. Eiusd., in 8. libr. Phisicor. Comp., 1640. 1t., $4^{\circ}$.

Disputationes in octo libros physicorum Aristotelis / authore R.P. Francisco Alphonso

... Societate Iesu ... Compluti : apud Antonium Vazquez ..., 1640

CCPB000032366-7

310. Eiusd., Summulę. Comp., 1639. 1t., $8^{\circ}$.

Disputationes in universam Aristotelis Logicam / authore R.P. Francisco Alphonso ... è Societate Iesu ... Compluti : apud Antonium Vazquez, 1639

CCPB000032367-5

311. Gabrielis Bazquez. G., Disputat. ${ }^{\mathrm{s}}$ Metaphisicę. Matriti, 1617. 1t., $4^{\mathrm{o}}$.

Patris Gabrielis Vazquez Societatis Iesu Disputationes Metaphysicae : desumptae ex varijs locis suorum operum... Matriti : apud Ludonicum Sanctium..., 1617

CCPB000042724-1

312. Gasparis Buon, Philosophia. Lug., 1723. 1t., fol.

Philosophia ad morem gymnasiorum finemque accommodata / auctore... Gaspare Buhon Societatis Iesu... ; tomus secundus ; Physicae. Lugduni : sumptibus Fratrum Bruyset..., 1723

CCPB000159209-2

313. Jonatii Franci Peinado, Disputat. ${ }^{\mathrm{s}}$ in Logicam. et 8, lib. Phisicor. Comp, 1679 et 74. $2 \mathrm{t} ., 4^{\circ}$.

Disputationes in octo libris physicorum Aristotelis / authore R.P. Ignatio Francisco Peinado ... Societate Iesu ... Compluti : apud Franciscum Garcia Fernandez ... : sumptibus Collegij Complutensis Societatis Iesu, 1674

CCPB000041500-6

314. Eiusd., in 8 lib. Phisicor. Comp., 1680. 1t., $4^{\circ}$.

Disputationes in octo libros physicorum Aristotelis / authore R. P. Ignatio Francisco Peinado ... è Societate Iesu ... Compluti : apud Franciscum Garcia Fernandez ... : sumptibus Collegij Complutensis Societatis Iesu, 1680

CCPB000051861-1

315. Josephi de Aguilar, Cursus Philosophic. Hispali, 1709. 3t., fol.

Cursus philosophicus dictatus Limae / a P. Iosepho de Aguilar Societatis Iesu ... ; Tomus primus ... Hispali.: ex Offic. Ioannis Francisci de Blas ..., 1701 (posible error en la escritura de la fecha)

CCPB000064702-0

316. Eiusd., operis tom $1 . \mathrm{s}$. Hispali, 1701. 1t., $4^{\mathrm{o}} .^{35}$

317. Josephi Falck, Mundus a spectabilis. Augustę, 1738. 1t., fol. ${ }^{36}$

318. Joan Bap. de Benedictis, Philosophia Peripateticę tom. 2. ${ }^{\mathrm{s}} 4$. $^{\mathrm{s}}$. Venet., 1749. 2t., $8^{\text {o }}$.

\footnotetext{
${ }^{35}$ Se trata de la misma edición consignada en el Nro: 265.

${ }^{36}$ Se trata de la misma edición consignada en el Nro: 267.
} 
Philosophia peripatetica : Tomis quatuor comprehensa / authore Jo. Baptista de Benedictis e Societate Jesu ; Tomus secundus... Venetiis : ex typographia Balleoniana, 1749

CCPB000125621-1

319. Juan de Torres, Philosophia Moral de Principes. Burg., 1596. 1t., fol.

Philosophia moral de principes para su buena criança y gouierno y para personas de todos estados / compuesta por el Padre Iuan de Torres de la Compañia de Iesus ... ; tratanse enella [sic] varias materias muy utiles para predicadores. En Burgos: por Philippe de Iunta y Iuan Baptista Varesio : a costa de Ambrosio du Port mercader de libros,

1596

CCPB000268834-4

320. Ludovici de Lossada, Cursus Philosophic.. Salmant., 1721, 24, 3, et 31. 4t., $4^{\text {o. }}{ }^{37}$

321. Eiusd., operis Summulę Logica, et metaphisica. Salmant., 1721. 3t., $4^{\text {o }}$.

Institutiones dialecticae, vulgo summulae ad primam partem philosophici cursus pertinentes / authore R.P. Ludovico de Lossada è societate Jesu ... Salmanticae: ex typographia Francisci Garcia Onorato \& San Miguel, 1721

CCPB000117692-7

322. Eiusd., id. Cursus. Salmant., 1521. 4t., $4^{\circ}$.

Edición no localizada.

323. Leonardi Lesii., vera ratio valetudinis bonę. Ant., 1614. No es duplicado. 1t., $8^{\circ}$.

Hygiasticon seu Vera ratio valetudinis bonae et vitae : vnà cum sensuum, iudicii \& memoriae integritate ad extremam senectutem $\mathrm{c}^{-}$oseruandae / auctore Leonardo Lessio Societatis Iesu ... ; subiungitur Tractatus Ludouici Cornari, eódem pertinens, ex italico in latinam sermonem ab ipso Lessio translatus. Antuerpiae : ex officina Plantiniana : apud viduam \& filios Io. Moreti, 1614

CCPB000128404-5

324. Petri Hurtado, Disputat. ${ }^{\mathrm{s}}$ a Summulis ad metaphisicam. Vallisoleti, 1615. 1t., fol.

Disputationes summulis ad metaphysicam / a Pedro Hurtado de Mendoza ... Societatis Iesu ... Vallisoleti : apud Ioannem Godinez de Millis, 1615

CCPB000046961-0

325. Roderici de Arriaga, Cursus Philosophic. . . Ant., 1631. 1t., fol.

Edición no localizada. El CCPB solo registra ediciones de Amberes a partir de 1632. Posiblemente se trate de un error de escritura.

326. Eiusd., yd. opus. Ant., 1632. 2t., fol. ${ }^{38}$

327. Eiusd., yd. opus. Lug., 1653. 1t., fol.

Cursus philosophicus auctore R. P. Roderico de Arriaga. Lugduni: sumptibus Claudii Prost ..., 1653.

\footnotetext{
${ }^{37}$ La edición de 1724 está consignada en el Nro: 277. Las restantes no se han localizado en los catálogos consultados.

${ }^{38}$ Se trata de la misma edición consignada en el Nro: 285.
}

212 Marcela A. Suárez, Luis Sánchez y María Soledad Justo. La Biblioteca del Antiguo... 158-254. 
CCFR: SA 180 E Sciences et Arts

328. Silbestri Aranha, Disputat. ${ }^{\mathrm{S}}$ Phisicę adversus thomistic. Sisthema. Conimbricę, 1747. 1t., $4^{\circ}$.

P.M. Silvestri Aranha ... Societate Jesu Disputationum physicarum adversus atomisticum systema / quod defendendum suscepit R.P. Thomas Vicentius Tosca ... Congregationis Oratorii ; pars prima. Conimbricae: ex typ. in Regio Artium Collegio Societ. Jesu, 1747

CCPB000726512-3

329. Thomę Comptini, introductio ad universam Logicam Aristot. Sine loco et anno Impresionis.

Edición no localizada.

\section{SECCIÓN HISTORIA PROFANA}

1. Admirables efectos de la Provid. ${ }^{\mathrm{a}}$ en la vida è Imperio de Leopoldo prim. ${ }^{\mathrm{o}}$ Milan, 1696. 3 t., fol.

Gualdo Priorato, Galeazzo, Admirables efectos de la prouidencia sucedidos en la vida e imperio de Leopoldo primero... : tomo primero en que se trata de los sucessos del año 1657 asta [sic] el de 1671 / [D.M.G.P.] En Milan : en la Emprenta Real : por Marcos Antonio Pandulpho Malatesta, 1696.

CCPB000036969-1

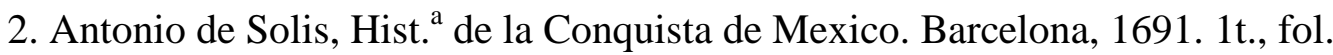

Solis y Ribadeneyra, Antonio de, Historia de la conquista de Mexico, poblacion, y progresos de la America Septentrional, conocida por el nombre de Nueva España / escribiala Don Antonio de Solis ... cronista mayor de las Indias, Barcelona : en la imprenta de Joseph Llopis... y a su costa : vendese en su casa, 1691.

CCPB000205964-9

3. Ambrosio de Morales, Chronica Grãl. de España continuando los cinco Libros q. ${ }^{\mathrm{e}}$ Florian de Ocampo dexo escritos. Alcala de Henares, 1574 y 76. 2. t., fol.

Morales, Ambrosio de, La Coronica general de España / que continuaua Ambrosio de Morales...; prossiguiendo adelante de los cinco libros, que el Maestro Florian de Ocampo... dexo escritos... En Alcala de Henares: en casa de Iuan Iñiguez de Lequerica, 1574.

CCPB000018901-4.

Morales, Ambrosio de, La Coronica General de España... Alcala de Henares : Iuan

Yñiguez de Lequerica, 1574-1577

CCPB000018908-1

4. Del mismo, prosiguiendo de la restauración de España, desde q. ${ }^{\mathrm{e}}$ se comenzó a ganar de los moros hasta el rey D. ${ }^{n}$ Bermudo el $3^{\circ}$, en los cinco Libros posteriores de la Chronica Grãl. de España. Cor. ${ }^{\text {ba }}$, 1586. 1 t., fol.

Morales, Ambrosio de, Los cinco libros postreros de la Coronica general de España Que continuaua Ambrosio de Morales... Prossiguiendo adelante la restauracion de España, desde que se començo a ganar de los Moros, hasta que el rey don Bermudo el tercero deste nombre... Cordoua : Por Gabriel Ramos Bejarano, 1586.

CCPB000018905-7

213 Marcela A. Suárez, Luis Sánchez y María Soledad Justo. La Biblioteca del Antiguo... 158-254. 
5. Viage del mismo, dado a luz p. ${ }^{\mathrm{r}}$ Enriq. ${ }^{\mathrm{e}}$ Flores. M. ${ }^{\mathrm{a}}, 1765.1 \mathrm{t}$, , fol.

Morales, Ambrosio de, Viage de Ambrosio de Morales por orden del rey D. Phelipe II a los reynos de León, y Galicia, y Principado de Asturias, para reconocer las reliquias de santos, sepulcros reales y libros manuscritos de las cathedrales y monasterios / dale à luz con notas, con la vida del autor, y con su retrato ... Fr. Henrique Flórez ... del Orden del Gran Padre S. Agustin En Madrid : por Antonio Marín, 1765

CCPB000060756-8

6. Antonii Nebrixensis, Hist. ${ }^{\text {, }}$ cum Historia Roderici Archiobisp. Toletam. Granatę, 1545. 1 t., fol.

Pulgar, Hernando del, Habes in hoc volumine amice lector Aelii Antonii Nebrissensis Rerum a Fernando et Elisabe Hispaniar ${ }^{-} u$ foelicissimis Regibus gesta[rum] Decades duas ; $\mathrm{Necn}^{-} \mathrm{o}$ belli Nauariensis libros duos. Annexa insuper Archie ${ }^{-}$pi Roderici Chronica aliisq[ue] historiis antehac non excussis, Apud inclytam Granatam : [Xantus et Sebastianus Nebrissensis], 1545.

CCPB000000360-3

7. Antonio Suarez de Alarcon, Comm. de los hechos del S. ${ }^{\text {or }}$ Alarcon. M. ${ }^{\mathrm{a}}, 1665.1$ t., fol.

Suarez de Alarcon, Antonio, Comentarios de los hechos del señor Alarcon, marques de la Valle Siciliana y de Renda, y de las guerras en que se hallò por espacio de cinquenta y ocho años / escriuiolos D. Antonio Suarez de Alarcon... ; publicalos don Alonso de Alarcon, En Madrid : por Diego Diaz de la Carrera..., 1665

CCPB000040854-9

8. Antonio de Herrera, $1^{\text {a }}$. parte de la hist. ${ }^{\mathrm{a}}$ Grãl. del Mundo. M. ${ }^{\mathrm{a}}$, 1601. 1 t., fol.

Herrera y Tordesillas, Antonio de, Primera parte de la Historia general del Mundo ... desde el año de M.D.LIX hasta el de M.D.LXXIIII / escrita por Antonio de Herrera ... En Madrid : por Luis Sanchez : a costa de Iuan de Montoya ..., 1601

CCPB000034244-0

9. Eiusd., Hist. ${ }^{\mathrm{a}}$ de lo sucedido en Escocia, è Inglat. ${ }^{\text {ra }}$ en t̃po. de Maria Estuarda. Madrid, 1589. 1.t., $8^{\circ}$.

Herrera y Tordesillas, Antonio de, Historia de lo sucedido En Escocia, è Inglaterra, en quarenta y quatro años que bivio Maria Estularda, Reyna de Escocia / Escrita por Antonio de Herrera .. En Madrid : en casa de Pedro Madrigal : $\mathrm{V}^{-}$edese en casa de $\mathrm{Iu}^{-} \mathrm{a}$ de $\mathrm{M}^{-}$otoya, 1589

CCPB000332000-6

10. Alvari Gomecii, de rebus gestis Frañci. Ximenii. Compluti, 1569. 1 t., fol.

Gómez de Castro, Álvaro, De rebus gestis a Francisco Ximenio Cisnerio ... libri octo / Aluaro Gomecio... authore. Compluti : apud Andream de Angulo, 1569.

CCPB000000244-5

11. Amadeo de Castellamonte, Palacio de placer, y de caza, ideado de la alteza R. ${ }^{1}$ de Carlos segundo Duq. ${ }^{\mathrm{e}}$ de Saboya (en Italiano). Turin, 1674. 1 t., $4^{\circ}$.

Castellamonte, Amedeo di, Venaria reale : palazzo di piacere, e di caccia, ideato dall'altezza reale di Carlo Emanuel 2. ... / disegnato, e descritto dal conte Amedeo di Castellamonte l'anno 1672, In Torino : per Bartolomeo Zapatta, 1674 


\section{IT\ICCU\RMRE\002286}

12. Alexandro Patricio, Marte Frances. M. ${ }^{\mathrm{a}}, 1637.1$ t., $4^{\circ}$.

Jansenio, Cornelio, Obispo de Ypres, Marte frances o De la iusticia de las armas y confederaciones del rey de Francia / de Alexandro Patricio Armacano, theologo ... ; traducido de latin y frances por el doctor Sancho de Moncada ... En Madrid : en la Imprenta Real, 1637.

CCPB000035936-X

13. Alonso Carrillo, Epitome del origen y decadencia de los Carrillos. Lisboa, 1639. 1t., $4^{\circ}$.

Carrillo Laso de Guzmán, Alonso, Epitome del origen y descendencia de de [sic] los Carrillos : desde que vinieron a España... hasta los reyes don Felipe III y IIII / por don Alonso Carrillo Laso de Guzman... En Lisboa : por Antonio Aluarez, 1639.

CCPB000039947-7

14. Andres de Ressendę, Hist. ${ }^{\mathrm{a}}$ de la antiguedad de la Ciu. ${ }^{\mathrm{a}}$ de Evora (en Portugues). Evora, 1753. 1t., $8^{\circ}$.

Edición no lozalizada. Se trata de la obra: Resende, André de, Historia da antiguidade da Cidade de Euora / fecta per meestre Andree de Reesende

15. Antonio de Aranda, verdadera informac. ${ }^{\text {on }}$ de la tierra $S .^{\text {ta }}$. Alcala, 1568.1 t., $8^{\circ}$.

Edición no localizada. Existe una edición que tiene una diferencia en el año de impresión: Antonio de Aranda, Verdadera informacion de la tierra sancta / $\mathrm{seg}^{-} \mathrm{u}$ la dispusicion $\mathrm{q}[\mathrm{ue}]$ en el año de mil y quinientos y treynta el muy reuer ${ }^{-}$edo padre $\mathrm{F}$. Antonio de $\mathrm{Ar}^{-}$ada dela ord ${ }^{-}$e de sant $\mathrm{Fr}^{-}$acisco ... vio y passeo ... mpresso en Alcala : en casa de Francisco de Cormellas y Pedro de Robles : vendese en casa de Luys Gutierrez, 1563

CCPB000485212-5

16. Alonso Venero, Enquiridion de los tiempos. Toledo, 1569. 1 t., $8^{\circ}$.

Venero, Alonso, Enchiridion de los tiempos / compuesto por ... Alonso Venero de la orden de $\mathrm{S}^{-}$acto Domingo de los predicadores. En Toledo : por Francisco de $\mathrm{Guzm}^{-} \mathrm{a}$ : a costa de Miguel Rodriguez, 1569

CCPB000027533-6

17. Antonio de Jesus Maria, Vida de D. ${ }^{\mathrm{n}}$ Balthasar de Moscoso y Sandoval. M. ${ }^{\mathrm{a}}, 1680.1$ t., fol.

Antonio, de Jesús María, D. Baltasar de Moscoso i Sandoval, Presbytero Cardenal de la S.I.R. del titulo de Santa Cruz en Ierusalem, Arzobispo de Toledo ... / describiale F. Antonio de Iesus Maria ... Religioso Descalzo de la Reforma de N. Señora del Carmen ... ; con un indice de los libros, i los Capitulos, otro de las cosas notables ; en ocho libros En Madrid : por Bernardo de Villa-Diego ..., 1680

CCPB000032694-1

18. M. Abad de la Ladrocat, Diccionario hist. ${ }^{\text {co }}$ abreviado traducido p. $^{\mathrm{r}}$ D. ${ }^{\mathrm{n}}$ Agustin Ibarra. M. ${ }^{\mathrm{a}}, 1753$ y 54.5 t., $4^{\circ}$.

Ladvocat, Jean Baptiste, Diccionario historico abreviado : que contiene la historia de los patriarcas, principes hebreos, emperadores... : en el qual se indica todo lo mas curioso i util de la historia sagrada i profana / compuesto en idioma frances por 
Monsieur el Abad Ladrocat... ; traducido al español por Don Agustín Ibarra..., tomo I [V] En Madrid : en la imprenta de Joseph Rico..., 1753-1754

CCPB000134884

19. Athenęi Naucratitis, Libri 15 de Deipnosophistarum versi in sermonem latinum, a Jacobo Delechampis. Lug., 1583. 1 t., fol.

Ateneo de Naúcratis, Athenaei Naucratitis ... Deipnosophistarum libri quindecim ... / in latinum sermonem versi a Iacobo Dalechampio ... Lugduni : apud Antonium de Harsy, 1583 (excudebat Ioannes Tornaesius, 1582)

CCPB000119512-3

20. Arnoldi Ferroni, libr. 10 de rebus gestis Gallorum, quibus accedit Chronicum de regibus francorum a Farromundo usq. ad Henricum $2^{\text {um }}$. Parisiis, 1550.1 t., $8^{\circ}$.

Le Ferron, Arnoul, Arnoldi Ferroni Burdigalensis, ... De rebus gestis Gallorum libri 9. Ad historiam Pauli Aemilij additi. Perducta historia usque ad tempora Henrici 2. Francorum regis, Parisiis : apud Vascosanum, via Iacobaea ad insigne Fontis, 1550 CCPB000015127-0

21. Anton Giulio, hist.a de España en 4 libri (en italiano). Venecia, 1640. 1t., $12^{\circ}$.

Brignole Sale, Anton Giulio, Della storia spagnuola libri quattro di Antongiulio Brignole Sale, In Venetia : presso Cristoforo Tomasini, 1640

CCPB000883089-4

22. Appiani Alexandrini, de ciuilibus bellis Rommanorum, cum alio libro eiusd. Authoris nominato Illirio et Celtico. Moguntię, 1529. $1 \mathrm{t}$., $4^{\circ}$.

Apiano, Appiani Alexandrini De ciuilibus Romanorum bellis historiaru[m] libri quinq[ue] : veterum collatione codicum à mendis accuratius quàm antehacunqua[m] repurgati, summaq[ue] diligentia excusi ... impressum Moguntiae : in aedibus Ioannis Schoeffer ..., 1529

CCPB000268743-7

23. Alonso Lopez de Haro, Nobiliario de España. Madrid, 1622. 1 t., fol.

López de Haro, Alonso, Segunda parte del Nobiliario genealogico de los reyes y titulos de España ... / compuesto por Alonso Lopez de Haro . En Madrid : por la viuda de Fernando Correa de Montenegro, 1622

CCPB000034067-7

24. Antonio Jacobo del Barco y Gasca, Disertac. ${ }^{\text {on }}$ Histórico-Geographica sobre reducir la antigua o nueva Huelba. Sevilla, 1765. 1 t., $8^{\circ}$.

Edición no localizada. Existe una edición que tiene una diferencia en el año de impresión: Barco y Gasca, Antonio Jacobo del, Dissertacion historico-geographica sobre reducir la antigua Onuba a la villa de Huelva / por el Doctor Antonio Jacobo del Barco y Gasca. En Sevilla: por Joseph Padrino, 1755

CCPB000205661-5

25. Blondii Flavii, Historiarum ab inclinatione Romanorum libri 31, de Roma Trinphante instaurata et Italia illustrata. Basileę, 1531. 2 t., fol.

Biondo, Flavio, Blondii Flavii, Histtoriarum ab inclinatione romanorum libri XXXI. Basilea, ex Officina Frobbiana, 1531.

CCPB 000000121F 
26. Bentibollo, Guerra de Flandes. M. ${ }^{\mathrm{a}}$, 1643. 1t., fol.

Guido Bentivoglio. III tomos Traduxola de la lengua Toscana en la española el Padre Basilio Varren de los Clérigos menores. Por Francisco Martínez a costa de Manuel López, mercader de libros, Madrid, 1643

CCPB000034950

27. Bern. ${ }^{\text {do }}$ Aldrete, varias antiguedades de España, África, y otras Provinc. ${ }^{\text {s }}$. Amberes, 1614. 1 t., $4^{\circ}$.

Aldrete, Bernardo, Varias antigüedades de España, África y otras Provincias- por el Doctor Bernardo Aldrete... En Amberes, Acosta de Luan Hafrey 1614

CCPB000032332-2

28. Bartholome María de Nogal y Gonzalo su herm. ${ }^{\text {no }}$, relación al estrecho nuevo de S. ${ }^{\text {n }}$ Vicente. M. ${ }^{\mathrm{a}}, 1621.1 \mathrm{t} ., 4^{\mathrm{o}}$.

García de Nodal, Bartolomé, Relacion del viaje que por orden de su Magd y acuerdo del Real Consejo de Indias hizieron los capitanes Bartolome Garcia de Nodal y Gonçalo de Nodal hermanos ... al descubrimiento del Estrecho nuebo de S. Vicente y reconosimj ${ }^{\circ}$ del de Magallanes ... En Madrid , por Fernando Correa de Montenegro, 1621.

\section{CCPB000038105-5}

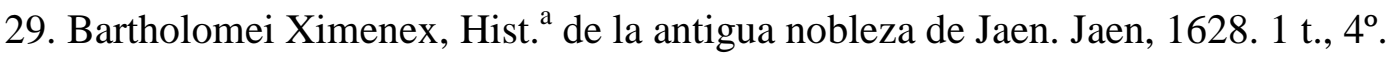

Bartolomé Ximénez Patón, Historia de la antigua y continuada nobleza de Jaén, muy famosa, y muy noble, y muy leal guarda, y defendimiento de los Reyes de España. Y de algunos varones famosos hijos de ella, Jaen, Pedro de Cuesta, 1628.

CCPB000036011-2

30. M. Blas. de Montluc, Comm. ${ }^{\text {s }}$ de las Guerras de Francia, en francés. Burdeos, 1593. $1 \mathrm{t} ., 8^{\mathrm{o}}$.

Montluc, Blaise de, Commentaires de Messire Blaise de Monluc, Mareschal de France, ou sont descris les combats, rancontres, escarmouches, batailles ... avecques plusieurs autres faicts de guerre ... , tome premier A Bourdeaus , par S. Millanges ..., 1593

CCPB000245512-9

31. Berosii, caldaicarum antiquitatum libr. 5, cum commentariis Joan Aunii. Ant., 1545. $1 \mathrm{t} ., 8^{\circ}$.

Berosus, el Caldeo, Berosi sacudotis chaldaici Antiquitatum libri quinque / cum commentariis Joannis Aunij... sub forma Enchiudij excusi \& castigati. Anturpiae. In aedibus Ioannis Steelfi, MDXLV.

CCPB000053688-1

32. Bartholome Domingo Gutierrez, Reflexion de la identidad de Asta, con Xerez de la Frontera. Sevilla, 1754. 1 t., $4^{\circ}$.

Gutiérrez, Bartolomé, Reflexión sobre la opinión admitida por el M.R. P. Enrique Flog. Que niega la identidad de asta con Xerez de la Frontera, Sevilla. En la imprenta de Joseph Padrino (s.a). 1754

CCPB000740267-8

33. Chronica de famoso Cid Rui Diaz Campeador. Burgos, 1593. 1 t., fol. 
Chronica del famoso cavallero Cid Ruy Diaz Campeador. En Burgos, en la imprimerie de Philippe de Iunta y Iuan Baptista Varerio, 1593.

CCPB00000295

34. Caroli Sigonii, Historian. de Regno Italię lib. 15. Francofurti, 1575. 1 t., fol.

Sigonio, Carlo, Caroli Sigonii historiarum de regno Italiae libri quindecim ..., qui libri historiam ab anno DLXX usque ad MCC continent ... Francofurti ad Moenum, ex officina And. Wechelli 1575.

CCPB000023588

35. Eiusd., historiarum de occidentali imperio lib. 1s. Basileę, 1579. 1t., $4^{\circ}$.

Sigonio, Carlo, Caroli Sigonii Historiarum de Occidentali imperio, libri XX ... Basileae, ex officina Thomae Guarini, 1579

CCPB000302126-2

36. Eiusd., de Antiquo iure Populi Romani, lib. 11. Lutetię, 1576. 1 t., fol.

Sigonio, Carlo, Caroli Sigonii De antiquo iure populi romani libri undecim. De Republica Atheniensium Libri IIII. De Atheniensium Lacedaemoniorumque temporibus liber I ... Lutetiae, apud Iacobum du Puys, excudebat Ioannes Tornaesius typographus, 1576

ССРB000023567-9

37. La Cyropedia de Xenophonte, traducida en francés $p .^{r}$ Jacobo de Cortes de Vintemille. Leon, 1555. 1t., fol.

Xenophon, La cyropedie de Xenophon : de la vie \& institucion de Cyrus Roy des Perses / Traduite de Grec par Iaques des Comtes de Vintemille Rhodien, Conseiller du Roy au Parlement de Dijon. A Lion : Par Ian de Tournes, 1555.

CCFr: FRBNF31673462

38. Caju Suetonius, Spartianus, Lampridius, Trebellius Pollio, Herodianus, Pomponius Laetus, Dion Cassius, Julius Capitolinus, Vulcatius Vopiscus, Aurelius Victor, Ammianus Marcellinus, ilustrati et annotationes de Erasmi et Egnatii. Basileę, 1533. 1t., $4^{\circ}$.

Omnia quam antehac emendatiora Annotationes Des. Erasmi \& Egnatij cognitu dignae, C. Suetonius Tranquillus. Aelius Spartianus. Aelius Lampridius. Trebellius Pollio. Herodianus Politiano interp. Pomponius Laetus. Dion Cassius. Iulius Capitolinus. Vulcatius Gallicabus Flauius Vopiscus. Sex. Aurelius Victor. Io. Baptista Egnatius. Ammianus Marcellinus quatuor libris auctus ; cum indicibus copiosis Basileae, in officina Frobeniana, mense iulio 1533 (per Hieronymum Frobenium et Nicolaum Episcopium.

\section{CCPB000024268-3}

39. Carlos Dractan, Relación de las Religiosas en el monasterio de Sion de Inglaterra. M. ${ }^{\mathrm{a}}, 1594.1 \mathrm{t} ., 8^{\circ}$.

Dractan, Carlos, Relacion que embiaron las Religiosas del Monasterio de Sion de Inglaterra, q eestauan en Roan de Francia, al padre Roberto Personio de la Compañia de Iesus, de su salida de aquella ciudad, y llegada a Lisboa de Portugal. Traduzida de Ingles en Castellano, por Carlos Dractan, sacerdote Ingles del Colegio de Valladolid. En la qual se descubre mucho el estado en que estan las cosas de Francia, despues de admitido Vandoma por Rey. Madrid, Por la biuda de P. Madrigal, 1594. 


\section{ССРB000024873-8}

40. Cornelii Loòs, Cathalogus illustrium scriptor. Germanię. Moguntię, 1581. 1 t., $8^{\circ}$.

Loos, Cornelius, Illustrium Germaniae scriptorum catalogus Mogunt, 1581.

COPAC: National Library of Scotland: North Reading Room (George IV Bridge); stored in George IV Jac.IV.5.61 ; Reference use in NLS

41. Cronica univer. ${ }^{1}$ del mundo. 1t., fol.

Edición no localizada

42. Dionis Casii Nieri, Romanę Historię lib. 25. Basileę, 1558. 1t., fol.

Dion Casio; Dionis Casii Nicaei Romanae historiae libri (tot enim hodie extant) XXV nimirum a XXXI ad LXI, quibus exponuntur res gestae a bello Cretico usque ad mortem Claudij Caesaris quae est historia annorum circiter CXX ... / Guilielmo Xylandro ... interprete ; his accesserunt eiusdem annotationes ... ; additum est Ioannis Xiphilini e Dione compendium Guil. Blanco Albiensi interprete quae versio ac eodem Xylandro diligenter est ... Basileae, apud Ioannem Oporinum, 1558 mense martio castigata.

\section{CCPB000008006-3}

43. Diego Ortiz de Zuñiga, Anales Ecclesiast. ${ }^{\text {cos }}$ y Seculares de Sevilla. Madrid, 1677. 1t., fol.

Edición no localizada. Existe una edición que tiene una diferencia en el año de impresión: Ortiz de Zuñiga, Diego, Annales eclesiasticos y seculares ... de Seuilla ... , que contienen sus mas principales memorias desde el año de 1246 en que emprendio conquistarla ... S. Fernando Tercero de Castilla y Leon hasta el de 1671 ... / formados por D. Diego Ortiz de Zuñiga. En Madrid, en la Imprenta Real, por Iuan Garcia Infançon, acosta de Florian Anisson. 1667.

CCPB000040893-X

44. Diego Ferñz., $1^{\mathrm{a}}$ y $2^{\mathrm{a}}$ parte hist. $^{\mathrm{a}}$ del Peru. en Sevilla, 1571. 1t., fol.

Fernández de Palencia, Diego, Primera y segunda parte de la historia del Peru / que se mando escreuir, a Diego Fernandez ... ; $\mathrm{c}^{-}$otiene la primera lo succedido en la Nueua España y en el Peru sobre la execucion de las nueuas leyes y el allanamiento y castigo, que hizo el Presidente Gasca, de Gonçalo Piçarro y sus sequaces, la segunda, contiene, la tyrannia y alçamiento de los Contreras y don Sebasti ${ }^{-}$a de Castilla, y de Francisco Hern $^{-}$adez Giron ... Fue impresso en Seuilla , en casa de Hernando diaz ..., 1571. CCPB000156255-X

45. D. ${ }^{\mathrm{n}}$ Diego de Saabedra Faxardo, Corona Gotica Castellana y Austriaca, comentada por Alonso Nuñez de Castro. Madrid, 1670, 71,78. 3 t., $4^{\circ}$.

Saavedra Fajardo, Diego, Corona gothica, castellana y austriaca , segunda parte / compuesta de algunos originales que quedaron de D. Diego de Saauedra Faxardo, y continuada por D. Alonso Nuñez de Castro ... ; dase noticia de todo lo sucedido en estos Reynos de España en mas de quinientos años, desde el de setecientos y catorce, en que empeçó su Restauracion, hasta el de mil docientos y diez y seis ... En Madrid, por Andrés García de la Iglesia , a costa de Francisco Serrano de Figueroa...,1670 CCPB000040704-6

Saavedra Fajardo, Diego, Corona gothica, castellana y austriaca, segunda parte / compuesta de algunos originales que quedaron de D. Diego de Saauedra Faxardo, y 
continuada por D. Alonso Nuñez de Castro ... ; dase noticia de todo lo sucedido en estos Reynos de España en mas de quinientos años, desde el de setecientos y catorce, en que empeçó su Restauracion, hasta el de mil docientos y diez y seis ... En Madrid, por Andrés García de la Iglesia , a costa de Francisco Serrano de Figueroa ..., 1671.

CCPB000038229-9

46. Dignus Cretensis, de hist. ${ }^{a}$ Belli Trojam. Venet., 1499. 1t., $4^{\circ}$.

Dictys, Cretensis, Dictys Cretensis de historia belli Troiani et Darses Priscus de eadem Troiana. Venice : Christophorus de Pensis, de Mandello, 1 February 1499 and 1 March 1499.

COPAC: Cambridge: University Library: Order in Rare Books Room: Inc.5.B.3.99[1721]

47. Diego de Villalobos, Comment. ${ }^{\mathrm{s}}$ de los sucesos de los Paises bajos desde 1594 hasta 1598. M. ${ }^{\mathrm{a}}, 1612.1 \mathrm{t} ., 4^{\mathrm{o}}$.

Villalobos y Benavides, Diego de, Comentarios de las cosas sucedidas en los paises baxos de Flandes, desde el año de mil y quinientos y nouenta y quatro hasta el de mil y quinientos nouenta y ocho / compuestos por don Diego de Villalouos y Benauides...En Madrid , por Luis Sanchez..., 1612 (1611)

CCPB000038151-9

48. Diego de Colmenares, Hist. ${ }^{\text {a }}$ de Segovia. Segovia, 1637. 1t., fol.

Colmenares, Diego de, Historia de la insigne ciudad de Segouia y conpendio de las historias de Castilla / autor Diego de Colmenares ... En Segouia, por Diego Diez ... , a costa de su autor, 1637.

CCPB0000397717

49. Diogenis Laertii, vitę Philosophorum. Brixię, 1485 cum Blondii Flavii operibus in Roman instaurat. et rebus gestis venetorum. 1t., fol.

Edición no localizada.

50. Dionisii Halicarnasęi, Antiquitatum sive originis Romanarum Lib. 10. Lug., 1561. 1 t., $8^{\circ}$.

Dionisio de Halicarnaso, Dionysii Halicarnassei Antiquitatum sive Originum romanarum libri decem / Sigismundo Gelenio interprete; adiecimus undecimum ex versione Lapi ; ac indicem rerum notatu dignarum locupletissimum. Lugduni, apud Ioannem Frellonium, excudebat Symphorianus Barberus, 1561

CCPB000156200-2

51. Diario de los Literatos de España. Madrid, 1737, 38, 39, 40 y 42. 7.t., $8^{\text {o }}$.

Diario de los literatos de España : en que se reducen a compendio los escritos de los autores españoles, y se hace juicio de sus obras, desde el año MDCCXXXVII ; tomo I [tomo VII] En Madrid, por Antonio Sanz, 1737. En Madrid : por Antonio Marín... [et al.], 1737-1742

CCPB000059146-7

52. Dionisio Alcedo, Aviso hist. ${ }^{\text {co }}$ del Peru, tierra firme, Chile y N. ${ }^{\text {a }}$ Granada. M. ${ }^{\mathrm{a}}, 1740$. 1t., $4^{\circ}$.

Alcedo y Herrera, Dionisio, Aviso historico, politico, geographico con las noticias mas particulares del Peru, Tierra-Firme, Chile y nuevo Reyno de Granada en la relación de 
los sucesos de 205. años por la chronología de los Adelantados ... desde el año de 1533. hasta el de 1740 y razón de todo lo obrado por los ingleses en aquellos Reynos ... desde el año de 1567. hasta el de 1739 / por Don Dionisio de Alcedo y Herrera ... En Madrid, en la oficina de Diego Miguel de Peralta, 1740.

CCPB000243446-6

53. Diodori Siculi, lib. 17. Bibliothecę historicę. Lug., 1552. 1.t., $12^{\circ}$.

Diodoro Sículo, Diodori Siculi Bibliothecae historicae libri XVI. Lugd., apud Seb. Gryphium, 1552

CCPB000007963-4

54. Esteban de Garivai, Compendio histor. ${ }^{1}$ de las Chrónicas y universal Hist. ${ }^{\text {a }}$ de España. Amberes, 1571. 3t., fol.

Garibay y Zamalloa, Esteban de, Los XL libros d'el compendio historial de las chronicas y vniuersal historia de todos los reynos de España / compuestos por Esteuan de Garibây y Çamálloa... Impresso en Anueres, por Christophoro Plantino ... , a costa d'el autor, 1571

CCPB000000928-8

55. Del mismo, Genealog. ${ }^{\mathrm{s}}$ de los Reyes de España, Francia y Constantinopla. M. ${ }^{\mathrm{a}}$, 1596. 1t., fol.

Garibay y Zamalloa, Esteban de, Illustraciones genealogicas de los catholicos Reyes de las Españas y de los... de Francia y de los Emperadores de Constantinopla, hasta... Philipe el II y sus... hijos, las mesmas hasta sus Altezas de muchos Sanctos confessores de la Iglesia Catholica Romana... / compuestas por Esteuan de Garibay... En Madrid , por Luis Sanchez, 1596

CCPB000000614-9

56. Enęi Sylbii, Opera Omnia. Basileę, 1t., fol.

Pío II, Papa, Aeneae Sylvii Piccolominei Senensis, qui post adeptum Pontificatum Pius eius nominis secundus appellatus est Opera quae extant omnia / nunc demum post corruptissimas aeditiones... castigata $\&$ in unum corpus redacta ... ; His quoque accessit Gnomologia ex omnibus Sylvii operibus collecta \& Index rerum ac uerborum .. Basileae: per Henrichum Petri, 1551.

CCPB000805366-9

57. Exemplar literarum missarum e Germania ad D. Guillelmun Cecilium per Joan Perniusgatię. Lipsię, 1592. 1t., $8^{\circ}$.

Cresswell, Joseph, Exemplar literarum missarum e Germania ad D. Gailielmum Cecilium consiliarum regium, [S.1. : s.n.], 1592, Dedicatoria fechada en Lipsiae idibus Martii 1592 por Ioannes Pernius (r. de [cristus]3), pseudónimo de Creswell (ICCU). CCPB000006855-1

58. Florian del Campo, Los cinco libr. prim. ${ }^{\text {s }}$ de la Chronica Gral. de España. Medina del Campo, 1553. 1 t., fol.

Ocampo, Florian de, Los cinco libros primeros de la Cronica general de España / que recopila el maëstro Florian do Campo ... Impresso en Medina del Campo , por Guillermo de Millis, 1553.

CCPB000018900-6 
59. Fern. ${ }^{\text {do }}$ Pizarro, varones illustres del nuevo mundo. M. ${ }^{\mathrm{a}}, 1639.1$ t., fol.

Pizarro y Orellana, Fernando, Varones ilustres del nuevo mundo, descubridores, conquistadores y pacificadores del... imperio de las Indias Occidentales, sus vidas, virtud, valor, hazañas y claros blasones..., con un discurso legal de la obligacion que tienen los reyes a premiar los servicios de sus vasallos... / escrive Don Fernando Pizarro y Orellana... ; lleva seis indices... En Madrid, por Diego Diaz de la Carrera , a costa de Pedro Coello..., 1639.

CCPB000041005-5

60. Felipe de Comines, memoria de Luis XI y Carlos VIII de Francia. Traducido. Amberes, 1643. 1t., fol.

Commynes, Philippe de, Las Memorias de Felipe de Comines,... de los hechos y empressas de Luis undecimo y Carlos octavo... traducidas de francés con escolios propios por Don Juan Vitrian, Amberes: empr. de J. Meursio, 1643

CCPB000039809-8

61. Felini Sandęi, de Regibus Sicilię e Apulię. Heindelberg, 1610. 1 t., $4^{\circ}$

Edición no localizada. Se trata de la obra: Sandeo, Felino Maria, De regibus Siciliae et Apuliae in queis et nominatim de Alfonso rege Arragonum, epitome Felini Sandei Ferrariensis IC. ad Alexandrum 6. pont. max. nunc primum in lucem edita. Item parallela Alfonsina siue apophthegmata Caesarum principumque Germanorum, \& aliorum, ... per Antonium Panormitam descriptis, sigillatim opposita per Aeneam Syluium Piccolomineum, episcopum Senensem qui postea papa Pius 2. nunc demum \& accurate, contra \& parallelos composita. Quibus accedunt Bartholomaei Faccii Genuensis, de humanae vitae felicitate liber, ... Item, de excellentia ac praestantia hominis, ... Ex bibliotheca Marq. Freheri, cum praefatione eiusdem, \& notis et Apuliae.

62. Fran. ${ }^{\text {co }}$ de Zepeda, Resumpta hist. ${ }^{\text {al }}$ de España. M. ${ }^{\text {a }}$, 1654. 1 t., $4^{\text {o }}$.

Cepeda, Francisco de, Resumpta historial de España, desde el diluuio hasta el año de 1642 / compuesta por... Francisco de Cepeda... ; aora añadida por don Luis de Cepeda y Carauajal... hasta el año de 1652... En Madrid, por Diego Diaz de la Carrera..., 1654 CCPB000039102-6

63. Fernan Perez de Guzman, Chronica del rey D. ${ }^{\mathrm{n}}$ Juan el II. Pamplona, 1591. 1 t., fol. Pérez de Guzmán, Fernán (atribuido), Cronica del ... rey don Iuan segundo deste nombre , impressa por mandado del catholico rey don Carlos su visnieto, en la ciudad de Logroño, el año de 1517 [Pamplona] Y agora de nueuo impressa ... en ... Pamplona por el original impresso en la dicha ciudad de Logroño ... , por Thomas Porralis , a costa de Iuan Boyer..., 1591 (1590)

CCPB000000297-6

64. Filipi Beroaldi, et aliorum comentarii in Suetonii 12 Cęsaris. 1548. 1 t., fol. Suetonio Tranquilo, Cayo, Caii Suetonii Tranquilli Duodecim Caesares / cum Philippi Beroaldi ..., Marcíque item Antonii Sabellici Commentariis \& Bapt. Aegnatii, aliorúmque doctorum virorum annotationibus, Lugduni : apud Ioannem Frellonium, 1548.

CСРB000000751-X

65. Fran. ${ }^{\text {co }}$ de los Santos, Descripcion breve del escorial. Madrid, 1657. 1 t., fol. 
Francisco de los Santos, Descripcion breue del Monasterio de S. Lorenzo el Real del Escorial, vnica marauilla del mundo, fabrica del ... rey Philippo segundo, aora nueuamente coronada por el ... rey Philippo quarto el Grande con la magestuosa obra de la Capilla ... del Pantheon y traslacion à ella de los cuerpos reales ... / por el P.F. Francisco de los Santos ... En Madrid, en la Imprenta Real, 1657 CCPB000042842-6

66. Fran. ${ }^{\text {co }}$ Montalvo, Hist. ${ }^{\text {a }}$ de las Guerras de Ungria. Palermo, 1693. 1 t., fol.

Montalvo, Francisco Antonio de, Historia de las guerras de Ungria, desde el año de 82. hasta el de 88... / Fray Francisco de Montalbo de la... En Palermo, por Pedro Copula, 1693.

ССРВ000033477-4

67. Felipe de la Gandara, Armas y Triunphos de los Gallegos. Madrid, 1662.1 t., $4^{\circ}$. Gandara, Felipe de la, Armas i triunfoas, hechos heroicos de los hijos de Galicia ... resumen de los seruicios que este reino a echo à ... Felipe IV... / escribelos ... frai Felipe de la Gandara de la Orden de San Agustin ... En Madrid, por Pablo de Val , a costa de Antonio de Riero...1662.

CCPB000036660-9

68. Fran. ${ }^{\text {co }}$ Moncada, Expedicion de Catalanes y Aragoneses contra Turcos y Griegos. Barcelona, 1623. 1. t., $4^{\circ}$.

Edición no localizada. Se trata de la obra: Aytona, Francisco de Moncada, Expedición de los catalanes y aragoneses contra turcos y griegos ... / por Francisco de Moncada, Conde de Osona.

69. Frañ.co Ferron, Noticia Histórica de la V. ${ }^{\text {a }}$ de Monclin. Gran. ${ }^{\text {da }}$, 1761. 1t., $4^{\circ}$.

Ferrón, Francisco, Noticia historica de la insigne, fuerte y celebre villa de Monclin y de la prodigiosa imagen de Jesus Nazareno... / la escrive Francisco Ferron. En Granada : por los herederos de Joseph de la Puerta, 1761.

CCPB000997391-5

70. Filipi Honorii, Thesaurus Politicus. Francofurti, 1617. 1 t., $4^{\circ}$.

Honorius, Philipus, Philippi Honorij I.V.D. Thesaurus politicus : hoc est selectiores tractatus, monita acta, relationes et discursus pluriuariam et exquisitam regiae prudentiae et principum rerum publicarum... : opus collectum ex italicis cum publicatis tum manuscriptis variis variorum ambassatorum obseruationibus $\&$ discursibus accurato cum de lectu concinnatum \& in gratiam politicae sapientiae \& linguarum studiosorum nunc latine simul \& italice editum : operis argumenta elenchus duplex italicus \& latinus indicabit, Francofurti : typis Nicolai Hoffmanni : impensis haeredum Iacobi Fischeri, 1617.

CCPB000128301-4

71. Gilberti Genebrardi, Chronographię lib. 4. Lug,. 1611. 1 t., fol.

Edición no localizada. Existe una edición que tiene una diferencia en el año de impresión: Genebrard, Gilbert. Gilberti Genebrardi. Chronographiae libri quatuor, priores duo sunt de rebus veteris populi, \& praecipuis quatuor millium annorum gestis... Lugduni, sumptibus Ioannis Pillehotte..., 1609

CCPB000225329-1

72. Geronimo de Qunitana, Hist. ${ }^{a}$ de Madrid. en M. ${ }^{\mathrm{a}}$, 1629. 1t., fol. 
Quintana, Jerónimo de, A la muy antigua, noble y coronada villa de Madrid, historia de su antiguedad, nobleza y grandeza / por el licenciado Geronimo de Quintana ... En Madrid, en la Imprenta del Reyno, [vendese este libro en casa del autor, en el Hospital de la Latina de Madrid], 1629

CCPB000038265-5

73. Gonzalo de Zespedes y Menesès, Hist. ${ }^{a}$ de Felipe IV. Lisboa, 1631. 1 t., fol.

Céspedes y Meneses, Gonzalo de, Primera parte de la historia de D. Felippe el IIII, rey de las Españas / por ... Gonçalo de Cespedes y Meneses ... En Lisboa ... , la imprimio Pedro Craesbeeck, 1631

CCPB000039405-X

74. Geronimo Zurita, Anales de Aragon. Zarag. ${ }^{\text {za }}$, 1610. 6 t., fol.

Zurita, Jerónimo, Anales de la Corona de Aragon / compuestos por Geronymo Çurita ... ; tomo primero ; Impressos en Çaragoça, en el Colegio de S. Vicente Ferrer por Lorenço de Robles ..., a costa de los Administradores del General, 1610

CCPB000038156-X

75. Gaspar Mercader de Cervellon, Retrato politico de Alfonso VIII. Valencia, 1679. 1t., fol.

Mercader y Cervelló, Gaspar, Conde de Cerbellón, Retrato politico del señor Rey D. Alfonso el VIII que dedica a la S.C.R.M. del Rey ... Don Carlos II / D. Gaspar Mercader y de Cerbellon, Conde de Cerbello . En Valencia, por Francisco Mestre ..., 1679

CCPB000033397-2

76. Geronimo de Mascareñas, Campaña de Portugal p. ${ }^{r}$ la parte de Extremadura. M. ${ }^{a}$, 1663. $1 \mathrm{t} ., 4^{\circ}$.

Mascareñas, Jerónimo, Obispo de Leyra, Campaña de Portugal por la parte de Estremadura el año de 1662 executada por... Don Iuan de Austria... / y escrita por don Geronymo Mascareñas En Madrid , por Diego Diaz de la Carrera..., 1663

CCPB000033174-0

77. Del mismo, Viage de S. ${ }^{a}$ Mariana de Austria. Madrid, 1650. 1 t., $4^{\circ}$.

Mascareñas, Jerónimo, Viage de la Serenissima reyna Doña Maria Ana de Austria segunda muger de Don Phelipe Quarto ... hasta la real corte de Madrid desde la imperial de Viena ... / por Don Hieronymo Mascareñas ... En Madrid, por Diego Diaz de la Carrera, 1650.

CCPB000033176-7

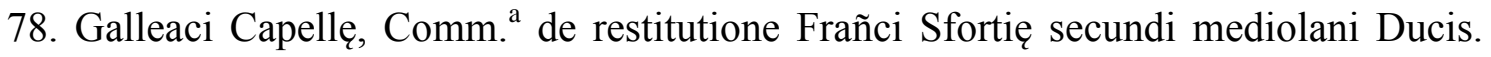
Argentorati, 1538. 1 t., $8^{\circ}$.

Capella, Galeazzo Flavio, Commentarii Galeacii Capellae de rebus gestis pro restitutione Francisci Sfortiae ... ; eodem accessit et historia belli Mussiani ... cum Praefatione Ioachimi Camerarii, Argentorati , apud Cratonem Mylium, 1538.

CCPB000753110-9

79. Geronimo Perez Garcia, traducción de Julio Cesar sin lugar ni año. 1t., $8^{\text {o }}$. Edicion no localizada. 
80. Geronimo de la Cruz, Defensa de los estatutos y Noblezas españolas. Zarag. ${ }^{\text {za }}, 1637$. 1t., fol.

Jeronimo de la Cruz, Defensa de los Estatutos y noblezas españoles, destierro de los abusos y rigores de los informantes / por el P.M. Fr. Geronymo de la Cruz... en el Real de San Geronymo de Madrid. En Zaragoza, en el Hospital Real y General de nuestra Señora de Gracia, 1637.

CCPB000035962-9

81. Gazetas de Madrid, desde el año 1637 hasta el de 1665, 21 t., $4^{\circ}$.

Edición no localizada.

82. Gaspar Ybañez de Segovia Marq. ${ }^{\text {s }}$ de Mondejar, Obras Chronológicas. Valencia, 1744. $1 \mathrm{t}$., fol.

Ibañez de Segovia Peralta y Mendoza, Gaspar, Marqués de Mondejar, Obras chronologicas / de Don Gaspar Ibañez de Segovia Peralta i Mendoza ... ; las publica de orden i a expensas de la academia valenciana don Gregorio Mayans i Siscar ... En Valencia , por Antonio Bordazar de Artazú, 1744.

CCPB000060550-6

83. Geronimo de Porras Vecentelo de Leca, Antidoto de la memoria y la verdad. V $V^{\mathrm{a}}$. Sevilla, 1707. 1t., fol.

Porras Vicentelo de Leca, Jerónimo de, Marqués de la Torre de Gines, Antidoto de la memoria, y la verdad, contra el veneno de la falsa doctrina de natural oposicion, que entre España, y Francia ha publicado la emulacion de las naciones, fomentada de la traycion de algunos vassallos, que olvidados de su obligacion, corren despeñados al precipicio de su loca temeridad / compuesto por D. Jeronimo de Porras Vicentelo de Leca... dedicado al Rey N. Señor Don Phelipe V... Impresso en Sevilla, por Lucas Martin de Hermosilla, 1707.

CCPB000739387-3

84. Gazetas francesas de los años 1762 y 63. Un legajo. Otras de Madrid desde el año de 62 hasta la expulsión de los jesuitas. En dos legajos.

Edición no localizada

85. Historię Romę scriptores latini veteres. Aurelię Allobrogum, 1611. 2 t., fol.

Edición no localizada. Existe una edición que tiene una diferencia en el año de impresión: Historiae Romanae scriptores Latini veteres : qui extant omnes, regum, consulum, caesarum res gestas ab vrbe condita continentes: nunc primum in unum redacti corpus. Aureliae Allobrogum: excudebat Petrus de la Rouiere ; Genevae : apud viduam \& haeredes Petri de la Rouiere, 1609-1623

CCPB000177042-X

86. Hieroniimi Osorii, de rebus gestis Emanuelis Regis Lusitanię Lib. 12. Olisipone. 1571. 1t., fol.

Osório, Jerónimo, De rebus Emmanuelis regis: Lusitaniae invictissimi virtute et auspicio gestis libri duodecim / auctore Hieronymo Osorio episcopo, Olysippone : apud Antonium Gondisaluu[m] typographum, 1571.

COPAC: Cambridge: University Library: Order in Rare Books Room: N.14.20.

87. Hieroniimi Osorii, Historię. Colonię, 1580. 1t., $8^{\circ}$. 
Osório, Jerónimo, Historiae Hieronymi Osorii, lusitani ... de rebus Emmanuelis, Lusitaniae regis invictissimi virtute et auspicio ... gestis libri duodecim ... Item Io. Matalii Metelli ... in eandem historiam praefatio et commentarius de reperta ab Hispanis et lusitanis, in Occidentis et Orientis Indiam navigatione, deq. Populorum eius vita, moribus ac ritibus ... / omnia iam recognita \& emendata ... Coloniae Agrippinae : apud Haeredes Arnoldi Birckmanni, 1580

CCPB000019370-4

88. Hernando de Ayora Balmisoto, el Arbitro entre el Marte frances y las vindicias Gallicas. Pamplona, 1646. 1t., $4^{\circ}$.

Ávila y Sotomayor, Fernando de, El arbitro entre el Marte Frances y las Vindicias Gallicas responde por la verdad, por la patria y sus reyes / escriuelo Hernando de Ayora Valmisoto ... En Pamplona [i.e. Sevilla] , por Carlos Iuan, 1646.

CCPB000032974-6

89. Henrique Puteano, Relaciones del Cardenal Bentibollo. M. ${ }^{\mathrm{a}}, 1638.1$ t., $4^{\circ}$.

Bentivoglio, Guido, Relaciones del Cardenal Bentivollo / publicadas por Enrico Puteano ... ; y traduzidas por ... Francisco de Mendoça y Cespedes de italiano en lengua castellana ... En Madrid , por Maria de Quiñones , a costa de Pedro Coello ..., 1638

CCPB000034953-4

90. Hieroniimi Blanca, rerum Aragonensium comment. ${ }^{a}$. Cęsaraugustę, 1588.1 t., fol. Blancas, Jerónimo de, Aragonensium rerum commentarii / Hieron. Blanca ... auctore ... Caesaraugustae, apud Laurentium Robles \& Didacum fratres ..., 1588

CCPB000000030-2

91. Honupri Pambini, Romanon Imperator liber. Basilę, 1558. 1 t., fol.

Panvinio, Onofrio, Onuphrii Panvinii veronensis fratris Eremitae Augustiniani Romanorum principum et eorum quorum maxima in Italia Imperia fuerunt libri IIII ; eiusdem de comitiis imperatoriis liber, in quo uniuersa imperatorum eligendorum ratio ab Augusto Caesare usque ad ... Carolum V ... explicatur ... Basileae , per Henricum Petrum, 1558.

ССРB000019795-5

92. Eiusd., Republicę Romanę, comm. ${ }^{\text {a }}$ Venet., 1558. 1 t., $8^{\circ}$.

Panvinio, Onofrio, Onuphrii Panvinii ... reipublicae romanae commentariorum libri tres, et alia quaedam quorum seriem sequens pagella indicabit, Venetiis, ex Officina Erasmiana , apud Vincentium Valgrisium, 1558.

CCPB000326145-X

93. Eiusd., Fasti et Triumphi, Venet., 1557 et 58. 2 t., fol.

Panvinio, Onofrio, Fasti et Triumphi Rom. a Romulo rege usque ad Carolum V ... sive Epitome Regum, Consulum, Dictatorum, Magistra. Hequitum, Tribunorum militum consulari potestate, Censorum, Impp. \& aliorum Magistratuum Roman ... ex antiquitatum monumentis ... desumpta / Onuphrio Panvinio ... authore ; Additae sunt ... Impp...icones, Venetiis , impensis Iacobi Stradae ..., 1557

CCPB000019782-3

Panvinio, Onofrio, Onuphrii Panvinii ... Fratris Eremitae Augustiniani Fastorum libri V : a. Romulo rege usque ad Imp. Caesarem Carolum V Austrium ... ; eiusdem in Fastorum libros commentarii ... ; his accedit appendix in qua imperatorum \& consulum 
ordinariorum fasti a Caesare dictatore usque ad Iustinianum Augustum. Venetia : [s.n., s.a.]. En las ports. de los Comentarios y Apéndice consta la fecha 1588

CCPB000180572-X

94. Eiusd., Elogia et imagines Pontificum. Romę, 1568, 1t., fol.

Panvinio, Onofrio, Viginti septem Pontificum romanorum elogia et imagines, Romae, Ant. Lafrerij formeis, 1568

CCPB000019799-8

95. Henrico Catherino Davila, Hist. ${ }^{\mathrm{a}}$ de las Guerras civiles de Francia. M. ${ }^{\mathrm{a}}$ 1660. 1 t., fol.

Davila, Enrico Caterino, Historia de las guerras ciuiles de Francia / de Enrico Caterino Dauila ... ; traduxola del idioma toscano en nuestra $1^{-}$egua castellana el M.R.P. Basilio Varen de Soto Prouincial de los Clerigos Reglares Menores y añadiola de nueuo en esta segunda impresion, desde al año 1598 hasta el de 1630. En Madrid, por Andres Garcia de la Iglesia, a costa de Iuan de San Vicente, 1660.

CCPB000034500-8

96. Historia de Carlos VI traducida p. ${ }^{\mathrm{r}}$ Jacinto de Lisasueta. M. ${ }^{\mathrm{a}}, 1742.2$ t., $8^{\circ}$.

Historia del emperador Carlos VI y de las reboluciones que sucedieron en el imperio... desde Rodulfo de Habsbourg hasta el presente... , tomo II / traducido del frances en castellano por don Jacinto de Lisasueta... Publicación, En Madrid, en la imprenta de Juan de San Martin, 1742.

CCPB000160089-3

97. Historia Geographica memoria de la Dalmacia, sin nombre de Author (en Italiano). Nápoles, 1668. 1., $8^{\circ}$.

Papacino, Onorato, Memorie Historiche, e Geografiche della Dalmazia, In cui sono le notitie più particolari de suoi Stati. e Dominij, Le Piazze ..., la ferie delli Prencipi, che la possederono, e ... presa di castel nuovo dallŽarmi venete, Raccolte da D. C. F. B ... Napoli , nella nuoua Stampa Di Dom. Anotnio Parrino, e di Michele Luigi Mutij, 1688 (1687)

\section{CCPB000883090-8}

98. Hist. ${ }^{\text {a }}$ de los Embajadores del Japon, sin nombre de Author. Zarag. ${ }^{\text {za }}$, 1591.1t., $8^{\text {o }}$. Bujeda de Leiva, Historia del Reyno de Iapon y descripcion de aquella tierra, y de algunas costumbres, cerimonias, y regimiento de aquel Reyno, Con la relacion de la venida de los embaxadores del Iapon a Roma, para dar la obediencia al Summo Pontifice; y todos los recebimientos que los Principes Christianos les hizieron por donde passaron, y de las cartas y presentes que dieron a su Magestad el Rey ... y a los demas Principes, Con la muerte de Gregorio XIII, y election de Sixto V y las cartas que dio su Sanctidad para los Reyes de aquel Reyno ... / Recopilada por el Doctor Buxeda de Leyua ... En Çaragoça , impressa ... en casa de Pedro Puig ... , a costa de Antonio Hernandez mercader de libros, 1591

CCPB000003687-0

99. Hist. ${ }^{\text {a }}$ de Henrique IV, Rey de España, sin nñe de Aucthor, lugar ni año de impresión. 1 t., $8^{\circ}$.

Edición no localizada. 
100. Jacobi Filipi Bergomati, suplementum chronicon. Parisiis, 1535. 2 t. fol.

Foresti, Giacomo Filippo; Supplementum supplementi chronicarum ab ipso mundi exordio vsque ad ... annum MCCCCCX / editum et nouissime recognitum ... a Iacobo Philippo Bergomate ... ; additis per eundem auctorem quampluribus ... additionibus ... Publicación, Venetiis, impressus opere \& ipensa [sic] Georgii de Rusconibus, 1513. CPB000013885-1

101. Ignacio de Salazar y Olarte, $2^{\mathrm{a}}$ p. ${ }^{\text {rte }}$ de la conquista de Mexico. Cor. ${ }^{\text {ba }}$, 1740. 1t., fol. Salazar y Olarte, Ignacio, Historia de la América septentrional de la Nueva España después de la toma de México y progressos de los castellanos [Manuscrito] / Salazar y Olarte, 1740.

CCPB001091138-3

102. Josephi Scaligeri, de emendatione temporum. Lutetię, 1583. 1t., fol.

Scaligero, Giulio Cesare, Iosephi Scaligeri ... opus nouum de emendatione temporum. Lutet. : apud M. Patissonium, 1583.

COPAC: Oxford : Byw. F 5.7.

103. Juan Ferñz, Sinopsis Chronologica de España. M. ${ }^{\text {a }}$, 1700, 1702. 15 t., $4^{\circ}$.

Ferreras, Juan de, Synopsis historica chronologica de España, parte primera que comprehende sus sucessos desde la creacion de el mundo hasta el nacimiento de Jesu Christo ..., formada de los autores seguros y de buena fee / por don Juan de Ferreras ... En Madrid, por Francisco de Villa-Diego , a costa de Diego Lucas Ximenez ... vendese en su casa ..., 1700

CCPB000035590-9

Ferreras, Juan de, Synopsis Historica Chronologica de España o Historia de España reducida à compendio, y à debida chronologia : parte segunda : comprehende los sucesos de los quatro primeros siglos Christianos ... / por Don Juan de Ferreras En Madrid : Francisco de Villa-Diego : a costa de Diego Lucas Ximenez, 1702 CCPB000140130-0

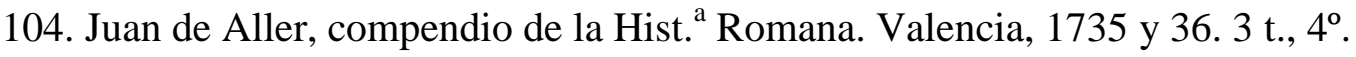

Catrou, François, Compendio de la historia romana / que modernamente dan a la estampa... los RR.PP. Catrou y Roville de la Compañía de Jesus ; compuesto y traducido de lengua francesa en española por... Juan de Hallèr...; tomo I, desde el año primero de Roma hasta el de 548, En Valencia , en la imprenta de Antonio Bordazar, 1735.

\section{CCPB000201738-5}

Catrou, François, Compendio de la historia romana/ que modernamente dan a la estampa... los RR.PP.Catrou y Roville de la Comañía de Jesús ; compuesto y traducido de lengua francesa en española por... Juan de Hallèr... ; tomo III, desde el año 647 hasta el 710 En Madrid : en la oficina de Antonio Marín, 1736

ССРВ000201740-7

105. Joan Bocatii, de claris mulierib. Bernę, 1539. 1 t., fol.

Boccaccio, Giovanni, Ioannis Boccatii de Certaldo insigne opus de Claris Mulieribus ... Bernae Heluet, excudebat Mathias Apiarius, 1539

CCPB000002984-X

106. Joan Ant. Viperani, obtenta Portugalia a Rege Filipo. Neapoli, 1588. 1 t., $4^{\circ}$. 
Viperano, Giovanni Antonio Io, Antonii Viperani de obtenta Portugalia a Rege Catholico Philippo historia Neapoli , Apud Horatium Salvianum, 1588

CCPB000028021-6

107. Juan de Guiñones, Explicac. ${ }^{\text {on }}$ de unas monedas de oro de emperadores Romanos. M. ${ }^{\mathrm{a}}, 1620.1 \mathrm{t} ., 4^{\mathrm{o}}$.

Quiñones, Juan de, Explicacion de unas monedas de oro de emperadores romanos que se han hallado en el puerto de Guadarrama, donde se refieren las vidas dellos y el orige dellas, con algunas aduertencias politicas y otras cosas antiguas y curiosas / lo uno y lo otro ofrece... el doctor Iuan de Quiñones... En Madrid , por Luis Sanchez..., 1620.

CCPB000041051-9

108. Joan Calderon, Fragmentum chronici Flavi Luci Destri. Cęsarsaug., 1619. 1 t., $4^{\circ}$.

Román de la Higuera, Jerónimo; Fragmentum Chronici siue omnimodae historiae Flavii Lucii Dextri ... , cum Chronico Marci Maximi \& Additionibus Sancti Braulionis \& etiam Helecae Episcoporum Caesaraugustanorum ... / in lucem editum ... \& labore P. Fr. Ioannis Calderon, Franciscanae familiae ... Cesarauguste, apud Ioannem à Lanaja \& Quartanet ..., 1619.

CCPB000033638-6

109. Juan Geronimo Favellanac, la Filipica en que se discurre de la Religión, Bondad y Poder del Rey de España, en Italiano. Nápoles, 1626. 1 t., $4^{\circ}$.

Favella, Giovanni Girolamo, La filippica nella quale si discorre della gran religione, bontà, amicitia, e potere delli ... redi Spagna e delle heroiche attioni de' spagnoli / di Gio. Geronimo Favella ... In Napoli , per Secondino Roncagliolo, 1626

CCPB000883541-1

110. Joan Naucleri, Chronica. Colonię, 1579. 1t., fol.

Nauclerus, Johannes, Chronica D. Iohannis Naucleri ... succinctim compraehendentia res memorabiles seculorum omnium ac gentium, ab initio mundi usque ad annum Chriati nati M.CCCC ... Coloniae , apud Geruinum Calenium et haeredes Iohannis Quentel..., 1579.

CCPB000188620-7

111. Juan Bap. Ramusio, Navegaciones y viajes. Venecia, 1563 y 74. italiano. 1 t., fol. Ramusio, Giovanni Battista, Primo volume, \& Terza editione Delle Navigationi et Viaggi / raccolto gia da M. Gio. Battista Ramusio ... ; nel quale si contengono la descrittione dell'Africa [et] del paese del Prete Ianni, con varij viaggi, dalla città di Lisbona, et dal Mar Rosso insino à Calicut, et all'isole Molucche, doue nascono le Spetierie, et la Nauigatione attorno il Mondo ; con la Relatione dellísola Giapan... et alcuni capitoli appartenenti alla Geographia, estratti dell'Historia del S. Giouan di Barros Portoghese, con tre Tauole ... ; con due indici In Venetia, nella Stamperia de Giunti, 1563 (nella Stamperia de gli heredi di Luc'Antonio Giunti)

CCPB000297577-7

Ramusio, Giovanni Battista, Secondo Volume Delle navigationi et viaggi / raccolto gia da M. Gio. Battista Ramusio, et hora in questa nuova editione accresciuto .. Venetia : Stamperia de Giunti, 1574 (1573)

CCPB000297753-2 
112. Joan Rosini, Romanarum Antiquitat. Libr. 10. Basilę, 1583. 1 t., fol.

Rosinus, Johannes, Romanarum antiquitatum libri decem , ex variis scriptoribus summa fide singularique diligentia / collecti a Ioanne Rosino Bartholomaei ... Basileae , ex officina haeredum Petri Pernae, 1583 (per Conradum Waldkirch).

CCPB000025441-X

113. Joan Curopalatis, Historian. compend. Venet., 1570. 1 t., fol.

Johannes Curopalates, Historiarum compendium, quod incipiens à Nicephori Imperatoris à benicis obitu, ad Imperium Isaaci Comneri pertinet / Ioanne Curopalate Scillizzae ... conscriptum et nunc recèns à Ioanne Baptista Gabio è graeco in latinum conuersum Venetiis , apud Domenicum Nicolinum, 1570.

CCPB000000670-X

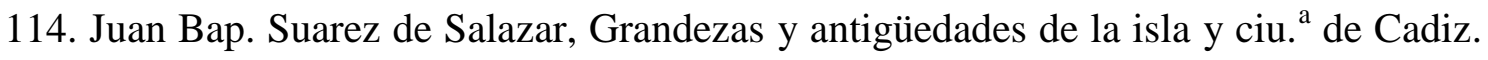
Cadiz, 1610.1 t., $4^{\circ}$.

Suarez de Salazar, Juan Bautista, Grandezas y antiguedades de la isla y ciudad de Cadiz, en que se escriuen muchas ceremonias que vsaua la Gentilidad, varias costumbres antiguas, ritos funerales con monedas, estatuas, piedras y sepulcros antiguos... / por Ioan Baptista Suarez de Salazar... En Cadiz, por Clemente Hidalgo, 1610.

CCPB000040863-8

115. El Inca Garcilaso de la Vega, la Florida. Lisboa, 1605. 1t, $4^{\circ}$.

Garcilaso de la Vega, La Florida del Ynca, historia del adelantado Hernando de Soto, Gouernador y capitan general del Reyno de la Florida, y de otros heroicos caualleros españoles è indios / escrita por el Ynca Garcilasso de la Vega. En Lisbona [sic] , impresso por Pedro Crasbeeck, 1605.

CCPB000036743-5

116. Jph. Lorenzo de Arenas, Oráculo de la Europa consultado por los Príncipes de ella. M. ${ }^{\mathrm{a}}, 1744.1 \mathrm{t} ., 8^{\circ}$.

Arenas, José Lorenzo de, trad., Oraculo de la Europa, consultado por los principes de ella... / traducido del frances al castellano por... Don Joseph Lorenzo de Arenas... En Madrid, en la Imprenta del Reyno..., se vende donde los Mercurios, 1744.

CCPB000116897-5

117. El Joven Aventurero, Hist. ${ }^{a}$ de lo más secreto y particular $\mathrm{q}^{\mathrm{e}}$ vendió al Príncipe Carlos Eduardo Stuard. M. ${ }^{\mathrm{a}}$, 1746. 1 t., $8^{\circ}$.

Ascanio o el joven aventurero, historia verdadera ... que sucedió al Principe Carlos Eduardo Stuard en el norte de Escocia desde la batalla de Culloden ... / traducida del frances y aumentada de muchas notas historicas, En Madrid, en la imprenta del Mercurio ..., se hallará en la libreria del Mercurio ..., [s.a.]

CCPB000526899-0

118. Joan Sarii Zamosci, de Senatu Romano lib. $2^{\circ}$. Argentorati, 1608. 1, t. $8^{\circ}$.

Zamoysky, Jan Sarius, Joannis sarii Zamosci, de Senatu romano libri duo, quibus, ob similem materiam, accesserunt, de Magistratibus Romanorum... / authore, Joachino Perionio, Hebraicarum \& Graecarum Literarum interprete regio...; Vvilhelmi Possardi, cum annexa Dissertatione... de Magistratibus Romanis et indice duplici authorum... Argentorati, sumptibus Lazari Zetzneri..., 1608.

CCPB000460652-3 
119. Juan Tom. ${ }^{\text {s }}$ Minadoy, Hist. ${ }^{\text {a }}$ de la Guerra Turca y Persiana, en Italiano. Turin, 1588. 1 t., $8^{\circ}$.

Minadoi, Giovanni Tomasso Historia della guerra fra Turchi et persiani descritta in quattro libri / da Gio. Tomaso Minadoi cominciando dallŽanno MDLXXVII nel quale furo li primi movimenti di lei seguendo per tutto lŽanno MDLXXXV... In Turino, apresso Gio. Battista Bevilacqua, 1588.

CCPB000578757-2

120. Juan Bap. Morales, Jornada de Africa del Rey D. ${ }^{\mathrm{n}}$ Sebastian. Sevilla, 1622.1 t., $8^{\circ}$. Morales, Juan Baptista de, Jornada de Africa del rey don Sebastian de Portugal / por Juan Baptista de Morales, natural de Montilla, En Sevilla, por Gabriel Ramos Vejarano, 1622

ССРВ000379515-2

121. Juan Ambrosio Marini, 2s p.te del Cayoandro, en Italiano, Bolonia 1651. 1 t., $8^{\circ}$.

Edición no localizada. Se trata de la obra: Marini, Giovanni Ambrosio, Parte seconda. Il calloandro fedele, stato fin'ora in tutte l'altre impressioni, per più conti manchevole e difetuoso.

122. Joan Huttiqui, Romanorum Imperator Libellus. Argentinę, 1526. 1 t., $8^{\circ}$.

Huttichius, Johannes, Imperatorum romanorum libellus. Argentinae, Wolfgangus Cephalaeus suo aere et impensis excussit, 1526.

CCPB000159558-X

123. Juan Lopez, Relacion de la nueva y honras del Principe $\mathrm{D}^{\mathrm{n}}$ Carlos, de la Reina Isabel de Valios con $3 \mathrm{serm}^{\mathrm{s}}$. Madrid, 1568. 1t., $8^{\circ}$.

López de Hoyos, Juan, Relacion de la muerte y honras funebres del SS. Principe D. Carlos, hijo de la Mag. del Catholico Rey D. Philippe el seg-udo nuestro Señor / compuesto y ordenado por el M. Iuan Lopez ... En Madrid : en casa de P. Cosin, 1568 CCPB000015956-5

124. Jvonis Episcopi Carnotensis, Epistolę et Chronicon de Regibus Francorum. Parisiis, 1584. 1 t., $4^{\circ}$.

Ivo de Chartres, Santo, Iuonis Episcopi Carnotensis Epistolae; eiusdem Chronicon de regibus Francorum, Parisiis, apud Sebastianum Niuellium ..., 1584

ССРВ000013833-9

125. Jph. Ant. de Villa Señor, Theatro Americano. Mexico, 1746. 1 t., fol.

Antonio Villa-Señor y Sánchez, Teatro Americano, Descripción general de los Reinos, y Provincias de la Nueva España, y sus jurisdicciones. ... su author D. Joseph Antonio de Villa-Señor, y Sánchez., México, de la Viuda de Joseph Bernardo de Hogal, 1746.

CCPB000351961-9.

126. Josephi Eguiara, Bibliotheca Mexicana. Mexico, 1755. 1 t., fol.

Eguiara y Eguren, Juan José de, Bibliotheca Mexicana sive Eruditorum Historia virorum qui in America Boreali nati, vel alibi geniti, in ipsam domicilis aut Studijs asciti, quaris linguâ scripto aliquid tradiderunt ... / authore D. Joanne Josepho de Eguiara et Eguren ... tomus primus exhibens literas ABC. Mexici, ex novâ Typographiâ in aedibus authoris editioni eiusdem Bibliothecae destinata, 1755. 


\section{CCPB000066455-3}

127. Juan Agust. de Mora, Huelba illustrada. Sevilla, 1762. 1 t., $4^{\circ}$.

Mora, Juan Agustin de, Huelva ilustrada, breve historia de la Antigua, y Noble Villa de Huelva / obsequio a su patria de uno de sus menores hijos, el Lic[encia]do D. Juan Agustin de Mora. En Sevilla, en la Imprenta del Dr. Don Geronymo de Castilla ..., 1762 CCPB000206019-1

128. Joan Basęi, tom. 1s Chronici rerum memorabilium Hispanię. Salamant., 1562. 1 t., fol.

Edición no localizada. Existe una edición que tiene una diferencia en el año de impresión: Vasaeus, Johannes, Chronici rerum memorabilium Hispaniae tomus prior / autore Ioanne Vasaeo brugensi ... ..Salmanticae, excudebat Ioannes Iunta, 1552.

CCPB000027355-4

129. Isacii Casauboni, animaduersiones in Athęneum. Lug., 1600. 1 t., fol.

Casaubon, Isaac, Isaaci Casauboni Animaduersionum in Athenæi Dipnosophistas libri 15. Lugduni : [Paul Frellon] : apud Antonium de Harsy sub signo scuti Coloniae, 1600 (Lugduni : excudebat Guichardus Iullieron, typographus regius, 1600)

\section{IT\ICCU\NAPE\004472}

130. Juan Andres Angelini, Histor ${ }^{\mathrm{a}}$. de la rebelión de Ungria, en Italiano. Milan, 1675. 1 t., $12^{\circ}$.

Angelini Bontempi, Giovanni Andrea, Istoria della ribellione d'Ungheria, di Gio. Andrea Angelini ... In Dresda, \& in Milano : per Fedrico Agnelli scultore, \& stampatore, 1675

CCPB000044049-3.

131. Juan Ferreras, historia de España. M. ${ }^{\mathrm{a}}, 1700.15$ t., $4^{\mathrm{o}}$.

Ferreras, Juan de, Synopsis historica chronologica de España, parte primera que comprehende sus sucessos desde la creacion de el mundo hasta el nacimiento de Jesu Christo ... , formada de los autores seguros y de buena fee / por don Juan de Ferreras ... En Madrid, por Francisco de Villa-Diego , a costa de Diego Lucas Ximenez ... vendese en su casa ..., 1700

CCPB000035590-9

132. Luis Moreri, El Gran Diccionario hist ${ }^{\mathrm{co}}$. Paris, 1732. en frances, $1 \mathrm{t}$., fol.

Moreri, Louis, Le grand dictionnaire historique ou le mélange curieux de l'histoire Sacrée et profane ... / par Mre Louis Moreri ... ; tomo I [-VIII] A Paris , chez JeanBaptiste Coignard Fils ..., 1732

CCPB000074237-6

133. Larmi overo de nobili estirpe Dal Signor, en italiano. Neapoli, 1610. 1., fol.

Campanile, Filiberto, L' Armi quero insegne de' nobili / scritte dal signor Filiberto Campanile... In Napoli, nella stamperia di Tarquinio Longo, 1610

CCPB000214504-9

134. Lucii Marinęi Siculi, de rebus hispanię memorabilibus opus. Compluti, 1533. 1 t., fol. 
Marineo Sículo, Lucio, L. Marinei Siculi regij historiographi Opus de rebus Hispaniae memorabilibus, modo castigatum atq[ue] Caesareae maiestatis iussu in lucem aeditum. Impressum Compluti, per Michaelem de Eguia, 1533

CCPB000000323-9

135. Ludovici Tuberonis, Comment. de rebus Panmoniis et Turciis. Francofurti, 1603. 1 t., $4^{\circ}$.

Tuberonis, Luis, Commentariorum de rebus, quae temporibus eius inilla europae parte, quam panmonii \& Turcae ... , libri undecim summa fidelitate nec non diligentia conscripti ... / Ludovici Tuberonis. Francofurti, impensis Claudii Marnii \& haeredum Ioannis Aubrii, 1603

ССРB000883316-8

136. M. Le Margne y Ant. ${ }^{\circ}$ Maria Herrero, Estado politico de Europa. M. ${ }^{\text {a }}$, 1740. 1 t., $4^{\circ}$.

Mañer, Salvador José, trad. Herrero, Antonio María, trad, Estado politico de la Europa / traducido del frances al castellano por Mr. Le-Margne, y... Antonio Maria Herrero; suplemento al tomo VI. En Madrid, en la imprenta del Reyno, [s.a.] Fecha de la introduccion a la obra 1740

CCPB000038275-2

137. Laurentii Surii, Comment. ${ }^{\mathrm{s}}$ brevis rerum in orbe gestarum ab anno 1500 ad 1574. Colonię, 1574. 1., $8^{\circ}$.

Surius, Laurentius, Commentarius brevis rerum in orbe gestarum, ab anno Salutis MD vsque in annum MDLXXIIII , ex optimis quibusque scriptoribus congestus ... auctus \& locupletatus / per F. Laurentium Surium Carthusianum Coloniae , apud Geruinum Calenium et haeredes Ioannis Quenteli, 1574

COPAC: National Library of Scotland. North Reading Room (George IV Bridge); stored offsite. E.92.e.7 ; Reference use in NLS.

138. Marci Cocci Sabelici, Enneadum Lib. 11. Basileę, 1538. 1 t., fol.

Sabellico, Marco Antonio, Opera M. Antonii Coccii Sabellici in duos digesta tomos. Rapsodiae Historicae Enneadum XI, Basileae, ex officina Hervagiana, 1538 CCPB001039046-4

139. Martini Crommeri, de origine et rebus gestis Polonorum libr. 30. Basileę, 1554. 1 t., fol.

Edición no localizada. Existe una obra en la cual existe una diferencia en el año de edición: Kromer, Martin, Martini Cromeri De origine et rebus gestis polonarum libri XXX / adiecta est in fine eiusdem autoris funebris oratio, Sigismundi regis uitam compendiose complexa, Basileae : per Ioannem Oporinum, 1555

CCPB000287181-5

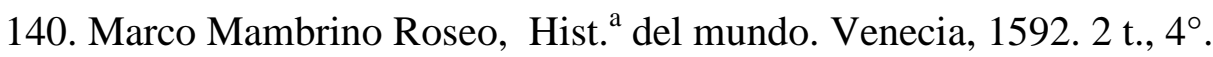

Tarcagnota, Giovanni. Roseo, Mambrino, Delle istorie del mondo di M. Giouanni Tarcagnota, le quali contengono quanto dal principio de mondo è successo sino all'anno 1513..., con la aggiunta di M. Mambrino Roseo et... Bartolomeo Dionigi da Fano, sino all'anno 1582, parte prima Venetia, appresso i Giunti, 1592

CCPB000188348-8 


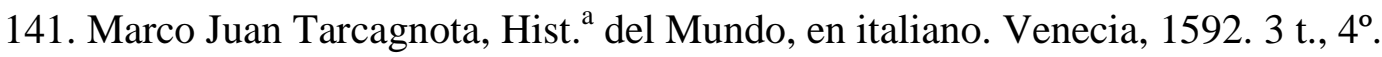

Tarcagnota, Giovanni, Delle istorie del mondo / di M. Giouanni Tarcagnota ; le quali contengono quanto dal principio del mondo è successo sino all'anno 1513 ... : parte seconda. In Venetia : appresso i Giunti, 1592

CCPB000188349-6

142. Michaelis Bosmeri, Principes Hollandię, Zellandię et Frisię laminis expressi: cum imagimbus omnium penegentium. Ant., 1578. 1., $4^{\circ}$.

Vosmer, Michael, Principes hollandiae et Zelandiae, domini frisiae / auctore Michaële Vosmero .. Antuerpiae, excudebat Christophorus Plantinus Philippo Gallaeo, 1578

CCPB000416006-1

143. Marci Antonii Sabelici, Hist. ${ }^{\mathrm{a}}$ rerum Venetar. 1556, 1 t., $4^{\circ}$.

Sabellico, Marco Antonio, M. Antonii Sabellici, Historiae rerum Venetarum ab urbe condita, libri XXXIII / Eiusdem in singulos libros Epitomae... Basileae, apud Nic. Episcopium iuniorem, 1556

ССРВ000022488-X

144. Man. ${ }^{1}$ Ant. ${ }^{o}$ de Mena, Estado Grãl del Imperio Rusiano. M. ${ }^{\text {a }}, 1736$ y 38. 1.t., $8^{\circ}$.

Manuel Antonio de Mena, Estado general del imperio rusiano, o moscovita, desde su origen en la presente guerra. Su autor Don manuel Antonio de Mena. En la oficina de L. P. Mojados. 1736.

CCPB000493781-3

Manuel Antonio de Mena, Estado general del Imperio Rusiano, ó Moscovita, desde su origen, hasta la toma de Azzof, en la presente guerra; tomo II en que continuando la historia de ... / su autor Don Manuel Antonio de Mena. En Madrid : [s.n.], 1738

CCPB000831434-9

145. Marco Leonardo Ghini, Traduccion de la Hist. ${ }^{a}$ Etiopeia de Liodoro, en Italiano. Venecia, 1560. 1 t., $8^{\circ}$.

Heliodoro de Émesa, Historia di Heliodoro delle cose ethiopiche : nella quale fra diuersi, compassioneuoli auenimenti di due amanti, si contengono abbattimenti, descrittioni di paesi ... / Tradotta dalla lingua greca nella Thoscana da M. Leonardo Ghini. In Vinegia : appresso Gabriel Giolito de'Ferrari, 1560 (1559)

CCPB000594936-X

146. Minucio Minutii, Hist. ${ }^{a}$ de los Vscoques. Venecia, 1617. en Italiano. 1.t., $8^{\circ}$.

Minucci, Minuccio Historia de gli Vscochi scritta da Minucio Minuci arciuescouo di Zara. Co i progressi di quella gente sino all'anno 1602. Pubblicato probabilmente a Venezia nel 1617.

IT\ICCUIVIAE\003144

147. Marcelo Bonito, Hist. ${ }^{a}$ de los terremotos, en italiano. Napoles, 1691. 1t., $4^{\circ}$.

Bonito, Marcello, Terra tremante overo continuatione de terremoti dalla creatione del monto fino al temo presente, in cui ... / del signo D. Marcello Bonito... Napoli : nella nuova stampa delli focci Dom. Ant. Parrino, e Michele Luigi Mutii, 1691

CCPB000882779-6 
148. Michaelis Casiri, Tom. prim. Bibliothecę Arabię, Hispanię escurialensis. Matriti, 1760. 1t., fol.

Casiri, Miguel, Bibliotheca arabico-hispana escurialensis sive Librorum omnium Mss. quos Arabicè ab auctoribus magnam partem Arabo-Hispanis compositos Bibliotheca coenobii Escurialensis complectitur, recensio \& explanatio / opera et studio Michaelis Casiri ... ; tomus prior. Matriti : Antonius Perez de Soto imprimebat, 1760.

CCPB000058023-6

149. Nicolai Antonii, Bibliotheca hispana. Romę, 1672 et 96.4 t., fol.

Antonio, Nicolás, Bibliotheca Hispana sive Hispanorum : qui usquam unquamve sive latinâ sive populari sive aliâ quâvis linguâ scripto aliquid consignaverunt notitia ... duabus partibus continens ... qui post annum secularem MD usque ad praesentem diem floruere : tomus primus / authore D. Nicolao Antonio ... Romae : ex Officina Nicolai Angeli Tinassii, 1672

CCPB000049797-5

Antonio, Nicolás, Bibliotheca Hispana vetus sive Hispanorum qui usquam unquámve scripto aliquid consignaverunt notitia..., tomus primus [-secundus] / auctore D. Nicolao Antonio... ; opus postumum.. Romae , ex Typographia Antonii de Rubeis..., 1696

CCPB000042889-2

150. Del mismo, Hist. ${ }^{\text {a }}$ fabulosa. Valencia, 1742. 1 t., fol.

Antonio, Nicolás, Censura de historias fabulosas / obra posthuma de don Nicolas Antonio... ; van añadidas algunas cartas del mismo autor, y de otros eruditos ; publica estas obras don Gregorio Mayans i Siscar, autor de la vida de don Nicolas Antonio. En Valencia , por Antonio Bordazar de Artazu ..., 1742

CCPB000057643-3

151. Nicephori Gregarę, Laonici Calcondilę, Georgii Logotetę, hist. ${ }^{a}$ Bicantina. Allobrogum, 1615. 1t., fol.

Historiae Byzantinae scriptores tres, graeco-latini, uno : I Nicephori Gregarae... II Laonici Chalcocondylae atheniensis... III Georgii Logothetae Acropolitae... : accesserunt indices necessarij, Coloniae Allobrogum : apud Petrum de la Rouiere, 1615 CCPB000177010-1

152. Noticias del siglo 17 y $18.16 \mathrm{t}$.

Edicion no localizada

153. Noticias de la California. Madrid, 1757. 1 t., $4^{\circ}$.

Venegas, Miguel, Noticia de la California y de su conquista temporal, y espiritual hasta el tiempo presente, sacada de la Historia manuscrita, formada en Mexico año de 1739 / por el Padre Miguel Venegas, de la Compañia de Jesus... ; añadida de algunos mapas particulares, y uno general de la America Septentrional, Assia Oriental, y Mar del Sur... ; tomo primero. En Madrid, en la imprenta de la Viuda de Manuel Fernández, y del Supremo Consejo de la Inquisición, 1757.

CCPB000168203-2

154. Olao Magno Gotho, Hist. ${ }^{a}$ de Gentib. septentrionalibus. Antuerp, 1562.1 t., $8^{\circ}$. 
Magnus, Olaus, Historia de gentibus septentrionalibus / auctore Olao Magno... ; a Cornelio Scribonio Graphaeo, in epitomen redactae, libri XXII Antuerpiae , apud Ioannem Bellerum. Probablemente impresa ca. 1562.

CCPB000016526-3

155. El oraculo de la Europa, anónimo, $S^{\mathrm{r}} \mathrm{D}^{\mathrm{n}}$ Jph. Lorenzo de Arenas. M. ${ }^{\mathrm{a}}, 1744.1 \mathrm{t} ., 8^{\mathrm{o}}$. Mañer, Salvador José. Lorenzo de Arenas, Joseph, trad, Oráculo de la Europa consultado por los principes de ella, sobre los negocios presentes políticos y militares / traducido del francés al castellano por el licenciado Don Joseph Lorenzo de Arenas ... En Madrid , en la Imprenta del Reyno, [s.a.] Es seudónimo de Mañer, Salvador José, según Aguilra Piñal, V, 386 y Rebium. Fecha sacada de la aprobación real en 1744.

CCPB000746330-8

156. Pauli Jobii, Regionum, $\arg ^{\mathrm{e}}$. Insularum, et locorum descriptiones. Basilę, $1577 \mathrm{y}$ 78. 3 t., fol.

Edición no localizada. Existe una edición que tiene una diferencia en el año de impresión: Giovio, Paolo, Pauli Iouii Nouocomensis episcopi Nucerini Descriptiones, quotquot extant. regionum atque locorum : Quibus ... De piscibus Romanis libellum ... adiunximus Basileae : [s.n], 1571.

\section{CCPB000011608}

157. Del mis. añadido, con 12 libr. q. faltaban a los sucesos del mundo. Granada, 1566. $1 \mathrm{t}$. , fol.

Giovio, Paolo, Paulo Iouio anadido con doze libros que hasta agora faltauan de todas las cosas succedidas en el mundo en estos cincu ${ }^{-}$eta años de nuestro tiempo : en que se escriuen las victorias del inuictissimo Emperador Don Carlos, dende que començo à reynar en España, hasta que prendio al Duque de Saxonia / escrita en lengua Latina por ... Paulo Iouio Obispo de Nochera; traduzido de Latin en Castellano por el Licenciado Gaspar de Baeca. En Granada : en casa de Hugo de Mena, 1566

CCPB000011651-3

158. Petri opmerii et Laurentii Beyerlinck, opus chronographicum a mundi exordio ad annum 1611. Ant. 1611, 1 t., fol.

Opmeero, Petro. Opus chronographicum orbis vniversi a mundi exordio vsque ad annum M.DC.XI. : continens historiam icones, et elogia summorum pontificum, imperatorum, regum ac virorum illustrium : in duos tomos diuisum / prior auctore Petro Opmeero Amstelrodamo Batavo ... posterior auctore Laurentio Beyerlinck Cive et Canonico Antuerpiano, Antuerpiae : ex Typographeio Hieronymi Verdussii, 1611

CCPB000184336-2

159. Pablo de Espinosa de los Monteros, antiguedades y grandezas de Sevilla. Sevilla, 1627. 1 ., fol.

Espinosa de los Monteros, Pablo: Primera parte de la historia, antiguedades y grandezas de la ... ciudad de Sevilla / compuesta por ... don Pablo de Espinosa de los Monteros ... En Sevilla : En la Officina de Matias Clavijo, 1627.

CCPB000036249-2

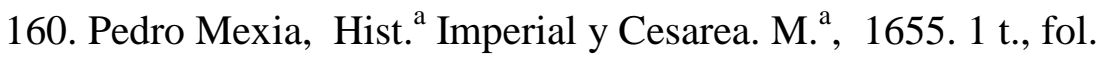

Pedro Mexia, Historia imperial y cesarea : en que sumariamente se contienen las vidas y hechos de todos los emperadores, desde Iulio Cesar hasta Maximiliano Primero / 
compuesta por ... Pedro Mexia ... ; prosiguela el Padre Basilio Varen, asistente de los Clerigos reglares Menores enriqueziendola con las proezas de los ultimos siete Cesares austriacos, desde Carlos Quinto à Ferdinando Tercero .. En Madrid : por Melchor Sanchez : a costa de Gabriel de Leon ..., 1655

CCPB000033200-3

161. Del mism., Silua de varia lection. Valladolid, $1551.1 \mathrm{t}$., fol.

Pedro Mexia, Silua de varia lection / $\mathrm{c}^{-}$opuesta por ... Pero Mexia, nueuamente agora en el año de mil e quinientos e cinquenta y vno ; añadida en ella la quarta parte por el mismo auctor ; en la qual se tractan muchas cosas y muy agradables y curiosa. Valladolid: en casa de Iuan de Villaquir ${ }^{-}$a..., 1551

CCPB000017470-X

162. Prudencio de Sandoval, Hist. ${ }^{\text {a }}$ de Carlos V. Amberes, 1681. 2 t., fol.

Sandoval, Prudencio de, Historia de la vida y hechos del emperador Carlos V... / por el maestro fray Prudencio de Sandoval... obispo de Pamplona... ; parte primera. En Amberes: por Geronymo Verdussen..., 1681

CCPB000051940-5

163. Pausanię, veteris Gręcię descriptio. Flotentię, 1551. 1t., fol.

Pausanias, Pausaniae Veteris Graeciae descriptio / Romulus Amasaeus vertit ... Florentiae : L. Torrentinus, 1551

CCPB000020079-4

164. Procopii Cęsariensis, De rebus Gothorum et vandalarum Hist. ${ }^{\text {a }}$ Basileę, 1571. 1 t., fol.

Edición no localizada. Existe una edición que tiene una diferencia en el año de impresión: Procopio de Cesarea, Procopii Caesariensis De rebus gothorum persarum ac vandalorum libri VII : una cum aliis mediorum temporum historicis ... Basileae : ex officina Ioannis Heruagii, 1531

CCPB000021952-5

165. Petri Alli, De topographia Constantinopoleos et de illius antiquitatibus. Lug., 1562. $1 \mathrm{t} .4^{\circ}$.

Gilles, Pierre, Petri Gyllii De topographia Constantinopoleos, et de illius antiquitatibus libri quatuor. Lugduni: apud Gulielmum Rouillium ..., 1562

CCPB000011495-2

166. Pedro Mantuano, aduertencias a la Hist. ${ }^{\mathrm{a}}$ de Mariana, con algunas adiciones. M. ${ }^{\mathrm{a}}$, 1613. 1 t., $4^{\circ}$.

Mantuano, Pedro: Aduertencias a la Historia del Padre Iuan de Mariana de la Compañia de Iesus impressa en Toledo en latin año de 1592 y en romance el de 1601 : en que se enmienda gran parte de la Historia de España / por Pedro Mantuano .. En esta segunda impression va añadida la respuesta a todas las dificultades que puso el Padre Iuan de Mariana, à los Discursos que prueuan la venida de Santiago a España ... y tambien se responde el Padre Iuan de Pineda, en lo que escriuio en su libro De Rebus Salomonis, de la Venida de Nabuchodonosor ..En Madrid : en la Imprenta Real, 1613

CCPB000033114-7

167. Plinii secundi, De viriis ilustribus liber. Parisiis, 1550. $1 \mathrm{t} ., 4^{\circ}$. 
Plinio Cecilio Segundo, Cayo C. Plinii Secundi... De viriis illustribus liber / Phillippi Praepositi Poncherij... commentariis illustratus Parisiis : apud Thomam Richardum, 1550

CCPB000190256-3

168. Pedro Diaz de Ribas, antigüedades y excelenc. ${ }^{\text {s }}$ de la Cor. ${ }^{\text {ba }}$. Cordoba, 1627. 1 t., $4^{\mathrm{o}}$.

Díaz de Ribas, Pedro De las antiguedades y excelencias de Cordoua: libro primero ... I [Pedro Diaz de Ribas] En Cordoua : por Saluador de Cea Tesa, 1627

CCPB000046346-9

169. Pauli Emilii, De rebus gestis Francorum libr. Basileę, 1569. 1 t., fol.

Emili, Paolo. Historiae iam denuò emendatae Pauli Aemylii ... De rebus gestis Francorum, à Pharamundo primo Rege vsque ad Carolum octauum, libri X. Arnoldi Ferroni ... De rebus gestis Gallorum libri IX ... à Carolo octauo usq[ue] ad Henricum II. Ioannis Thomae Freigii Paralipomena ad Aemylium \& Ferronum adiecta usq[ue] ad ... MDLXIX ... ; Adiunctum est Chronicon Ioan. Tilii de Regibus Francorum, à Pharamundo usque ad Henricum II. à D. Thoma Freigio auctum usque ad Carolum IX ... Basileae : [per Sixtum Henricpetri], [s.a]

CCPB000000562-2

170. Polivii, Hist. ${ }^{\text {arum }}$ rerum libri 5, Volumen dinviditum. 1 t., $12^{\circ}$.

Edición no localizada. Se trata de la obra: Polibio, Polibii Megalopolitani historiarum librij V.

171. Papeles varios, 12 t.. $4^{\circ}$

Edición no localizada.

172. Quinto Curcio, Traducido p. ${ }^{r}$ Matheo Ibañez de Segovia. M. ${ }^{\mathrm{a}}$, 1699. 1 t., fol.

Curcio Rufo, Quinto, De la vida y acciones de Alexandro el Grande / Quinto Curcio Rufo; traducido de la lengua latina en la española por D. Matheo Ybañez de Segovia y Orellana... En Madrid: en la imprenta de los herederos de Antonio Romàn: a costa de Antonio Bizarròn..., 1699

CCPB000039339-8

173. Rodrigo Ordoño Alvarez, Mem. ${ }^{1}$ al Rey ntro. S. ${ }^{\text {or }}$ de la gran calidad y servicios del claro Linage de Asturias y sus condes. Granada, 1653. 1 t., fol.

Asturias, Nava y Noroña, Rodrigo Ordoño Alvarez, señor de, Memorial al Rey N. Señor de la gran calidad y servicios, del claro y antiguo linage de Asturias y sus condes y de su legitima descendencia y varonia de la Real Casa de León... / representa legitimamente este gran linage como su cabeça y pariente mayor Don Rodrigo Ordoño Alvarez de las Asturias... En Granada: En la Imprenta Real, por Francisco Sanchez..., 1653

ССРB000127774-X

174. Raphaelis Vorraterrani, Commentarios Vrbano. libr. 38 cum Chonomico Xenophontis. Basileę, 1530. 1 t., fol.

Maffei, Raffaele, Commentariorum Vrbanorum Raphaelis Volaterrani, octo \& triginta libri / accuratius quam antehac excusi cum duplici eorundem indice... Item Oeconomicus Xenophontis, ab eodem latio donatus Basileae: in officina Frobeniana, 
1530 (per Hieronymum Frobenium, Ioannem Hervagium et Nicolaum Episcopium) CCPB000016479-8

175. Rodrigo Mendez de Silva, Parangon de los cromueles de Inglaterra. M. ${ }^{\mathrm{a}}, 1657,1 \mathrm{t}$. $8^{\circ}$.

Méndez Silva, Rodrigo, Parangon de los dos Cromueles de Inglaterra / observado por Rodrigo Mendez Silva ... En Madrid : en la Imprenta de D. Francisco Nieto y Salcedo : a costa de Gabriel de Leon, 1657

CCPB000033240-2

176. Salazar de Mendoza, origen de las Dignidades seculares de Castilla y Leon. Toledo, 1618. 1 t., fol.

Salazar de Mendoza, Pedro, Origen de las dignidades seglares de Castilla y Leon: con relacion summaria de los reyes de estos reynos, de sus actiones, casamientos, hijos, muertes, sepulturas: de los que las han creado y tenido y de muchos ricos homes confirmadores de priuilegios ... / por el doctor Salazar de Mendoça. En Toledo: por Diego Rodriguez de Valdiuielso ..., 1618

CCPB000041619-3

177. Suidę, Opera historica. Basileę, 1581. 1 t., fol.

Suidas, Suidae Historica caeteraque omnia que ulla ex parte ad cognitionem rerum spectant ... / opera ac studio Hier. Wolfii ... in Latinum sermonem conversa ... Basileae: ex officina Heruag. per Eusebium Episcop., 1581

CCPB000024293-4

178. Tariq Aventarique, Segunda parte de la hist. ${ }^{a}$ de la perdida de España traducida $p .{ }^{r}$ D. ${ }^{\mathrm{n}}$ Mig. ${ }^{1}$ de Luna. Granada, 1600. 1 t., $4^{\circ}$.

Luna, Miguel de, Segunda parte de la historia de la perdida de España, y vida del Rey Iacob Almançor: en la qual el Autor Tarif $\mathrm{Ab}^{-}$etarique que prosigue la primera parte, dando particular quenta de todos los sucessos de España y Africa, y la Arabias, hasta el Rey don Fruela ... / Traducida de lengua Arabiga por Miguel de Luna ... En Granada : por Sebastian de Mena, 1600 (1599)

CCPB000335784-8

179. Thom. ${ }^{\text {s }}$ Venci, El Pimandro de mercurio Trimegistro, traducido en Italiano. Florencia, 1548. 1 t., $8^{\circ}$.

Hermes : Trismegistus, Il Pimandro / di Mercurio Trismegisto ; tradotto da Tommaso Benci in lingua fiorentina, [con una lettera di Carlo Lenzoni] in Firenze, 1548

IT\ICCU\CFI 0489128

180. Vicentii Burgundi, Speculi maioris tom. 4. Venetiis, 1591. 4 t., fol.

Vincent de Beauvais, Speculi maioris Vincentii Burgundi praesulis Beluacensis, Ordinis Praedicatorum ... tomi quatuor : quorum primo tota naturalis historia, altero omnium doctrinarum disciplinarum ..., tertio vero omnis moralis philosophia, quarto denique uniuersa totius orbis omniumque populorum ab orbe condito, ad auctoris vsque tempus, cum sequentis annorum appendice, historia continetur ... Nunc e tenebris, in quibus iampridem iacuit, omni adhibita solertia emendatum, in lucem prodit, cum indice Venetiis : apud Dominicum Nicolinum, $1591 \ldots$

CCPB000293310-1 
181. Ventura de Argumossa, Hist. ${ }^{a}$ de la ultima guerra de Europa. M. ${ }^{\text {a }}, 1738.3$ t., $4^{\text {o }}$. Massuet, Pierre, Historia de la ultima guerra, negociaciones, y conclusion de la paz, que contiene todo lo mas importante acontecido en Italia, el Rhin, Polonia, y la mayor parte de las Cortes de Europa, desde el año de 1733 h[asta] el de 1736 ... / [compuesto ... por Monsieur P. Mansuet] ; y traducida del idioma frances al español por Don Bentura de Argumossa; En Madrid : en la Imprenta de Gabriel Ramirez, 1738.

CCPB000116737-5

182. Velazquez de Mena, del origen del linaje de Vera. Burgos, 1617. 1 t., $4^{\circ}$.

Velázquez de Mena, Tratado del origen generoso e ilustre del linage de Vera, y sucession de los Señores de la casa de Vera, y villa de Sierrabraua / recogido de las historias impressas y manuscritas ... por el licenciado Velazquez de Mena . [S.l.] : [s.n.], 1617.

CСРB000275368-5

183. Vicente Bacallar, Comentar. ${ }^{\text {s }}$ de la guerra de España y de su Rey Felipe V. Genova. 2 t., $4^{\circ}$.

Bacallar y Sanna, Vicente, Marqués de San Felipe, Comentarios de la Guerra de España e Historia de su Rey Phelipe V el Animoso, desde el principio de su reynado hasta el año de 1725: dividido en dos tomos / por don Vicente Bacallar y Sanna ... In Genova : per Matheo Garvizza, [s.a.]

CCPB000058725-7

184. M. Voltaire, hist. ${ }^{\text {a }}$ de Carlos XII, Rey de Suecia. Madrid, 1734. 2 t., $8^{\circ}$.

Voltaire, Historia de Carlos XII, Rey de Suecia : traducida del idioma frances al español / por Don Leonardo de Uria y Orueta... En Madrid : en el Convento de la Merced, 1734

CCPB000069941-1

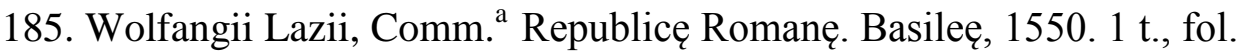

Lazius, Wolfgang, Commentariorum Reipub. Romanae illius, in exteris prouinciis, bello acquisitis, constitutae, libri duodecim ... / autore VVolfgango Lazio .. Basileae : per Ioannem Oporinum, [s.a.]

CCPB000015069-X

\section{DUPLICADO DE HISTORIA PROFANA}

186. Appiani Alexandrum, de civilibus Bellis Romanurum cum alio libro eiusd. Aucthoris nominato Ilirio et Celtico. Moguntię, 1529, 1 t., $4^{\text {o }}{ }^{39}$

187. Laurentii Surii, Comentar. brevis rerum in orbe gestarum ab anno 1500 ad 1567. Colonię, 1567.1 t., $8^{\circ}$.

Surius, Laurentius, Comentarius brevis rerum in orbe gestarum ab anno Salutis 1500 usque in annum $1567 .$. congestus \& nunc... / auctus... per F. Laurentium Surium... Coloniae : Apud Gervinum Calenium \& haeredes Iohannis Quentel, 1567

ССРВ000024325-6

${ }^{39}$ Se trata de la misma edición consignada en el Nro: 22

240 Marcela A. Suárez, Luis Sánchez y María Soledad Justo. La Biblioteca del Antiguo ... 158-254. 
188. Berosii, Libr. 5 antiquitatum, cum commentarii Joan Annii Vicentencis. Ant., 1545. $1 \mathrm{t} ., 8^{\circ} .{ }^{40}$

189. Poxo Mexia, Hist. ${ }^{a}$ Impe. ${ }^{1}$ y Cesarea. Sevilla, 1556.1 t., fol.

Edición no localizada. Existe una edición que tiene una diferencia en el año de impresión: Mexía, Pedro, Historia imperial y Cesarea : en la qual en su[m]ma se co[n]tiene[n] las vidas y hechos de todos los Cesares emp[er]adores de Roma, d'sde Julio Cesar hasta el emp[er]ador Maximiliano ... / la qual compuso y ordeno ... Pero Mexia ... En Seuilla : en casa de Iua[n] de Leo[n], 1545 postrero dia del mes de junio CCPB000017455-6

190. Lucii Marinęi Siculi, opus de rebus memorabilis Hispanię. Compluti, 1533. 1 t., fol. $^{41}$

191. Dionisii Halicarnassęi, lib. 10 antiquitatum Romanarum cum interpretatione Segismundi Gelen. Lug., 1555. 1 t., $12^{\circ}$.

Dionisio de Halicarnaso, Dionysii Halicarnassei Antiquitatum siue originum romanorum libri X / Sigismundo Gelenio interprete ; adiecimus undecimum ex uersione Lapi ac indicem rerum notatu dignarum locupletissimum, Lugduni : apud seb. Gryphium, 1555

CCPB000156886-8

192. Eiusd., id opus cum interpretation Emilii Portis. Colonię Allobroug, 1603. 1 t., $8^{\circ}$. Edición no localizada se trata de la obra: Dionysii Alexandri F. Halicarn. antiquitatum rom. libri XI. ab Emilio Porto Fr. F. Recens et post aliorum interpretationes ... quibus adiunximus H. Glareani, chronologicam cum Indice locupletissimo

193. Diogenis Laertii, de vita decem Philosophor. Parisis, ab anno impresion. 1 t., $4^{\circ}$.

Diógenes Laercio Diogenis Laertii historiographi de philosophorum vita decem perquam fecundi libri ad bene beateque vivendorum commotini Parisius : in vico diui Iacobi sub intersignio Leonis argentei, [s.a.]

CCPB000007981-2

194. Herodiani, liber 1s ex Gręco translato historię de suis temporibus, cum interpretationes Angeli Politiani. Cordubę, 1557. 1 t., $8^{\circ}$.

Edicion no localizada. Se trata de la obra: Herodiano, Herodiani Historiae de Imperio post Marcum vel de suis temporibus libri VIII / Angelo Politiano interprete.

195. Geronimo Zurita, Los 5 primeros libros de la prim. ${ }^{\text {a }}$ parte de la corona de los Anales de Aragon, los 5 primeros de la seg. y los cinco prim. ${ }^{\mathrm{s}}$ de la Hist. ${ }^{\mathrm{a}}$ del rey Do. ${ }^{\mathrm{n}}$ Fernando el Cathólico. Zaragoza, 1562, 79, 80. 3 t., fol.

Zurita y de Castro, Jerónimo. Los cinco libros postreros de la primera parte de los Anales de la Corona de Aragon / $\mathrm{c}^{-}$opuestos por Geronymo Çurita. Çaragoça : en casa de Pedro Bermuz, 1562.

CCPB000000764-1

\footnotetext{
${ }^{40}$ Se trata de la misma edición consignada en el Nro: 31

${ }^{41}$ Se trata de la misma edición consignada en el Nro: 134
} 
Zurita y de Castro, Los cinco libros postreros dela segunda parte de los Anales de la Corona de Aragon / compuestos por Geronymo Çurita chronista del reyno Imprimio se ... en ... Çaragoça : en la officina de Domingo de Portonariis y Vrsino ..., 1579 CCPB000189047-6

Zurita y de Castro, Los cinco libros postreros de la historia del Rey Don Hernando el Catholico, de las empresas y ligas de Italia / compuesta por Geronymo Çurita ... Imprimieron se en ... Çaragoça : en la officina de Domingo de Portonarijs y Vrsino ..., 1580

\section{CCPB000000430-8}

196. Paulii Jobii, Tom. 1 Historiam sui temporis. Venetii, 1553.1 t., $8^{\circ}$.

Giovio, Paolo, Pauli Iouii ... Historiarum sui temporis tomus primus [-secundus] Venetiis , apud Cominum de Tridino Montisferrati, 1553 (1554) Dos colofones el del primer tomo (v. de h. 415) lleva la fecha de 1554; el del segundo (r. de Yy7) lleva la fecha de 1553

CCPB000011621-1

197. Eiusd., id opus. Argentorati, 1556. 1 t., $8^{\circ}$.

Giovio, Paolo, Pauli Iouii ... Historiarum sui temporis , tomus primus. Argentorati, apud Agustinum Frisium, 1556

CCPB000292027-1

198. Eiusd., tom. 2. Basileę, 1559. 1 t., $8^{\circ}$.

Edición no localizada. Existe una obra en la cual existe una diferencia en el año de edición: Giovio, Paolo, Pauli Iouii ... Historiarum sui temporis tomus primus [secundus] ; accessit rerum Turcicarum commentarius eiusdem Iouii ad finem operis, ex Italico Latinus factus Basileae : [Henricus Petri \& Petrus Perna], 1560 Basileae : [Henricus Petri \& Petrus Perna], 1560

CCPB000011625-4

199. Eiusd, Vidę illustrium virorum. Florentię, 1549. 1 t., fol.

Giovio Pauli, Pauli Iouii Nouocomensis Episcopi Nucerini Illustrium Virorum vitae Florentiae : in officina Laurentii Torrentini ..., 1549

CCPB000155356-9

200. Eiusd., una ex partibus Tomi 2 s. historiam. Venet., 1553.1 t., $8^{\circ}{ }^{42}$

201. Eiusd., 2s Historiarum. Venet., 1553. 1t., $8^{\circ} .{ }^{43}$

202. Joan Rosini, Roman. antiquitat. libr. 10. Lug., 1585. 1 t., fol.

Rosinus, Iohannes, Romanarum antiquitatum libri decem ex variis scriptoribus summa fide singularique diligentia collecti a Ioanne Rosino Bartholomaei F. Isennacensi Thuringo. Cum indicibus locupletissimis, Lugduni : ISybille de La Porte!, 1585.

IT \ICCU\BVEE\007457

203. Juan Augusto de Mora, Huelba Illustrada. Sevilla, 1762, 1 t., $4^{\mathrm{o}} .{ }^{44}$

\footnotetext{
${ }^{42}$ Se trata de la misma edición consignada en el Nro: 196

${ }^{43}$ Se trata de la misma edición consignada en el Nro: 196
} 
204. Antonii Nebrisensis, Decades duas, quibus accedit Chronica Archiepiscopi Roderici. Granatę, 1545. 1t., fol.

Pulgar, Hernando del, Habes in hoc volumine amice lector Aelii Antonii Nebrissensis Rerum a Fernando et Elisabe Hispaniar ${ }^{-} \mathrm{u}$ foelicissimis Regibus gesta[rum] Decades duas ; Necn ${ }^{-}$o belli Nauariensis libros duos. Annexa insuper Archie ${ }^{-}$pi Roderici Chronica aliisq[ue] historiis antehac non excussis Apud inclytam Granatam : [Xantus et Sebastianus Nebrissensis], 1545

CCPB000000360-3

205. Joan Naucleri, Chronica. Colonię, 1544. 1t., fol.

Nauclerus, Johannes, D. Iohannis Naucleri praepositi Tubingem. Chronica, succinctim $\mathrm{c}^{-}$opraehendentia res memorabiles seculor ${ }^{-} \mathrm{u}$ omnium ac gentium, ab initio mundi usq[ue] ad annum Christi nati M.CCCCC / Cum auctario Nicolai Baselii ab anno Domini M.D.I. in annum M.D.XIIII ; et appendice noua ... ab anno videlicet M.D.XV. usq[ue] in $a^{-} n^{-}$u praesentem, qui est post Christum natum M.D.XLIIII. Rhapsodis artim D. Cunrado Tigemanno, partim Bartholomaeo Laurente ... Coloniae, ex officina Petri Quentel, 1544

CCPB000018536-1

206. Gaspar Mercader, Retrato Politico del Rey D. " Alonso el VIII. Valencia, 1679. 1., $4^{\circ} .{ }^{\circ}$

207. Pedro Mantuano, adverten. ${ }^{\mathrm{s}}$ a la Hist. ${ }^{\mathrm{a}}$ de Mariana. M. ${ }^{\mathrm{a}}, 1613.1$ t., $4^{\mathrm{o}}{ }^{46}$

208. Fran. ${ }^{\text {co }}$ de los Santos, Descrip. ${ }^{\text {on }}$ del Escorial. M. ${ }^{a}, 1657.1$ t., fol. ${ }^{47}$

209. Marco Juan Tarcagnota, Hist. ${ }^{a}$ del Mundo q. ${ }^{\mathrm{e}}$ contiene desde el Principio del hasta su tiempo en dos partes (en Italiano). Venecia, 1562- 92.2 t., $4^{\text {o }}{ }^{48}$

\section{HISTORIA PROFANA DE JESUITAS}

210. Alvaro Semmedo, Imperio de la China. M. ${ }^{\mathrm{a}}, 1642.2$ t., $4^{\circ}$.

Semmedo, Alvaro Imperio de la China i cultura evangelica en èl por los religios [sic] de la Compañia de Iesus / compuesto por el padre Alvaro Semmedo de la propia Compañia... ; publicado por Manuel de Faria i Sousa... [Madrid] : Impresso por Iuan Sanchez en Madrid : a costa de Pedro Coello..., 1642

CCPB000040804-2

211. Antonii Vasconzelii, Summa capita actorum Regum Lusitainię. Ant., 1621. 1 t., $4^{\text {o }}$. Vasconcellos, Antonio, Anacephalaeoses id est Summa capita actorum Regum Lusitaniae / auctore P. Antonio Vasconcellio Societatis Iesu ... ; acceserunt

\footnotetext{
${ }^{44}$ Se trata de la misma edición consignada en el Nro: 127.

${ }^{45}$ Se trata de la misma edición consignada en el Nro: 75.

${ }^{46}$ Se trata de la misma edición consignada en el Nro: 166.

${ }^{47}$ Se trata de la misma edición consignada en el Nro: 65.

${ }^{48}$ Se trata de la misma edición consignada en el Nro: 141.
} 
Epigrammata in singulos reges ab insigni poeta Emmanuele Pimenta eiusdem societatis ; et illorum effigies ad viuum expressae, curâ \& sumptibus Emmanuelis Sueyro ... Antuerpiae : apud Petrum \& Ioannem Belleros, 1621

CCPB000051011-4

212. Antonii Frañci, Sinopsis Annalium Soc. in Lusitanię. Augustę, (ab anno 1540-00). 1726. 1t., fol.

Franco, Antonio, Synopsis annalium Societatis Jesu in Lusitania ab anno 1540 usque ad annum 1725 / authore R.P. Antonio Franco Societatis ejusdem ... AugustaeVindelicorum \& Graecii : sumptibus Philippi, Martini, \& Joannis Veith, Haeredum, 1726

CCPB000463620-1

213. Antonii Posseuini, apparatus ad omnium Gentium historiam. Venetiis, 1597. 1 t., $8^{\circ}$.

Possevino, Antonio, Antonii Posseuini ... Societatis Iesu Apparatus ad omnium gentium historiam ... Venetiis : apud Io. Bapt. Ciottum Senensem ..., 1597 CCPB000021587-2

214. Balthasar de Moncada, Descrip. ${ }^{\text {on }}$ de la casa de los Exer. ${ }^{\mathrm{s}}$ de S. ${ }^{\mathrm{n}}$ Ign $^{.0}$ en Lima. Sevilla, 1757. $1 \mathrm{t}$., fol.

Moncada, Baltasar de, Descripcion de la casa fabricada en Lima, corte del Perù, para que las señoras ilustres de ella y las demàs mugeres devotas, y las que desean servir a Dios Nuestro Señor ...puedan tener ... los exercicios de de San Ignacio de Loyola consagrase a Maria Señora nuestra / la ofrece à las señoras Ilustres de Lima .. el doctor Balthasar de Moncada. Con licencia en Sevilla : por Joseph Padrino Impressor, 1757 CCPB000829585-9

215. Commentarii de gestis in aggregationis Provincię Gallo-Belgicę a Rege christianissimo $1682.1 \mathrm{t} ., 4^{\circ}$.

Commentarii de rebus gestis in negotio aggregationis provinciae Gallo-Belgicae Societatis Iesu petitae à Rege Christianissimo ab anno 1682 pars prima [S.1. : s.n., s.a.] CCPB000373437-4

216. Caroli Scribani, Antuerpia. Ant., 1610. 1t., $4^{\circ}$.

Scribani, Charles, Caroli Scribani è Societate Iesu Antuerpia, Antuerpiae : ex Officina Platiniana, apud Ioannem Moretum, 1610

CCPB000493307-9

217. Claudio Clemente, tablas Chronologicas. Valencia, 1689. 1t., $4^{\circ}$.

Clément, Claude, Tablas chronologicas en que se contienen los sucessos eclesiasticos y seculares de España, Africa, Indias Orientales y Occidentales : desde su principio hasta el año 1642 ... : con los catalogos de los pontifices, emperadores ..., varones ilustres en Letras y Armas ... / compuestas por ... Claudio Clemente, de la Compañia de Iesus ... ; ilustradas y añadidas desde el año 1642 hasta el presente de 1689 ... por Vicente Ioseph Miguel ... En Valencia : en la imprenta de Iayme de Bordazar : a costa de la Compañía de libreros, 1689

CCPB000039699-0

218. Dionisii Petavii, de Doctrina Temporum. versiones 1633, 35, 36.3 t., fol. 
Edición no localizada. Se trata de la obra: Petau, Denis, Dionysii Petavii Aurelianensis e Societate Jesu De doctrina temporum.

219. Eiusd., Rationarium temporum. Venetii, 1749. 2 t., $8^{\circ}$.

Dionysii Petavii Aurelianensis e Societ. Jesu Rationarium Temporum, Venetiis :apud Laurentium Basilium, 1749

IT \ICCU\BRIE\014688

220. Famiani Stradę, de Bello Belgica. Ant., 1604 et 1648. 2 t., $8^{\circ}$.

Strada, Famiano, Famiani Stradae ... e Societate Iesu De bello belgio decas secunda : ab initio praefecturae Alexandri Farnesii Parmae Placentiaeque Ducis III an. MDLXXVIII usque ad an. MDXC Antuerpiae : Typis Viduae Cnobbari, 1648

CCPB000205835-9

221. Frac. ${ }^{\text {co }}$ Ruano, Hist. ${ }^{\text {a }}$ Grãl. de Cor. ${ }^{\text {ba, }}$. Cor. ${ }^{\text {ba. }}, 1760.1$ t., $4^{\circ}$.

Ruano, Francisco, Historia general de Cordoba / compuesta por ... Francisco Ruano ... ; tomo I. Impresso en Cordoba : en el Colegio de Nuestra Señora de la Assumpcion ... por Francisco Villalòn, [s.a.]

CCPB000202878-6

222. Fernan Guerrero, Relacion de los hechos de los PP. de la Comp. ${ }^{\text {a }}$ de la India oriental en los años 1600 y 1601 . Valladolid, 1614. 1 t., $4^{\circ}$.

Edición no localizada. Existe una versión de la misma obra con una diferencia en el año de impresión: Guerrero, Fernan, Relacion anual de las cosas que han hecho los padres de la Compañia de Iesus en la India Oriental y Iapon en los años de 600 y 601... / sacada de las cartas generales que han venido de alla por el padre Fernan Guerrero de la Compañia de Iesus... ; traduzida de portugues en castellano por el padre Antonio Colaço... de la misma Compañia... En Valladolid: por Luys Sanchez, 1604

CCPB000036982-9

223. Gabriel Henao, De la Antiguedades de la Cantabria. Salam., 1689 y 91.2 t., fol.

Henao, Gabriel de, Averiguaciones de las antiguedades de Cantabria: enderezadas principalmente a descubrir las de Guipuzcoa, Vizcaya y Alaba, prouincias contenidas en ella... / autor el padre Gabriel de Henao, de la... Compañia [de Jesus]... En Salamanca: por Eugenio Antonio Garcia, 1689.

CCPB000037050-9

Henao, Gabriel de, Averiguaciones de las Antiguedades de Cantabria : ocupadas en explorar sucesos de los cantabros, quando dominaron España los godos y en los de empresas contra moros y en defenderse dellos : enderezadas principalmente a descubrir los de las tres provincias Cantabricas vascongadas en esos tiempos ... / autor el Padre Gabriel de Henao ...

En Salamanca : por Eugenio Antonio García, 1691

CCPB000040357-1

224. Hermani Hugonis, de militia equestri antiqua et nova. Ant., 1620. 1 t., fol.

Edición no localizada. Existe una versión de la misma obra con una diferencia en el año de impresión. Hugo, Hermann, De militia equestri antiqua et noua ad regem Philippum IV: libri quinque / auctore Hermanno Hugone. Antuerpiae: Ex Officina Plantiniana Balthasaris Moreti, 1630 


\section{ССРB001007287-X}

225. Horatii Turselini, Epitome historiarum, Lug., 1619. 1 t., $8^{\circ}$.

Edición no localizada. Existe una edición que tiene una diferencia en el año de impresión: Torsellini, Orazio, Horatii Tursellini e Societate Iesu epitomae historiarum libri X: Lugduni : sumptibus Iacobi Cardon \& Petri Cauellat, 1620.

CCPB000497712-2

226. Ignatii Squarz. Efigies historię Babarię. Godefridi. 1 t. fol.

Schwarz, Ignacio, Effigies historiae bavarae in collegiis historico-politicis ratione methodica adumbratae, et sub...Caroli Alberti otriuque Bavariae...In Alma, \& Electorali Universitate Ingolstadiensi, a perillustri, ac generoso domino Francisco Xaverio Leonardo Carolo Ruperto L. B. de Lerchenfeld, amerland...praeside P. Ignatio Schwarz, Soc. Jesu... [Ingolstad] : typis variarum urbium. Praecipuè Godefridi Zipper, typogr. Acad. Ingolstad, [s.a.]

227. Eiusd., Collegia Historica. Ingoltadii, 1734 et 35 et alii Veissenburgi 1736-37. 3 t., fol.

Schwarz, Ignacio, Collegia historica seu quaestiones historiae criticae : ex institutionibus historicis in ordine ad dilucidandas praecipuas quaesque difficultates extractae, atque accommoda methodo pro studio academico praesertim catholico propositae / authore P. Ignatio Schwarz, Soc. Jesu ... ; pars I Ingolstadii : sumptibus Joannis Andreae de la Haye ..., 1734

CCPB000381251-0

Schwarz, Ignacio, Collegia historica seu quaestiones historiae criticae : ex institutionibus historicis in ordine ad dilucidandas praecipuas quaesque difficultates extractae, atque accommoda methodo pro studio academico praesertim catholico propositae / authore P. Ignatio Schwarz, Soc. Jesu ... ; pars III. Ingolstadii : sumptibus Joannis Andreae de la Haye ... : typis Godefridi Zipper ..., 1735

CCPB000381253-7

Schwarz, Ignacio, Collegia historica seu quaestiones historiae criticae : ex institutionibus historicis in ordine ad dilucidandas praecipuas quaesque difficultates extractae, atque accommoda methodo pro studio academico praesertim catholico propositae / authore P. Ignatio Schwarz, Soc. Jesu ... ; pars V. Weissenburgi Nortgojae : sumptibus viduae Joannis Andreae de la Haye ... ; 1736

CCPB000381255-3

Schwarz, Ignacio, Collegia historica seu quaestiones historiae criticae : ex institutionibus historicis in ordine ad dilucidandas praecipuas quaesque difficultates extractae, atque accommoda methodo pro studio academico praesertim catholico propositae / authore P. Ignatio Schwarz, Soc. Jesu ... ; pars VI. Weissenburgi Nortgojae : sumptibus viduae Joannis Andreae de la Haye ... ; 1737

CCPB000381256-1

228. Eiusd., Imperii Princeps Ecclesiasticus. Ingolstadii, 1694. 1 t., fol.

Edición no localizada. Se trata de la obra: Schwarz, Ignacio, Imperii princeps ecclesiasticus, selectis aliquot lineamentis, parergisque historico-hierarchicis 
adumbratus et sub gloriosissimis auspiciis reverendissimi ac serenissimi principis et domini, domini Joannis Theodori ... Praeside P. Ignatio Schwarz, Soc. Jesu ..

229. Joan Bussieres, Hist. ${ }^{\text {a }}$ Francica. Lug., 1661. 1 t., fol.

Bussières, Jean, Ioannis de Bussieres... e Societate Iesu Historia Francica: pars secunda : ab Hugone Capetio ad Carolum VII. Lugduni : sumpt. Guill. Barbier, Ioan. Girin \& Franc. Comba, 1661

CCPB000149327-2

230. Joan Noni Barreti et Andrę Oviedo, De abassinorum rebus. Lug., 1615. 1 t., $8^{\circ}$.

Godinho, Nicolao, De Abassinorum rebus dique Aethiopiae Patriarchis Ioanne Nonio Barreto \& Andrea Ouiedo libri tres / P. Nicolao Godigno Societatis Iesu auctore, Lugduni: Sumptibus Horatij Cardon, 1615

CCPB000225403-4

231. Joan de Mariana, Hist. ${ }^{a}$ de rebus Hispanię. Toleti, 1592. 2 t., fol.

Mariana, Juan de, Historiae de rebus Hispaniae Libri XX, Toledo, 1592. CCPB000016969-2

232. La misma obra en Castellano, 2 tom. M. ${ }^{a}$, 1635. otra Toledo, 1601. 2 t., fol.

Mariana, Juan de, Historia General de España / compuesta emendada y añadida por el padre Iuan de Mariana de la Compañía de Iesus; con el sumario y tablas; tomo primero, En Madrid: por Francisco Martinez: a costa de Domingo Gonçalez..., 1635 CCPB000210254-4

Mariana, Juan de, Historia General de España / compuesta emendada y añadida por el padre Iuan de Mariana de la Compañía de Iesus; con el sumario y tablas; tomo primero En Toledo : por Pedro Rodriguez..., 1601

CCPB000033330-1

233. Joan Baptistę Riccioli, Chronologia reformata. Bononię, 1669. 3t., fol.

Riccioli, Giovanni Battista, Chronologiae reformatae et ad certas conclusiones redactae tomus primus [-quartus] ... auctore r.p. Io. Baptista Ricciolio Ferrariensi Societatis Iesu .. Bononiae : ex typographia haeredis Dominici Barberij, 1669

IT\ICCU\BVEEI041679

234. Jacobi Gordoni, Opus chronoligicum S. ${ }^{\mathrm{T}}$ Tom. ${ }^{\mathrm{s}}$. Colonię, 1614. 2 t., alter Augostorii, 1617. 2 t., fol.

Gordon, James Opus chronologicum : annorum seriem, regnorum mutationes et rerum toto orbe gestarum memorabilium sedem annumque, à mundi exordio ad nostra vsque tempora complectens / auctore R.P. Iacobo Gordono Cesmoreo... Societatis Iesu... Coloniae Agrippinae : apud Ioannem Crithium..., 1614 CCPB000223678-8

Gordon, James. Opus chronologicum annorum seriem regnorum muntationes \& rerum toto orbe gestarum narrationem : à Mundi exordio ad annum vsq. Christi 1617 complectens / curis secundis auctum [et] recognitum auctore ... Iacobo Gordono ... Societatis Iesu ... Augustoriti Pictonum : ex officina Antonij Mesnerij ..., 1617 CCPB000225438-7 
235. Joan Petri Maffęi, historiarum indiarum lib. 16. Lug., 1589. 1 t., $4^{\circ}$.

Maffei, Giovanni Pietro, Ioannis Petri Maffeii Bergomatis e Societate Iesu, Historiarum indicarum libri XVI; Selectarum item ex India Epistolarum eodem interprete Libri IIII: Accessit Ignatii Loiolae vita postremo recognita ... Lugduni : ex officina Iunctarum, 1589

CCPB000016472-0

236. Jph. Humilla, El Orinoco Illustrado. M. ${ }^{\mathrm{a}}, 1745$. 1t., $4^{\circ}$.

Gumilla José: El Orinoco ilustrado y defendido: historia natural civil y geographica de este gran rio y de sus caudalosas vertientes... / escrita por... Joseph Gumilla de la Compañia de Jesus... ; tomo primero [-segundo] En Madrid: por Manuel Fernandez..., 1745

CCPB000118252-8

237. Man. ${ }^{1}$ Rodrig. ${ }^{\mathrm{z}}$, El Marañon y Amazonas. M. ${ }^{\mathrm{a}}$, 1684. 1 t., fol.

Rodriguez, Manuel, El Marañon y Amazonas: historia de los descubrimientos, entradas y reduccion de naciones, trabajos malogrados de algunos conquistadores y dichosos de otros, assi temporales como espirituales, en... America / escrita por el padre Manuel Rodriguez, de la Compañia de Iesus... En Madrid: en la imprenta de Antonio Gonçalez de Reyes, 1684

CCPB000040673-2

238. Martin de Roa, Principado de Cord. ${ }^{\text {ba }}$. Cord. $.^{\text {ba }}, 1636.1$ t., $4^{\circ}$.

De Roa, Martin, Antiguo Principado de Cordova en la España Vlterior o Andaluz / traducido del latino i acrecentado... por su autor el P. Martin de Roa de la Compañia de Iesus. En Cordova: por Salvador de Cea Tesa, 1636

CCPB000040660-0

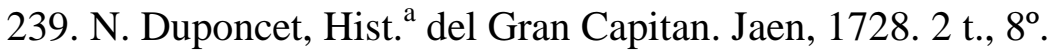

Duponcet, Jean Nicolas, Historia de Don Gonzalo Fernández de Cordova renombrado El Gran Capitán / escrita en francés por el R. P. Duponcet; y traducida en español por Don Joseph Fernández de Cordova; tomo segundo, Impresso en Iaen: por Thomas Copado, 1728

CCPB000341245-8

240. N.N. Trevoux, memoria para la hist. ${ }^{\mathrm{a}}$ de las Ciencias y buenas Artes. Traducidas del frances p. ${ }^{\mathrm{r}}$ D. ${ }^{\mathrm{n}} \mathrm{Jph}$ Vicente Rustant. M. ${ }^{\mathrm{a}}, 1752$ y 54.7 t., $8^{\mathrm{o}}$.

Rustant, José Vicente de, (trad), Memorias para la historia de las ciencias y artes: que se empezaron a imprimir año de 1701 en Trevoux / traducidas en castellano por D. Joseph de la Torre. En Madrid: en casa de Juan de Zuñiga, 1742-1754

CCPB000068363-9

241. Philippi Brietii, Annales Mundi. Parisis, 1662 et 63.7 t., $8^{\circ}$.

Briet, Philippe, Annales mundi, sive Chronicon universale : secundum optimas chronologorum epochas, ab orbe condito ad annum Christi millesimum sexcentesimum sexagesimum perductum / opera et studio Philippi Brietti ... Parisiis : apud F. Muguet ..., 1662-1663

CCPB000610339-1 
242. Pedro Murillo Velarde, Hist. ${ }^{a}$ de la provin. ${ }^{a}$ de Filipinas de la Comp. ${ }^{a}$. Manila, 1749. $1 \mathrm{t}$, fol.

Murillo Velarde, Pedro, Historia de la provincia de Philipinas de la Compañia de Jesus : segunda parte... desde el año de 1616 hasta el de 1716 / por el P. Pedro Murillo Velarde de la de la Compañia de Jesus.. En Manila: en la Impr[enta de la Compañia] de Jesus, por D. Nicolas de la Cruz Bagay, [1749]

CCPB000116832-0

243. Pedro Abarca, Annales de los reyes de Aragon, 1 tomo. M. ${ }^{\mathrm{a}}$, 1682, otro en Salam. ${ }^{\text {ca }}$, 1684. 2 t., fol.

Abarca, Pedro, Los Reyes de Aragon en anales historicos: distribuidos en dos partes ... / por el padre Pedro Abarca de la Compañia de Iesus ... ; primera parte. En Madrid: en la Imprenta Imperial, 1682

CCPB000032082-X

Abarca, Pedro, Los Reyes de Aragon en anales historicos: distribuidos en dos partes ... / por el padre Pedro Abarca de la Compañia de Iesus ... ; primera parte. En Salamanca : por Lucas Perez..., 1684

CCPB000032083-8

244. Pedro Franc. ${ }^{\text {co }}$ Xavier de Charlevoix, Hist. ${ }^{\text {a }}$ del Japon, en francés. Parisis, 1754. 6 t., $8^{\circ}$.

Charlevoix, Pierre-François-Xavier, Histoire du Japon... / par le Pere de Charlevoix, de la Compagnie de Jesus; tome premier [-sixième] A Paris : chez Ganeau... [y 2 más], 1754

CCPB000059120-3

245. Del mismo, Hist. ${ }^{a}$ de Paraguai, en Frances. Paris, 1757. 6 t., $8^{\circ}$.

Charlevoix, Pierre-François-Xavier de, Histoire du Paraguay / par le P. Pierre FrançoisXavier de Charlenoix, de la Compagnie de Jesus; tome premier, A Paris: de l'imprimerie de Didot : chez Didot..., Giffart..., Nyon ..., 1757

CCPB000147759-5

246. Reparos historiales apologeticos de los misioner. ${ }^{\mathrm{s}}$ Apostolicos de la China. Pamplona, 1677. 1t., $4^{\circ}$.

Cortes Ossorio, Juan, Reparos historiales apologeticos... propuestos de parte de los missioneros apostolicos del Imperio de la China representando los descuidos que se cometen en vn libro que se ha publicado en Madrid en graue perjuizio de aquella mission : contiene las noticias mas puntuales y hasta aora no publicadas de la vltima persecucion contra la Fè, con vna breue chronologia de aquel Imperio ... hasta el año de 1677 En Pamplona : por Tomás Baztan, [s.a.]

CCPB000039255-3

\section{DUPLICADO HISTORIA PROFANA DE JESUITAS}

247. Famiani Stradę, de Bello Belgio Decades. Romę, 1648, 2 t. $8^{\circ}$.

Strada, Famiano, Famiani... e Societate De bello Belgio decas secunda : ab initio praefecturae Alexandri Farnesii Parmac Placentiaeque Ducis III Anno MDLXXVIII 
usque ad Annum MDXL. Juxta exemplar Romae : apud Haeredes Francisci Corbellcth, 1648

CCPB000136574-6

248. Id. opus, Lug., 1645. 6 t. $8^{\circ}$.

Strada, Famiano, Famiani Stradae Romani e Societate Iesu De bello belgico decas prima. Ab excessu Caroli 5. imp. vsque ad initia praefectura Alexandri Farnesii Parmae, ac Placentiae ducis 3. Additis hominum illustrium ad historiam praecipue spectantium imaginibus ad vivum expressis. Lugd. Bat. : ex officina Iacobi Marci, 1645

ITIICCUIPAREI039346

249. Franc. ${ }^{\text {co }}$ Ruano, tomo $1^{\circ}$ de la Hist. grãl. de Cor. ${ }^{\text {ba }}$. Cor ${ }^{\text {ba }}, 1760.7$ t., $4^{\text {o }} .^{49}$

250. Joan Marianę, libri 25 historię de rebus hispanię. Toleti, 1592. 1 t., fol ${ }^{50}$.

251. Eiusd. id Opus per ommia. 1t. fol ${ }^{51}$

252. Del mismo, La hist. ${ }^{\mathrm{a}}$ Grãl. de España tom. $1^{\circ}$. M. ${ }^{\mathrm{a}}, 1669.1$ t., fol.

Juan de Mariana, Historia general de España / compuesta, emendada, y añadida por el Padre Iuan de Mariana de la Compañia de Iesus ; con el sumario y tablas. En Madrid : por Andres Garcia de la Iglesia : a costa de Iuan Antonio Bonet ..., [s.a.]

CCPB000033745-5

253. Del mismo, la misma obra completa. Madrid, 1733, 34, 45. 3 t., fol.

Juan de Mariana, Historia general de España: dividida en tres tomos / primero y segundo compuestos, enmendados y añadidos por el P. Juan de Mariana, de la Compañia de Jesus; y proseguida en el tercero hasta el año de 1.700 por el Pdo. Fr. Manuel Joseph de Medrano... ; tomo primero, En Madrid : en la imprenta de la viuda de Geronymo Roxo : sale a luz a expensas de don Toribio Ruiz de Villa y don Pedro Iturralde..., 1733,

CCPB000074117-5

Juan de Mariana, Historia general de España : dividida en tres tomos / primero y segundo compuestos, enmendados y añadidos por el Rmo. P. Juan de Mariana, de la Compañia de Jesus ; y proseguida en el tercero hasta el año 1.700 por... Fr. Manuel Joseph de Medrano...; tomo segundo

En Madrid : en la imprenta de la viuda de Geronymo Roxo : sale a luz a expensas de don Toribio Ruiz de Villa : y don Pedro Iturralde..., 1734

CCPB000074118-3

Juan de Mariana, Continuacion de la historia general de España : desde el año de mil quinientos y diez y seis en que acabó la suya el R. Padre Juan de Mariana, de la Compañia de Jesús, hasta el de mil y setecientos / por el maestro fray Fray Manuel Joseph de Medrano, de la Orden de Predicadores ... ; tomo primero, reinado del augustissimo emperador Carlos quinto En Madrid : por Manuel Fernández ... : sale a luz

\footnotetext{
${ }^{49}$ Se trata de la misma edición consignada en el Nro: 221.

${ }^{50}$ Se trata de la misma edición consignada en el Nro: 231.

${ }^{51}$ Se trata de la misma edición consignada en el Nro: 231.
} 
a expensas de los Herederos de D. Pedro Yturralde y de D. Toribio Ruiz de Villa ..., 1741

CCPB000074202-3

254. Joann Petri Maffęi Bergomatis, Lib. 16. Historiam Indię. Florentię, 1588. 1 t., fol. Maffei, Giovanni Pietro, Ioannis Petri Maffeii ... e Societate Iesu Historiarum indicarum libri XVI ; selectarum item ex India epistolarum eodem interprete libri IV ; accessit Ignatii Loiolae vita postremo recognita, et in opera singula copiosus index. Florentiae : apud Philippum Iunctam, 1588.

CCPB000188576-6

255. Martini de Roa, De Cordubę Principatu lib. Veticus. Lug., 1617. 1 t., $8^{\text {o }}$.

Roa, Martin de, Martini de Roa ... ex Societate Iesu ... De cordubae in Hispania Betica principatu liber unus ... : Item de Antiquitate \& auctoritate SS. Martyrum Cordub. ac de breviario cordubensi liber alter ... Lugduni : sumptibus Horatij Cardon, 1617

CCPB000141359-7

256. Eiusd. id opus per ommia 1 t., $8^{\text {o }}{ }^{52}$

257. Id. per ommia. 1 t., $8^{\text {o }} .^{53}$

258. Pedro de Abarca, $2^{\circ}$ pte. de los Annales de los reyes de Aragon. Salama. ${ }^{\text {ca }}, 1684.1$ t. fol.

Abarca, Pedro Segunda parte de los Anales historicos de los Reyes de Aragón / por... Pedro Abarca de la Compañia de Iesus... En Salamanca : por Lucas Perez..., 1684

CCPB000032083-8

\section{Bibliogreafía}

Aranda Doncel, Juan (2003), "Época moderna (siglos XVI-XVIII): las reformas y la Ilustración", en Historia de las diócesis españolas: Iglesias de Córdoba y Jaén. Madrid: Biblioteca de Autores Cristianos, pp. 91-150.

Arias de Saavedra, Inmaculada (1997), "La biblioteca de los jesuitas de Granada en el siglo XVIII: una aproximación”. En Mestre Sanchís, E. y Giménez López, E. (eds.) Disidencias y exilios en la España Moderna. Alicante: Caja de Ahorros del Mediterráneo, pp 609-626.

Aspell, Marcela y Page, Carlos (2000), La biblioteca Jesuítica de la Universidad Nacional de Córdoba. Córdoba: Universidad Nacional de Córdoba.

Bartolomé Martínez, Bernabé (1988), "Las librerías e imprentas de los jesuitas (15401767): aportación notable a la cultura española". Hispania Sacra. España, n 40, pp. 315-388.

Castillo Gómez, Antonio (2003), Libro y lectura en la Península Ibérica y América (siglos XIII a XVIII). Junta de Castilla y León: Consejería de Cultura y Turismo.

Chevalier, Maxime (1976), Lectura y Lectores en la España de los siglos XVI y XVII. Madrid: Turner.

\footnotetext{
${ }^{52}$ Se trata de la misma edición consignada en el Nro: 255.

${ }^{53}$ Se trata de la misma edición consignada en el Nro: 255.
} 
Chinchilla Pawling, Perla (2004), De la compositio loci a la República de las letras. Predicación jesuita en el siglo XVII novohispano. México: Universidad Iberoamericana.

Fabre, Pierre y Maire, Catherine (2010), Les Antijésuites. Discours, figures et lieux de l'antijésuitisme à l'époque moderne. Rennes : Presses Universitaires de Rennes.

García Gómez, María Dolores (2010), Testigos de la memoria. Los inventarios de las Bibliotecas de la Compañía de Jesús en la expulsión de 1767. Alicante: Universidad de Alicante.

Haskell, Yasmin (2003), Loyola's Bees. Ideology and Industry in Jesuit Latin Didactic Poetry. Oxford: Oxford University Press.

Hernández González, María Isabel (1998), "Suma de inventarios de bibliotecas del Siglo XVI". En López Vidriero, M. L y Cátedra, P. (dir.), El libro antiguo español IV. Coleccionismo y Bibliotecas (siglos XV-XVIII). Salamanca y Madrid: Sociedad Española de Historia del libro \& Universidad de Salamanca \& Patrimonio Nacional, pp. 375-446.

Hernández Palomo, José y Del Rey Fajardo, José (coords.) (2009), Sevilla y América en la historia de la Compañía de Jesús. Córdoba: CajaSur.

Huarte Morón, Fernando (1955), "Las bibliotecas particulares españolas en la Edad Moderna". Revista de archivos, bibliotecas y museos. Madrid, ${ }^{\circ}$ 61.2, pp. 555576.

Martín Abad, Julián (2004), “Del ejemplar o de ciertas historias (casi) siempre pasadas por alto". Jornadas sobre Patrimonio Bibliográfico en Castilla-La Mancha. Toledo, pp. 15-35.

Martín Abad, Julián (2010), El enredijo de mil y un diablos (de manuscritos, incunables $y$ raros y de fondos y fantasmas bibliográficos). Madrid: Ollero y Ramos.

Martínez Millán, José, Pizarro Llorente, Henar y Jiménez Pablo, Esther (edd.) (2012), Los jesuitas. Religión, política y educación (siglos XVI-XVIII). Madrid: Universidad Pontificia Comillas.

Martínez Tornero, Carlos (2010), Carlos III y los bienes de los jesuitas. La gestión de las temporalidades por la monarquía borbónica (1767-1815). Alicante: Universidad de Alicante.

Mateo Ripoll, Vicente (2002), La cultura de las letras. Estudio de una biblioteca eclesiástica en la Edad Moderna. Alicante: Universidad de Alicante.

O’Neill, Charles y Domínguez, Joaquín (2001), Diccionario histórico de la Compañía de Jesús. Madrid: Universidad Pontificia Comillas.

Solana Pujalte, Julián (2007), "El fondo del siglo XVI de la Biblioteca del Antiguo Colegio de Santa Catalina de la Compañía de Jesús de Córdoba”. Archivum historicum Societatis Iesu. Roma, n76, 151, January-June pp. 113-137.

Solana Pujalte, Julián (2007), “Obras gramaticales de autores jesuitas en la Antigua Biblioteca del Colegio de Santa Catalina de la Compañía de Jesús en Córdoba". En Soto Artuñedo, W. (ed.), Los jesuitas en Andalucía. Estudios conmemorativos del 450 aniversario de la fundación de la Provincia Bética. Granada: Universidad de Granada, pp. 355-385.

Valdenebro, José María (2002), La imprenta en Córdoba: ensayo bibliográfico. Córdoba: Diputación de Córdoba, Delegación de Cultura. 
Vergara, Javier (2009), "El proceso de inventario y expropiación de la biblioteca de los jesuitas de Pamplona en tiempos de la expulsión (1767)". En Hernández Palomo, José y Del Rey Fajardo, José (coords.), pp. 375-394.

\section{Catálogos y repertorios bibliográficos on line}

Alcocer Martínez ALCOCER Y MARTÍNEZ, M., Catálogo razonado de obras impresas en Valladolid :(1481-1800). Ed. facs. Valladolid, Junta de Castilla y León, Consejería de Cultura y Turismo, 1993.

Fernández Valladares FERNÁNDEZ VALLADARES, M., La imprenta en Burgos (1501-1600). - Madrid, Arco Libros, 2005.

H. HAIN, L., Repertorium bibliographicum: in quo omnes ab arte typographica inventa usque ad annum MD, Milano, Görlich, cop. 1966.

H.C. COPINGER, W.A., Supplement to Hain's Repertorium Bibliographicum or collections towards a new edition of that work, Milano, Görlich, 1950.

ICEP Inventaire chronologique des éditions parisiennes du XVI siècle / par Brigitte Moreau; d'apres les manuscrits de Philippe Renouard, Paris, Imprimerie Municipale, 1972-1985.

López Huertas LÓPEZ HUERTAS, M.J., Bibliografía de impresos granadinos de los siglos XVII y XVIII, Granada, Servicio de Publicaciones de la Universidad, 1997.

Martín Abad MARTíN ABAD, J., La imprenta en Alcalá de Henares (1502-1600). Madrid, Arco, 1991.

Moreno Garbayo MORENO GARBAYO, J., La imprenta en Madrid (1626-1650). Madrid, Arcolibros, 1999.

Palau PALAU Y DULCET, A. Manual del librero hispano-americano: bibliografía general española e hispanoamericana desde la invención de la imprenta hasta nuestros tiempos, con el valor comercial de los impresos descritos. $2^{\mathrm{a}}$ ed., corr. y aum. por el autor. Barcelona, Librería Anticuaria de A. Palau, 1948-1977.

Valdenebro VALDENEBRO, J.M., La imprenta en Córdoba: ensayo bibliográfico, Ed. facs. Córdoba, Diputación de Córdoba, Delegación de Cultura, 2002.

CCFR Bibliothèque Nationale de France. CCFr [en línea]: Catalogue collectif de France. [Paris]: Bibliothèque Nationale de France. http://www.ccfr.bnf.fr.

CCPB Dirección General del libro, archivos y bibliotecas. CCPB [cd-rom]: Catálogo colectivo del patrimonio bibliográfico español, Madrid, 2003. También disponible en www.mcu.es/ccpb 
COPAC Consortium of University Research Libraries. COPAC [en línea]: Union catalogue of 24 major university research libraries in the UK and Ireland plus the British Library \& the National Library of Scotland. [Manchester]. http://copac.ac.uk

ICCU Ministero per i beni e le attività culturale. ICCU [en línea]: Istituto Centrale per il Catalogo Unico delle Biblioteche Italiane e per le Informazioni Bibliografiche. [Roma]. http://www.iccu.sbn.it.

IDS Basel Bern Universität Basel. IDS Basel Bern [en línea]. Online-Katalog des Bibliotheksverbunds Basel Bern. [Basel]. http://www.ub.unibas.ch

HBZ Hochschulbibliothekszentrum des Landes Nordrhein-Westfalen. HBZ [en línea]: Verbundkatalog der Hochschulbibliotheken Nordrhein-Westfalens und eines großen Teils von Rheinland-Pfalz. [Köln]. http://www.hbz-nrw.de

KVK Universität Karlsruhe. $K V K$ [en línea]: Karlsruhe Virtueller Katalog. [Karlsruhe]. http://www.ubka.uni-karlsruhe.de 